\title{
Seafloor instabilities and sediment deformation processes: the need for integrated, multi-disciplinary investigations
}

\author{
Maarten Vanneste ${ }^{\mathrm{a}}$, Nabil Sultan ${ }^{\mathrm{b}}$, Sebastian Garziglia $^{\mathrm{b}}$, Carl Fredrik Forsberg ${ }^{\mathrm{a}}$, \\ Jean-Sebastien L'Heureux ${ }^{a}$
}

\author{
${ }^{a}$ Norwegian Geotechnical Institute (NGI), Oslo, Norway \\ ${ }^{b}$ IFREMER, Brest, France
}

\begin{abstract}
:
In this paper, we present the current practice of investigations of seafloor instabilities and deformation processes, based on extensive research conducted over the last years, which sets the scene for future research activities in this field. The mapping of the continental margins and coastal areas with ever increasing resolution systematically reveals evidence of instabilities and deformation processes, both active and palaeo-features. In order to properly assess the hazards and risks related to these features, an integrated and multi-disciplinary approach is essential, but challenging. Such an approach consists of combining field data (geophysics, geology, sedimentology, geochemistry and geotechnical data) with numerical simulations constrained by results from laboratory data. As such, it is of paramount importance to build a common knowledge base and understanding that unify these disciplines into more complete and conceptual models constrained by all the data.
\end{abstract}

We review the status of this integrated approach adopted to palaeo-landslides (e.g., Storegga, Ana, Vesterålen) and recent deformations (Finneidfjord, Nice, Gulf of Guinea), allowing to identify gaps in our knowledge at these sites. By reviewing these case studies, one can conclude that each case remains highly site-specific in which both the regional and local geological-tectonic setting has a distinct effect of the type of instability or deformation taking place (or that can take place). Our knowledge on the actual triggers remains poorly constrained, and there is even ambiguity for historic landslides (e.g., Finneidfjord). Also our knowledge of the preconditioning factors is incomplete. There is a general lack of geotechnical data, both in situ and from laboratory, and therefore, modelling the dynamics (e.g., rheology) of the instabilities relies on a number of assumptions rather than facts. In addition, excess pore pressure and its evolution is one of the key parameters driving instabilities. Despite this fact, in situ (excess) pore pressure is rarely measured or monitored. Much work remains to be done to relate and integrate geotechnical data with geophysics, e.g., through inversion and rock physical models, in order to obtain additional quantitative information from the sub-surface, but also with respect to partial saturation (free gas, hydrate) and pore pressure behaviour, or lithologies.

It is of critical importance to be able to identify the different processes which can lead to hazardous situations which includes establishing recurrence intervals (timing and frequencies, through event recognition and age control) and magnitudes, so that proper mitigation measures can be developed. In this perspective, the smaller-scale instabilities deserve much attention, as there are many instances where such features had far-reaching consequences for society (e.g., Nice, Finneidfjord). In that perspective, human interferences (e.g., exploitation, drilling, blasting, loading) must be one of the factors taken into consideration. 


\section{Highlights}

Sediment deformation and instability processes require integrated investigations $>$ Regional geology and environment control pre-conditioning factors - There is paucity of high-quality geotechnical data and links with geophysics - Challenges remain with triggers, pore pressure, landslide dynamics and weak layers - Hazard and risk require event identification, recurrence frequency and magnitudes

Keywords : marine geotechnics ; slope stability ; sediment failures ; fluid flow ; shear strength ; marine geophysics ; monitoring ; excess pore pressure ; site investigations 


\section{Introduction}

\section{Outline of this paper}

The structure of this manuscript is different from a typical journal paper. Following a general introduction to our current knowledge of submarine instabilities and deformation features (Figure 1), we present the state-of-the-art with respect to data and analysis methods required for a multidisciplinary investigation of offshore geohazards, including suggestions for improvements. A significant part of the paper discusses results from carefully selected but generally well-known case studies (for location of these sites, see Figure 2), all the scene of extensive and longer-term research activities. In our selection criteria, we considered the type of sediment instability or deformation, its present or recent level of activity, our current knowledge about the controlling parameters as well as the variety of the data collected. None of these investigations is complete, and therefore, it allows for a gap analysis of our present-day knowledge of instabilities and deformation processes, shedding light on parameters or processes that are as of yet not well understood, are difficult to quantify properly, or assess. As such, lessons learned from these sites should be used to improve the current practise in this field, from survey planning over data acquisition, defining suitable laboratory programmes, numerical simulations and - importantly - integration of the multi-disciplinary data set.

We do not present a complete overview of all these case studies, but rather their unique or specific character in terms of the investigations performed from the authors' involvement. As such, we have all inside information necessary to evaluate the cases, from data acquisition to the integration of the results, and it is our aim to do so in an objective and unbiased way. Ultimately, we put the information into a larger perspective, with recommendations for further research and development, with implications for site investigations, deep water engineering applications, in situ testing, and data integration.

Nevertheless, our case studies are not representative for all instabilities worldwide. We emphasize that investigations on instabilities will retain a site-specific character where all possible factors need 
to be addressed. A few examples of causative or preconditioning factors not addressed in this paper are permafrost and freeze-thaw cycles, large sediment input at deltas, large tidal fluctuations, static and cyclic liquefaction, or creep. Other types of instabilities, like rock falls, lie beyond the scope of this work.

\section{Offshore Geohazards}

A geohazards is defined as a geological condition which represents - or has the potential to develop further into - a situation leading to damage or uncontrolled risk. Submarine landsliding is one of the most critical of offshore geohazards. Other examples include shallow sediment deformation phenomena (e.g., mud diapirism, gas chimneys, pockmarks, gas hydrates), but also shallow water flows, shallow gas accumulations, and seismicity (Figure 1). Specific threats to society are the disappearance of valuable land near the shorelines, devastation of coastal areas by landslidegenerated tsunamis and the destruction of seafloor installations (e.g., communication cables, pipelines, templates). Assessing and mitigating offshore geohazards also implies estimating of risks, where probabilities associated with the different scenarios are difficult to quantify (Vanneste et al., 2011a). This becomes of primary importance as exploration and field development has developed rapidly in areas where geohazards may pose a risk since the 1990's, considering that both natural causes and human interferences may provide the ultimate trigger for instability.

The results from large-scale national and international geosurvey efforts (e.g., MAREANO, Norway; MaGIC, Italy; ZEE project, Spain; UNCLOS, USA; NEREIDA, Canada) - in addition to the site surveying and reservoir imaging done by the offshore industry - to map the continental margins in ever increasing resolution, clearly indicate that recent mass movements with a variety of dimensions are common features on the seabed. More data were collected in the framework of dedicated slope stability investigation programmes, e.g., COSTA. In this paper, we discriminate between mass movements or slope instabilities on the one hand side and more local sediment deformation processes on the other side, as these phenomena may require different investigation methods due to 
their spatial extent. Having said this, all types of geohazards investigation imply the use of multiple disciplines across the geosciences, particularly geology, geophysics, geotechnics and geochemistry, but also numerical modelling/simulations and risk assessment.

\section{Submarine landslides - Go with the flow}

Submarine landslides occur worldwide in a large variety of geological-tectonic environments, for example open ocean settings on passive margins (e.g., Grand Banks (Piper et al., 1999), Storegga (Bugge et al., 1988; Solheim et al., 2005a), Hinlopen-Yermak (Vanneste et al., 2006; Vanneste et al., 2011b), Big'95 (Lastras et al., 2004a), on active margins (Goldfinger et al., 2000; Cochonat et al., 2002), in volcanic areas and island flanks (Moore et al., 1989; Masson et al., 1998), but also in lakes (Bøe et al., 2004; Strasser et al., 2007; Vardy et al., 2010) and fjords (Longva et al., 2003; Levesque et al., 2006; L'Heureux, 2009; Vanneste et al., 2013). Most - if not all - of the submarine landslides develop in a common pattern, irrespective of the landslide type (slump, slide, debris flow, etc.) (Canals et al., 2004); nevertheless, from the pre-failure, failure to the post-failure stage, each deformation phase and landslide process depends on a number of predisposing, triggering or aggravating and revealing factors (Vaunat and Leroueil, 2002). Several of these factors remain poorly understood and are site-specific.

1. The first factor consists of long-and short-term preconditioning, during which a combination of global, regional and local environmental conditions (e.g., sedimentation, erosion, fluid migration, rainfall, and the like) bring the slope close to failure. Destabilizing factors include high sedimentation rates, unfavourable sediment layering, climate variability affecting sedimentation processes, oversteepening, and fluid flow related factors (e.g., gas, hydrates, diapirism, mud volcanoes) (Locat and Lee, 2002). A common factor is the build-up of excess pore pressure, which reduces the effective stress and therefore also the resistance to failure under gravity. Particular conditions apply to coastal areas in formerly glaciated margins, where quick clays (defined as 
clays with extreme sensitivity,the ratio of undisturbed and remoulded undrained shear strength) are a major hazard in the near-shore area.

2. The second factor is the actual trigger, setting off the instability, facilitated by weakened local and regional conditions. The trigger depends on how far the preconditioning has progressed but also on the sediment behaviour. Seismicity, particularly (large) earthquakes, are the most commonly cited triggers. The reasons for this are that seismicity can provide pore pressure build up due to ground shaking, and subsequently sediment deformations or - ultimately - liquefactions. However, the actual trigger is for many submarine mass movements unknown, and even for historical cases, there is commonly a large degree of uncertainty, as multiple factors can play a role. A recent compilation of historic landslides in the Norwegian fjords indicates that human activity (e.g., loading of the foreshore area, blasting for tunnel or road works) has triggered about $60 \%$ of these instabilities (L'Heureux et al., 2011). A recent compilation of late-Quaternary landslides suggests that there is no distinct correlation between landslide frequency and sea level changes (Urlaub et al., 2013).

3. Once triggered, the landslide typically evolves rapidly. Many of the submarine landslides have a multi-phase and retrogressive development, thus cutting upslope after losing support at the toes (Kvalstad et al., 2005a), leaving a particular geomorphology in the slide scar area. During the mass movement, the sediments disintegrate, mix and erode before being deposited downslope, including the generation of turbidity currents. The remobilized mass frequently travels over large distances, even on gently dipping slopes (Kvalstad et al., 2005a), which is one of the main differences with instabilities happening onshore. Often, the debris slurry embeds rafted blocks (Lastras et al., 2005; Vanneste et al., 2006). The landslide dynamics and run-out depend on the lithology (e.g., clay-rich or sand-rich sediments), rheology and thickness; and they may involve different flow regimes (Elverhøi et al., 2010). Modelling landslide dynamics (including hydroplaning, progressive remoulding, pore pressure variations, water entrainment, $2 \mathrm{D}$ vs. 3D, ...), constrained by the field data, is therefore a highly complex but essential topic to understand 
and forecast the implications for society. In addition, available data from submarine landslides are largely restricted to run-out distance and final deposition, with little information on e.g., flow velocities. Therefore, laboratory measurements, including tests with mixed lithologies, are important to fill these gaps.

4. The potential consequences of the instabilities are related to impacts of either the water displaced (tsunamis) or the interaction of the moving masses with seabed infrastructure (impact). Mass movements along the seabed invariably create waves. Landslide-generated tsunamis propagate less efficiently compared to their earthquake-triggered counterparts. Nevertheless, high local sea surface elevations may occur, with more locally constrained run-up pattern. Tsunami hazards depend on acceleration and volume (Harbitz et al., 2006). Mitigation is essential for reducing the impact of debris flows on infrastructure. Designing proper mitigation measures relies on the integration of field data with extensive laboratory flume tests and numerical simulations, as it depends on the drag forces for the given rheologies (Zakeri, 2008).

Submarine landslides differ in several aspects from subaerial landslides. Submarine instabilities often involve (much) larger volumes of sediments, and can develop over much lower gradients. Despite this, their mobility or run-out can be orders of magnitude higher. Furthermore, turbidity current can be generated as one of the by-products in the marine environment. The geomorphology in the submarine headwall areas can resemble escarpments in, for example, quick clay landslide scars or flank collapses.

It is worth noting that the methods used to study submarine and subaerial landslides differ as well. Whereas the former is predominantly investigated using seismo-acoustic methods, one has typically more geotechnical data and aerial photographs for the latter. Furthermore, monitoring of active processes is more common onshore. 


\section{Sediment deformation structures}

Sediment deformation structures, typically caused by active processes at depth (e.g., subduction, folding, mud or salt diapirism, fluid migration) can also be considered a geohazard, particularly with respect to seabed infrastructure (e.g., templates, pipelines, foundations). Some examples are mud volcanoes, active seeps and pockmarks, which are the surface expressions typically related to fluid migration or movement of muds (Milkov, 2000; Judd and Hovland, 2007). Activity of these features can be highly variable, from dormant, to episodic and nearly-continuous. The Håkon Mosby mud volcano, off the Barents Sea margin, is one example (Perez-Garcia et al., 2009).

Pockmarks are common features in many areas around the world and in various depositional settings, from fine-grained sedimentary environments around the equator (Pilcher and Argent, 2007; Sultan et al., 2010a) to high-latitude environments (Hovland and Svensen, 2006; Forsberg et al., 2007a). They occur in shallow (Rogers et al., 2006) and deep waters (Judd and Hovland, 2007; Moss et al., 2012), but also in lacustrine environments (Pickrill, 1993; Van Rensbergen et al., 2002) and fjords (Forwick et al., 2009; Webb et al., 2009). It is generally accepted that pockmarks form as a result of fluid seepage through the seabed (Judd and Hovland, 2007), and often they appear on top of gas chimneys (Bouriak et al., 2000; Hustoft et al., 2007). However, the mechanisms through which seepage occurs and how the seabed is deformed over time remain poorly constrained, but hydro-fracturing - i.e., fracturing of the sediment due to overpressured fluids - plays an important role (Sultan et al., 2010a).

Deformation structures develop in a similar way as the mass movements described above, i.e., they typically require preconditioning, triggers, and are characterised by various phases in their evolution. Considering the need for hydro-fracturing, fluid pressure must exceed the least principal stress and tensile strength of the sediment (Sultan et al., 2010a; Davies et al., 2012).Also for deformation structures, the actual trigger mechanisms are difficult to pin-point. The evolution of sediment deformation structures is site-specific and controlled by the local settings as well as the intensity and continuity of the processes involved. Most often, different phases of development can be identified 
from geophysical and geochemical data (Judd and Hovland, 2007; Perez-Garcia et al., 2009; Sultan et al., 2010a). In this perspective, long-term monitoring of pressure and temperature are critical parameters for investigating the dynamics and activity of such features. The time scale over which deformation structures evolve are highly variable. Often they require geological time scales,e.g., for the Håkon Mosby mud volcano (Perez-Garcia et al., 2009). There are, however, also instances of deformation structures that form on very short time scales, in the order of weeks to months, and often involving human interference. Seabed depressions may form as a result of injection of muds or fluids in sand reservoirs, due to fracturing, formation bypassing or poor well integrity. Several examples exist from the North Sea area, where such features appear shortly after the injection process was initiated (Koldgaard Eriksen, 2012). Similar processes related to puncturing overpressured gas may lead to blow-out craters (Judd and Hovland, 2007).

\section{Hazard assessment}

Sediment instabilities or deformation processes are not necessarily a hazard, as they may occur without affecting society through damage or uncontrolled risk. Nevertheless, geohazards are typically investigation for all offshore projects (installation of seabed infrastructure and boreholes), particularly now the offshore energy sector moves beyond the continental shelf areas. When addressing the hazards, the most critical aspect is the likelihood of instabilities or deformation to occur, but also the time frame of multi-phase events, considering the implications for e.g., tsunami generation. Therefore, geoscientists need to address the current activity, multi-phase nature, the timing and frequency of palaeo-events as well as their magnitudes, which inherently rely on proper identification of relevant features, age-control and impact scenarios. This can only be accomplished by a multi-disciplinary investigation.

\section{Approaches, Data and Methods, and Challenges}

\section{Geophysical mapping}

A proper understanding of the local and regional geology is of paramount importance in geohazard assessment, particularly for defining the preconditioning factors and finding evidence of past 
instabilities. Such knowledge primarily depends on the use of several geophysical techniques, particularly backscatter, bathymetry and a variety of seismic data. Geophysical mapping has improved significantly over the last decade, due to advances in source and receiver sensor technology, data transfer, hardware architecture and computational facilities. These improvements gradually allow establishing a more detailed image of the seafloor and sub-seafloor geomorphology over larger areas.

We note that there is a significant degree of variation with respect to the tools used in, e.g., academia and the offshore industry. Whereas the former typically use simpler systems operated from research vessels, the latter often deploy much larger seismic arrays and sweep the seabed with deeptow ROV or AUV systems, in the quest for higher-resolution characterization. Spatial resolution and illumination are important parameters in the survey planning as it has implications on geohazards assessment (Ker et al., 2010).

\section{Bathymetry data}

Bathymetry data are the primary source to identify relatively recent deformations and instabilities, as these typically have a subtle to very distinct geomorphological imprint on the seabed. Beam-forming techniques like multibeam or swath bathymetry data have become the standard for seabed mapping over the last decades, and most of the research vessels have at least one (often hull-mounted) bathymetric system operating these days. Alternatively, interferometric systems are available as well. The spatial resolution of the swath bathymetry data decreases with increasing water depth and increasing source frequencies, and comes down on the number of beam hits per unit area, a characteristic that is rarely reported in publications, but which is essential for reliable mapping of seabed features. Depending on water depth and source frequency, bin sizes for bathymetry grids are typically around $1 \times 1 \mathrm{~m}^{2}$ (very shallow) to $100 \times 100 \mathrm{~m}^{2}$ (deep water). As a reference, for pipeline surveys and inspection, the offshore industry often collects AUV bathymetry data with $0.1 \times 0.1 \mathrm{~m}^{2}$ bin size along the entire route. In deep-water environments, the seafloor reflection from 3D seismic 
data volumes may well provide bathymetric data with higher spatial resolution compared to hullmounted swath bathymetry systems (Mosher et al., 2006).

High-resolution bathymetry data are the primary tool to identify failures on the modern seafloor; nevertheless, the occurrence of landslide features does not imply recent instability. As sedimentation tends to flatten out topographic relief with time, slide scars will eventually be partially or completely draped by post-slide sediments. In areas with (very) low sedimentation rates, this may take tens of thousands of years. On the other hand, the Godovari River delta is an area with extreme sedimentation rates.a recent landslide (few hundred years old) with a more than $100 \mathrm{~m}$ high escarpment is completely filled with sediments (Forsberg et al., 2007b), leaving a smooth seabed topography.. Therefore, the lack of seafloor expression does not imply that recent mass movements have not taken place, and is not sufficient for a hazard assessment. Geophysical data indicate that many submarine instabilities and deformations develop in multiple phases. However, only dedicated age-control programmes on the retrieved samples can establish the proper time frame of the different phases (Haflidason et al., 2005).

\section{Side-scan sonar and backscatter data}

Side-scan sonar data, obtained from ROV or AUV, provide images of the seabed that are used for seabed classification, including maritime archaeology. These data are complementary to bathymetry data. The image is based on the intensity of the acoustic signal (typically tens of $\mathrm{kHz}$ in frequency) that is backscattered from the seabed. Compared to hull-mounted systems, the spatial resolution of side-scan sonar systems can well be superior. One example is the observation of different types of mass movements on side-scan sonar that went unnoticed on swath bathymetry data off the Lofoten Islands, Norway (Baeten et al., 2013). Resolution is often different across-track and along-track for side-scan sonar data.

Swath bathymetry systems can also collect backscatter data, using the intensity of the returned signal rather than the travel time. Despite this possibility and the fact that these data are complementary to 
bathymetry data, backscatter data from multibeam systems are either not systematically recorded during the survey, or not processed and presented.

\section{Seismic data and remote physical properties}

$P$-wave seismic data remain the primary tool to understand the regional geological history of an area, as well as providing the evidence for previous landsliding and deformation. Whereas seabed mapping is relatively straightforward, sub-seafloor imaging becomes complex as attenuation may degrade the wavefields and complicate the data interpretation. Depending on the power, frequency and bandwidth of the source and layout of the receiver array(s), one obtains 2D to 4D cross-sections and volumes of the sub-surface in either time or depth domain (Yilmaz, 2001). Most often, a variety of 2D profiles using different sources remain the most prominent source of information. For shallow features, the so-called sub-bottom profiling data (parametric systems like TOPAS) are popular. Otherwise, sparker, water gun, and (tuned) sleeve gun data using either single-channel or multichannel streamers provide the bulk of the data used in such studies. For proper imaging, a 3D seismic approach is essential. Many 3D surveys show buried MTDs, but few 3D data reveal landslides at the modern seafloor, 3D data come with different flavours, from conventional exploration 3D (Bünz et al., 2005; Frey Martinez et al., 2005; Gee et al., 2007), but recently also from novel high-resolution 3D (Berndt et al., 2012) and ultra-high-resolution 3D (Vardy et al., 2012) systems. Sediment deformation structures, like pockmarks and mud volcanoes, are also imaged using high-resolution 3D systems (Hustoft et al., 2007; Sultan et al., 2007b; Perez-Garcia et al., 2011; Sultan et al., 2011; Bünz et al., 2012). There is furthermore a wealth of specific 3D seismic attributes (e.g., coherency, chimney cubes) that can assist in geohazard investigations (Meldahl et al., 2001; Cartwright and Huuse, 2005). With respect to hazard assessment, the frequency of failures is one of the critical parameters, and therefore, recognition of palaeo-events like MTDs and escarpments from 2D and 3D seismic data is essential. In addition to seismic stratigraphy, the geophysical data can furthermore be used to target horizons or samples for age control (e.g., AMS ${ }^{14} \mathrm{C}$, isotopic methods, tephrachronology, magnetostratigraphy). 
Including S-wave data has several advantages, particularly with respect to imaging (e.g., gas charged sediments, fluid migration, faulting), sub-surface characterization (lithology discrimination, anisotropy, geomechanics) and quantification (e.g., hydrate saturation, excess pore pressure) (Engelmark, 2001; Stewart et al., 2003; Vanneste et al., 2007; Westbrook et al., 2008). These techniques rely on conversion of $P$-waves into $S$-waves upon reflection, using conventional airguns and four-component (three geophones and one hydrophone) receivers coupled to the seabed, necessitated by the fact that $S$-waves do not propagate through fluids. $S$-waves are not yet used to their full potential, except for investigating the distribution and accumulation mode of hydrates in combination with rock physical models (Katzman et al., 1994; Minshull et al., 1994; Guering et al., 1999; Yuan et al., 1999; Ecker et al., 2000; Jakobsen et al., 2000; Tinivella and Carcione, 2001; Westbrook et al., 2005). For geotechnical purposes (top few tens of metres), inversion of surface waves can yield a high-resolution shear wave velocity profile with depth (Socco et al., 2011; Vanneste et al., 2011c). Whereas this is common-practise for land applications, it is a rare feat in the marine environment as there are stringent conditions to be applied on the source and receiver side (Vanneste et al., 2011c).

In addition to seismic velocities, seismic wave propagation also depends on intrinsic attenuation and scattering. Attenuation can be inverted for physical properties, which adds further detail to the characterization of the site under investigation. In the case where only near-zero-offset seismic data are available - and hence seismic velocities cannot be determined - attenuation is one of few parameters that can be derived from variable-window time-frequency transforms of the data (Reine et al., 2009). Different theories that relate intrinsic attenuation or quality factors $Q$ to sediment properties exist. The two main theories are (i) grain sliding and (ii) squirt flow. In the former, shearing between grains causes energy loss or dissipation, and the quality factor can be inverted into mean grain sizes of the sediment (Pinson et al., 2008). In the latter, velocity dispersion between the different phases composing the sediment or rock causes energy dissipation (Pride et al., 2004). Combined with a genetic inversion algorithm, the quality factor yields information on partial 
saturation values, e.g., gas content (Morgan et al., 2012). The importance is that both lithology and partial saturation can have implications for geohazards, and therefore, inversion schemes are necessary for a more quantitative approach to characterize the sub-surface.

Other non-seismic geophysical techniques, like electromagnetism (EM), are rarely used for geohazard assessment. Nevertheless, combining EM with seismic adds complementary information, particularly for porosity and fluid saturation (Weitemeyer et al., 2011).

\section{Sampling and in situ geotechnical characterization}

A geohazard assessment cannot be successfully conducted without samples and geotechnical data, as they provide the ground truth and essential parameters for hydro-mechanical modelling and engineering applications. Geotechnical investigations combining laboratory and in situ tests allow for a reliable and comprehensive analysis of sediment strength, deformation and flow properties as well as pore pressure regime. Table 1 includes examples and references illustrating the importance of such in situ testing in both academic and industrial projects. A detailed review of these tools lies beyond the scope of this paper, but Figure 3 presents a representative selection of state-of-the-art academic seabed sampling tools used for in situ geotechnical data collection, including IFREMER's Calypso piston corer and MARUM's MeBo (Meeresboden-Bohrgerät or sea floor drill rig) sampling systems; IFREMER's Penfeld cone-penetration test system (CPTU) and MARUM's FF-CPTU in situ logging systems; and IFREMER's piezometer and tiltmeter systems for monitoring purposes (Strout and Tjelta, 2005; Tjelta et al., 2007; Sultan et al., 2010a; Sultan et al., 2010b; Lunne, 2012; Steiner et al., 2012; Vanneste et al., 2013).

Cone penetration testing (CPT), preferentially with pore pressure response measurements (CPTU), is the primary geotechnical tool used to collect continuous, in situ geotechnical data, and is widely used for offshore site investigations (Lunne et al., 1997; Lunne, 2012) (Figure 3). The standard CPTU instrument is pushed in the seabed, with a fixed penetration velocity of $2 \mathrm{~cm} / \mathrm{s}$, and it logs (i) the resistance at the tip $\left(q_{c}\right)$, (ii) the friction along the sleeve above the tip $\left(f_{s}\right)$, and (iii) the pore pressure 
response $\left(u_{2}\right)$. CPTU is a highly efficient method to obtain the geotechnical stratigraphy, lithology, shear strength, relative density, and other engineering parameters. Furthermore, the cone can be equipped with additional sensors (e.g., inclinometer, temperature, density, etc.). In addition to the CPTU deployed from a seabed rig or frame, new developments include free-fall CPTU systems, which require several additional accelerometers to calculate the depth accurately (Steiner et al., 2012) (Figure 3). The free-fall data typically require further processing compared with conventional systems, as they yield dynamic properties over static ones (constant penetration rate).

The pressure measured with CPTU is not the in situ pore pressure, but rather the fluid pressure response due to penetration of the cone. The same systems can be used for pore pressure dissipation tests, by measuring how the pore pressure evolves over time at a given sub-surface depth. However, it takes a very long time to reach equilibrium (i.e., in situ pore pressure) in fine-grained sediments. Therefore, reliable pore pressure measurements require long-term monitoring (Strout and Tjelta, 2005). A variety of piezometer systems exists (Figure 3; Table 1), either reading differential or total pressure, single- or multi-level instruments that can be installed in boreholes or using CPTU frames (Strout and Tjelta, 2005), or deployed from free-fall systems (Stegmann et al., 2011). In any case, it is vital to identify pore pressure regimes from mid- to long-term for a proper understanding of the activity of geological processes, but also for planning and execution of laboratory tests (Kvalstad, 2007).

Ideally, one should conduct a variety of complementary laboratory tests on samples retrieved from the seabed, for both physical, sedimentological and geotechnical purposes (Craig, 1997; St-Onge et al., 2007):

a) Physical logging, e.g., using multi-sensor core logging (MSCL), yields very-high-resolution density, $P$-wave velocity and magnetic susceptibility measurements per default. Other sensors can be mounted to scan other physical properties. In addition to the logged parameters, the curves can provide information on e.g. provenance and sedimentary processes. 
b) X-ray and CT (computer tomography) reveals the internal structure and partly lithofacies within the sediment core. These data are important to select the proper target intervals for advanced geotechnical testing.

c) Similarly, $X$-ray fluorescence scans for relative abundance of major chemical elements that can be used for sedimentology and provenance, in addition to clay mineralogy through X-ray diffractometry.

d) For dating purposes, one needs sufficient volume of material, e.g., organic material for $\mathrm{AMS}^{14} \mathrm{C}$, both to determine a sedimentation model as well as accurately dating landslide events.

e) Standard geotechnical tests include grain size distribution, water content (i.e., the ratio of mass of water and the mass of the solids), bulk density, and for fine-grained sediments the Atterberg limits and derived variables (e.g., plastic and liquid limits, plasticity and liquidity index). Often, fall-cone tests or vane shear tests give an indication of the shear strength and sensitivity of cohesive sediments. For grain size distributions, one has to pay attention to the technique used, as results from different techniques (e.g., falling drop, laser diffraction) are not necessarily comparable. From our experience, laser diffraction techniques systematically underestimate the clay fraction ( $<2$ microns). The difference in clay fraction can be easily 10 to $20 \%$ when compared to other methods. This discrepancy has significant consequences for describing the lithology and thus the models used for analysing the geotechnical behaviour of the sediment.

f) Advanced geotechnical laboratory tests are a variety of shear strength tests (undrained triaxial test under compression or extension (taking into account anisotropy); direct simple shear (DSS); ring shear tests; resonant column) and consolidation tests (e.g., oedometer tests to define preconsolidation stresses and over-consolidation ratio, OCR). One should carefully evaluate the appropriate stress levels (as well as in situ pore pressure conditions) for conducting these tests. During some of these tests, other key parameters like permeability, can be measured. These specific tests also allow calibration of the CPTU data (e.g., triaxial tests to constrain cone factors used in determining undrained shear strength) (Lunne et al., 1997; Lunne, 2012). Furthermore, 
the behaviour of the sediment under cyclic loading should be evaluated, particularly to study the effect of e.g., seismicity and wave action. All tests should be performed according to international standards.

One important observation is that sediment sampling (e.g., box coring, gravity coring, piston coring, vibro coring) is a destructive and invasive method. Therefore, samples retrieved from the seabed and analysed in the laboratory may be disturbed, so that the measured properties may not be representative for the in situ conditions (Lunne et al., 1998; Lunne et al., 2001). Recently, the use of accelerometers and pressure gauges on IFREMER's Calypso corers (Bourillet et al., 2007) and Fugro's STACOR system allows for improved sample quality, recovery and penetration depth. However, sample deformation (Figure 3) is almost inevitable with all types of coring equipment, even those specifically designed to reduce piston movements, like STACOR. Some of the geotechnical parameters affected are the natural structure, the volume change when consolidating back to the in situ stresses, the shear strength, the strain at peak stress, natural structure, consolidation coefficients, and other. Figure 4 illustrates the effect of tube sampling compared to results on a virtually undisturbed block sample for anisotropically-consolidated triaxial compression tests and constant-rate-of-strain oedometer tests. Sample quality is, however, rarely mentioned despite its importance. We realise that determining the sample quality is not a straightforward task. One method for assessing sample quality for cohesive sediments (with OCR less than 4) is an evaluation (from oedometer, DSS, triaxial or resonant column testing) based on the change in void ratio (volume of voids per volume of solids) relative to the initial void ratio when consolidating the specimen back to the best estimate of the in situ vertical stress (Lunne et al., 1998). One often finds that the sample quality can be poor, which should be taken into account when evaluating the results, as it implies that the fine-scale structure providing strength, deformation and fluid flow properties to the sediment is damaged. Specific handling of the samples is also important, particularly for very soft or loose sediments (e.g., Holocene clays, loose sands). 


\section{Constitutive soil modelling}

The interaction between the mechanical behaviour of materials and mechanisms triggering instability is key to understanding and explaining the causes of landslides and sediment deformation. Depending on the type of loading and the sediment properties, various constitutive models exist to simulate deformation processes. Table 2 summarizes examples of such interactions and presents some critical conditions for sediment deformation. For example, the most critical material under an earthquake loading is a loose sand that may liquefy. On the other side, overloading may be detrimental for structured and sensitive clays, as these sediments may develop strain-softening behaviour (Andresen and Jostad, 2007).

The presence of gas bubbles can have a significant effect on the behaviour of fine-grained sediments, as it leads to a higher compressibility, typically a lower shear strength and a reduction in the intrinsic permeability of the medium (Wheeler, 1988b, a; Lunne et al., 2001; Sultan et al., 2012). The most critical stress path occurs during unloading, as it induces gas exsolution and subsequent expansion, during which the sediments often deform or become damaged (Sobkowicz and Morgenstern, 1984; Lunne et al., 2001; Amaratunga and Grozic, 2009; Sultan et al., 2012). As an illustration, Figure 5 presents two mechanical behaviours under different loadings. Note that there is some similarity with sample deformation discussed above (see Figure 4).

Figure 5 presents data from Bothkennar clays undergoing anisotropically-consolidated undrained triaxial shear in compression (CAUC). The results revealed the effect of gas exsolution upon unloading of marine clays for the first time (Lunne et al., 2001). This soft to firm silty clay, with high organic content, has a relatively high plasticity index around $50 \%$ and undrained vane shear strength around $30 \mathrm{kPa}$. However, bioturbation and subsequent partial cementation are responsible for natural variability in these sediments (Lunne et al., 2001). Gas exsolution and expansion cause a significant reduction in peak shear strength of the sediments. The same authors illustrate that destructuring by gas exsolution affects the effective stress path. 
For Gulf of Guinea (GoG) clays, the structure of the material largely governs its mechanical behaviour (Figure 5). These clays have high sensitivity, water content, plasticity and compressibility (Sultan et al., 2012). The rigid pre-yield response of the natural GoG sediments is related to the strong structure of the clay, whereas the high effective friction angle is related to a sand-like behaviour of the material in which aggregates play the role of sand-sized elements (Le et al., 2008). When performing tests at a stress state four times higher than the in situ stress, the response is different and smaller effective friction angles characterise the failure (Figure 5). Progressive destructuring of the material explains the pronounced effect on the mechanical properties of the clay under increasing stress level.

These figures and observations (Figure 4, Figure 5, Table 2) clearly indicate that different constitutive relations exist between materials under loading and unloading. Therefore, it is of paramount importance to carefully select a proper constitutive law in the assessment of landslides and sediment deformation processes.

\section{Numerical simulations of landslide dynamics}

A number of methods exist to numerically analyse the stability of a slope, with varying degree of complexity. Examples are infinite slope method (ISM), limit-equilibrium method (LEM), limit-analysis method (LAM), energetic method (EM), finite-element method (FEM), but also computational fluid dynamics (CFD). In practise, the ISM is commonly used as a first approach, irrespective of whether or not the landslide is translational or rotational. LEM is attractive, as one can easily include the geometry, sediment heterogeneity and pressure conditions in the analysis, but it requires a failure mechanism. The critical failure plane is the one that corresponds to the lowest Factor of Safety (FoS), from examining a large number of different failure planes. LAM includes the upper bound theorem of plasticity in the analysis, and is a more rigorous approach (Michalowski, 1995; Chen et al., 2001a; Chen et al., 2001b). The failure surface must satisfy mechanical boundary conditions, and the velocity field must be kinematically in agreement with boundary conditions, thus allowing calculation of the strain rates delimited by the failure surface. These type of models were used successfully to evaluate 
and illustrate the effects of some external mechanisms on submarine slope stability. Examples are the 2D-wedge model (Nadim et al., 2003), and the 3D slope stability model - SAMU-3D (Sultan et al., 2007a). The slide block model, successfully applied to Storegga (Kvalstad et al., 2005a), falls into the EM category. The model is based on conservation of energy, but assumes that an initial block has moved at the toe. Initial unloading causes expansion of the sediment and strain concentration at the toe, with strain softening within specific sediment layers. This leads to unfavourable conditions (FoS $<$ 1) and retrogression. The evolution of this process can involve different failure planes within the stratigraphy (stepping upwards), until too little energy remains available for failure to propagate further. This model creates a morphology similar to what can be observed in the Storegga area (Kvalstad et al., 2005a). Governing equations in the CFD approach are mass balance and momentum (Gauer et al., 2005). Combined with strain-softening behaviour, numerical simulations from the CFD approach are in good agreement with the geomorphology of the (latest phase of the) Storegga slide, and illustrate the effect of strain softening (Gauer et al., 2005). In all cases, the input geotechnical and rheological parameters and rheology are essential.

Determining the FoS using finite element methods (FEM) consists in calculating the maximum displacement for various FoS values. The FoS is used to reduce the shear strength parameters (cohesion or shear strength and internal friction angle) to bring the slope to a limiting state or failure. The main advantage of the FEM over the conventional limit-equilibrium method is the possibility to consider the complex stress-strain behaviour of the sediments involved (e.g., strain softening of the materials). Nevertheless, accounting for spatial variations in sediment properties remain a challenge.

The results obtained from the slope stability modelling and geophysical data define the initial geometry and volume for post-failure sediment evolutions, and are key input parameters into numerical modelling of gravity flows. Often, the yield shear strength of the involved material is the main strength parameters in these calculation (i.e. BING software (Imran et al., 2001)). However, one of the critical issues for this type of modelling is the material strength evolution from porous medium 
behaviour (pre-failure) to fluid-like behaviour (post-failure). The interaction between the seabed and sediment currents (erosion/deposition) is another important concern to consider in the gravity flow modelling (Mulder et al., 1998).

\section{Selected case studies: knowns and unknowns}

In this section, we review a number of case studies of sediment instabilities and deformations (for location, see Figure 2). All these have been the scene of several years of investigations by international consortia, typically including different parties (academia, government, offshore industry). The selection was based on several criteria, including dimensions, geographic location, triggers, and the type of data that was collected at the sites. The list is of course not exhaustive; however, we consider the selected cases as exemplary for a multi-disciplinary approach on sediment instabilities and deformation.

\section{Palaeo-slope failures and deformations}

\section{Giant landslides: Storegga}

The discovery of a significant gas field within the slide scar area of the Storegga landslide, off Norway (for location, see Figure 2), resulted in an unprecedented multi-disciplinary investigation for the safe development of the reservoir by a joint venture between the offshore industry and research institutes (Solheim et al., 2005b). This investigation is undoubtedly the largest effort undertaken to understand the causes and consequences of submarine landsliding, and this would not have been possible without the commercial interest.

The Storegga landslide, dated at around $8.20 \pm 0.25 \mathrm{ka}$, is the latest phase of repeated and giant failures that characterize the Quaternary record off Norway (Bugge et al., 1988; Evans et al., 1996; Solheim et al., 2005a). The $850 \mathrm{~km}$ long landslide involved about $3000 \mathrm{~km}^{3}$ of sediments, and developed on a very low angle slope. The headwall located at the shelf break is approximately $300 \mathrm{~km}$ long (Bryn et al., 2005). The glacial imprint is very distinct on the continental shelf, with crossshelf troughs that served as conduits for fast-flowing ice streams between overconsolidated 
segments where slowly moving to stagnant ice domes were located during glacial periods (Ottesen et al., 2005). The ice streams are responsible for depositing large volumes of sediment derived from the hinterland and the shelf on the upper slope, building out large glacigenic submarine fans, like the North Sea Fan (Ottesen et al., 2005). During interglacial periods, warmer ocean currents sweep the margin, and typically deposit and rework fine-grained sediments (contourites). Pre-Quaternary oozes were also deposited over large areas, but they became rapidly buried by prograding shelf and slope deposits during the Quaternary. Ice stream pathways may well vary from one glacial period to the next (Dowdeswell et al., 2006), resulting in large variability with latitude. Seismic and chronostratigraphy indicate that single (but multi-phase) massive failures events typically occur once every interglacial and that the contouritic marine clays define the slip planes. During the Last Glacial Maximum, sediment was mainly fed by ice streams into the North Sea Fan through the Norwegian Channel, and to a lesser extent from the shelf areas north of the escarpment. However, no landslide had occurred during the previous interglacial period (Eemian). Therefore, the Saalian depocentres which coincided with the Storegga escarpment, were still in place and available for remobilization, and they contributed to the Storegga landslide when it developed.

A wealth of multi-disciplinary data were collected from the Storegga area, in undisturbed areas, the slide scar area, and the different depositional lobes. The site was, to our knowledge, the first landslide that was mapped with high-resolution swath bathymetry data ( $25 \mathrm{~m}$ by $25 \mathrm{~m}$ ), side-scan sonar, a variety of single-channel, 2D multi-channel and 3D geophysical data, ocean-bottom seismometers, a series of deep boreholes for geotechnical analysis (full scope of tests applied) and sedimentological-geochemical analysis (Solheim et al., 2005b). All data were used for advanced landslide dynamics (Gauer et al., 2005) and tsunami simulations (Løvholt et al., 2005). As the terrain shaped by the failure provides significant challenges with respect to pipeline routing and site locations, additional higher-resolution geophysical data were collected where necessary. 
Interpretation of the geomorphology (Figure 6) as well as a large number of ${ }^{14} \mathrm{C}$ AMS radiocarbon dates lead to the conclusion that the Holocene Storegga Slide had developed in multiple phases but at the same time, in a retrogressive way (Haflidason et al., 2005; Kvalstad et al., 2005a). The trigger could have been a large-magnitude earthquake, and preconditioning of the sediments was a combination of excess pore pressure from rapid periglacial sedimentation and sediment stratigraphy (interlayered glacial and contouritic sediments). The large-magnitude earthquake is thought to be the result of crustal stress induced by isostatic adjustments due to glacial retreat and sediment loading. While the excess pore pressure was greatest under the glacial depocentres, the oozes are both more compressible and have a much higher permeability ( 2 orders of magnitude) than the Quaternary sediments. Modelling demonstrated that the excess pore pressure from sediment loading would migrate towards the mid-slope area, where the overburden is thinnest (Figure 7), causing a larger excess pore pressure ratio at about the time of failure.

The stratigraphic preconditioning is demonstrated by geotechnical data that show a distinct difference in strength behaviour between the lower-plasticity, normally-consolidated glacial clays and the higher-plasticity slightly overconsolidated marine clays (OCR around 1.5), with the latter showing strain softening (i.e., loss of strength after peak strength is reached with ongoing strain) (Figure 8). As such, these layers gradually become weaker when strained, and are often called "weak layers". However, the weakening depends on the type of loading (e.g., static or cyclic), and it therefore only becomes weaker under given circumstances (Kvalstad et al., 2005b). The lack of support at the base caused progressive failure in these marine clays, causing back-stepping of the failure. Retrogression came to a halt at the shelf break, where glacially-overconsolidated sediments are dominant and the layering becomes sub-horizontal (Gauer et al., 2005; Kvalstad et al., 2005a).

Long-term pore pressure measurements indicate that there remains elevated pore pressure on the shelf and upper slide scar area where less sediments were removed (Strout and Tjelta, 2005). There is 
no remaining excess pore pressure at the Ormen Lange location, where the thickest material was removed by the landslide (Strout and Tjelta, 2005).

There remains controversy on the actual role gas hydrates play in setting off submarine landslides, e.g., the Storegga Slide. There is indirect evidence of gas hydrates (i.e., bottom-simulating reflection (BSR)) along the northern flank of the Storegga slide area (Bouriak and Akhmetjanov, 1998; Bünz et al., 2003). Hydrate dissociation likely generates excess pore pressures, and thus undermine stability, as a peculiar preconditioning factor. The main phase of hydrate dissociation around the BSR, in response to changing environmental conditions takes place well before the landslide set off (Mienert et al., 2005). When including solubility, pore water chemistry and pore sizes, hydrate dissolution would initiate at the top of the hydrate accumulation zone rather than at the base, and hydrate melting due to a change in gas solubility could be at the origin of a retrogressive failure (Sultan et al., 2004). Hydrate dissociation would only be a contributing factor along the northern flank. Arguments against this hypothesis are disparity of the inferred zone of dissociation along a horizon that crosscuts the stratigraphy whereas the geophysical and geotechnical data support failure within specific stratigraphic layers (contourites), as well as the staircase profile with multiple escarpments involving sediments at different depths. The very low slope also necessitates a retrogressive development. Furthermore, climate-induced hydrate dissociation is most sensitive in relatively shallow water areas (less than about $750 \mathrm{~m}$ ) whereas the initial instability likely took place on the steeper lower slope where environmental changes left the hydrate stability conditions virtually untouched. These observations call for further investigations and particularly calibration with proper laboratory testing of the effect of hydrate melting and partial gas saturation on the stress-strain behaviour of the sediments (including fine-grained sediments).

The understanding of the Storegga Slide is based on the long-term geological setting characterized by rapid glacial sediment accumulation on top of fine-grained, contouritic marine deposits. The alternating sequences of glacial and interglacial deposits provide critical preconditioning factors. Also 
the structural setting plays a role, as this area lies in between stable structural elements (volcanic margins), being the Faeroe high and the Vøring high, providing a gateway for sediment transport and therefore focusing landslides to this area. The geological record indicates that a combination of both led to instabilities within the marine deposits during successive glacial cycles, for the last 1 million years (Solheim et al., 2005a).

Knowledge gaps: The Storegga Slide is undoubtedly one of the best-known submarine landslides. The pre-slide conditions are based on assumptions and reconstructions. There are far more uncertainties about the processes leading to or triggering other giant landslides, like those off the Barents Sea margin (Hjelstuen et al., 2007) and Svalbard (Vanneste et al., 2011b). Nevertheless, the initial failure, actual triggers, and fluid flow processes (including hydrate) involved in the Storegga slide are to some extent based on assumptions.

Smaller-scale landslides I: Ana Slide, Eivissa channel

The Ana Slide lies on the eastern Balearic flank of the Eivissa Channel, western Mediterranean Sea (for location, see Figure 2), in water depths between approximately 630 and 790 m (Figure 9). The mean dip of the regional margin is about $1.6^{\circ}$ (Lastras et al., 2004b; Lastras et al., 2006). The main horseshoe-shaped escarpment extends from 635 to $740 \mathrm{~m}$ water depth (Figure 9). The depositional area has numerous arcuate ridges normal to the direction of landslide movement, interpreted as compressional features that developed by back-push during the final stages of the run-out (mass movement slows down) (Lastras et al., 2004b).

The Ana Slide is one of four landslides in the Eivissa Channel (Ana, Joan, Nuna, Jersi, Figure 9) with a common slip plane along the same stratigraphic level (Lastras et al., 2004b; Lastras et al., 2006). Whether or not these instabilities happened at the same time is uncertain; however, as they have a common slip plane, it is likely that these individual landslides have the same preconditioning factors and triggering mechanism(s). The presence of several pockmarks in the immediate vicinity of the 
headwall area suggests a possible relationship with fluid migration, and thus excess pore pressure, for the landslides.

Further supporting evidence for this hypothesis comes from both seismic data as well as geochemical analysis. High-resolution 3D seismic data reveal several high-amplitude reflection anomalies at several stratigraphic levels, but with higher abundance underneath the failed mass (Berndt et al., 2012). Despite the lack of gas in the samples retrieved, $\delta^{13} C$ analysis of benthic foraminifera provides a proxy for palaeo-methane seepage from the seafloor during the recent past (Panieri et al., 2012). In addition, in situ geotechnical data indicate that the base of the Ana landslide is slightly coarser compared to the sediments surrounding the slip plane (Lafuerza et al., 2012). This unit is therefore a likely candidate for methane accumulation during upward migration. Partial gas saturation at the time of failure in this unit may well be one of the critical preconditioning factors resulting in the instability (Lafuerza et al., 2012).

The most unfavourable effects of gas on the geotechnical properties of marine sediments occur during unloading, when gas comes out of solution and expands. This process leads to a significant decrease in effective stress (Sobkowicz and Morgenstern, 1984), but it also affects the compressibility and shear strength of the sediments (Lunne et al., 2001; Hight and Leroueil, 2002). In this respect, one should take into account sea level conditions at the time of failure. Indirect dating yields an age of approximately 65 ka for the Ana Slide, i.e., following a period of sea level fall over nearly $50 \mathrm{~m}$ (Lafuerza et al., 2012). This sea level drop enhanced methane exsolution and subsequent seepage during at least the interval from 71 to $65 \mathrm{ka}$. Numerical simulations suggest that the strength degradation generated by gas exsolution and expansion during that period may explain the Ana Slide event.

In situ piezocone measurements helped to characterize the post-failure stage of the Ana Slide. In situ geotechnical data from the slide area (scar, toe and deposit), the slip plane and the unfailed area, show the state of consolidation varies across the different parts of the Ana Slide. Figure 10 presents 
the corrected cone resistance $\left(q_{t}\right)$ obtained and shows that around $2.5 \mathrm{~m}$ of sediment are draping the sliding area and confirms the very old age of Ana slide (Lafuerza et al., 2012). The high $q_{t}$ values measured at several sites and mainly at PFM-06S2 and PFM-06S3 from the scar and PFM-05S4 (Figure 10) allow reconstructing the initial geomorphology of the area and defining the different failure stages and movements of Ana Slide. For instance, overconsolidated sediments within the headwall area are due to the removal of between 1 and $10 \mathrm{~m}$ of overburden.

Knowledge gaps: The role of earthquake shaking as a trigger mechanism of the Ana slide was not fully investigated. Only one fault occurs within the study area, underneath the Ana Slide. The lack of noticeable offset in the overlying sedimentary units raises doubts about the ability of such faults to generate an earthquake of sufficient magnitude to trigger the Ana slide (Lafuerza et al., 2012). The consequence of the combination of free gas and earthquake as trigger mechanisms needs a more detailed laboratory analysis combined with theoretical studies for different lithologies.

\section{Smaller-scale landslides II: Vesterålen margin}

Several smaller-scale isolated landslides occur on the poorly-understood Vesterålen margin, off Norway (for location, see Figure 2; Figure 11). These landslides are unconnected from the larger submarine canyon systems or glacial termini in the area. The Lofoten and Vesterålen mountain chains formed a natural barrier for ice flow in the area, diverting the ice streams away from the area under investigation. Therefore, there was significantly less glacial sediment input compared to other areas off the Norwegian mainland. Seismicity in this area is amongst the highest along the Norwegian margin; however, there is a lack of accurate long-term seismicity data. The present sedimentary environment off the Vesterålen is characterized by low sedimentation rates (hemipelagic), with continuous sub-parallel stratigraphy for the upper sedimentary units.

Data collected in the area consists of swath bathymetry data, 2D TOPAS sub-bottom profiler data, several gravity and multi-cores and one $12 \mathrm{~m}$ long piston core, the latter retrieved between two landslides (Figure 12). Analysis included $X$-ray imaging, MSCL, sedigraph GSD, water content, fall cone 
and pocket vane undrained shear strength measurements of undisturbed and remoulded cohesive sediments, Atterberg limits. Advanced geotechnical tests on specific samples from the different lithofacies observed on the $X$-ray data included constant-rate-of-strain oedometer, anisotropicallyconsolidated triaxial tests under compression and direct simple shear (DSS) (for some examples, see Figure 12).

This part of the margin is relatively smooth compared to neighbouring segments. However, several submarine landslides, with limited run-out in a confined depositional lobe and fairly small horseshoeshaped slide scars with $\sim 20^{\circ}$ slope, occur (Figure 11). Several of these failures have their headwalls around the $500 \mathrm{~m}$ isobaths, others around $750 \mathrm{~m}$, and all occur on a gently dipping slope (around $3^{\circ}$ ). The areal extent ranges between 0.7 and $2 \cdot 10^{6} \mathrm{~m}^{2}$, whereas the displaced volume is estimated between 15 and $60 \cdot 10^{6} \mathrm{~m}^{3}$ per landslide. Due to the limited data coverage, there is some uncertainty on the volumes involved. The slip planes of these isolated landslides occur in well-defined stratigraphic units. The two slip planes are located at, or very close to, high-amplitude reflections (Figure 12). The failed mass is largely remoulded and deformed, as nearly all internal stratification is lost (Figure 12) (L'Heureux et al., 2013).

The geotechnical data indicate relatively little variation in the strength behaviour of the close to normally-consolidated sediments at different levels of the stratigraphy (Figure 12). One sample retrieved from the shallowest slide planes shows evidence of modest strain-softening (L'Heureux et al., 2013). The geological and geochemical data indicate alternating depositional regimes, including intervals of rapidly-deposited fall-out from glacial, sediment-laden meltwater plumes. In general, these fine-grained plumite deposits have lower undrained shear strength, greater plasticity and higher sensitivity than the surrounding glacial clays which comprise more sands and gravels. The finegrained, laminated layers are more prone to failure.

Dating of the landslides themselves is challenging with the currently available samples. This is due to a lack of core material from stratigraphic levels that can unambiguously be linked with the base of the 
post-slide deposits on the nearby seismic data. However, a tentative relatively young age between about 1000 and 3000 years ago is obtained for one of the deeper landslides (landslide SLW, for location, see Figure 11). Large uncertainty remains, and it is not yet known whether these landslides occurred synchronously or not.

Slope stability analyses (2D limit equilibrium using Slope/W) reveal that the margin in se is stable (Factor of Safety >> 1) (L'Heureux et al., 2013; L'Heureux et al., submitted). Hence, for these landslides to occur, one needs external triggers and specific preconditioning factors, like seismicity, so-called weak layers and excess pore pressure. The effect of seismicity was evaluated through both pseudo-static (Slope/W) and dynamic analyses (AMPLE2000, SIMPLE DSS constitutive soil model (Pestana and Nadim, 2000)). Dynamic slope stability analyses indicate that during an earthquake, the largest shear strains occurs within the top $10 \mathrm{~m}$ of the sediment with maximum values of about 0.5 $1.0 \%$. This is equivalent to a permanent displacement in the order of $10-20 \mathrm{~cm}$. Whereas such displacements cannot explain complete failure, they could explain the development of small seafloor cracks observed in the study area (Figure 11). Results (for a summary, see Table 3) show that one needs a very large earthquake with a peak ground acceleration (PGA) close to the 10,000 years return period for failure to occur. Such large earthquake may have been frequent following the last glaciations due to glacio-isostatic uplift of the area.

The mobility of these landslides, modelled with BING (Imran et al., 2001) in combination with observations from the geophysical data, is restricted with run-out limited to a few hundreds of $m$ to over $1 \mathrm{~km}$, indicating that the energy of the moving mass was limited. The mass decelerated and was deposited as a consequence of a change in seabed slope angle (from 4 to 2) (L'Heureux et al., 2013). The acceleration phase is completed within 1 minute, and the mass flows with a velocity up to 17 $\mathrm{m} / \mathrm{s}$. These values are similar to historical records from e.g., the Grand Banks landslide (Piper et al., 1999), Orkdalsfjorden (L'Heureux et al., 2014), and Rissa (L'Heureux et al., 2011). The consequences of such landsliding for seabed infrastructure would be devastating. 
The landslides observed in the Eivissa Channel and on the Vesterålen margin are to some extent similar, particularly in shape, dimensions, and water depths of occurrence (see Figure 9 and Figure 11). However, the Vesterålen area lacks direct and indirect evidence of fluid flow phenomena (free gas, pockmarks, mud diapirs, hydrate) from geophysical data or core samples. Excess pore pressure due to sediment load is highly unlikely, considering that the area received very limited sediment input ( 0.15 to $0.40 \mathrm{~m} / \mathrm{ka}$ over 20 to $30 \mathrm{ka}$ ).

Knowledge gaps: Failure in this area is the least understood of all case studies discussed here. The most likely explanation for the landslides at Vesterålen is a combination of earthquake-induced shear strains, strain softening in the sensitive fine-grained units, and post-earthquake pore pressure dissipation or redistribution (L'Heureux et al., 2013). One critical observation is that accurately dating the landslides off Vesterålen proved difficult with the collected data. Nevertheless, this information is paramount for establishing preconditioning factors and suitable triggering mechanisms. Slope stability analyses are based on a very limited database, particularly the number of samples and there are currently no in situ geotechnical tests. Several additional sediment cores and CPTU data should thus be collected. Considering that most of the samples are disturbed, the laboratory results should be carefully examined, and our knowledge of pore pressures in this area is very poor.

\section{Recent and/or active instabilities}

Until now, we focused on palaeo-landslides. In this sub-section, we discuss a number of active or recent instabilities and deformation processes. Their occurrence allows for real-time monitoring of the deformation processes and understanding of the actual triggering mechanisms, processes that are often difficult to address with palaeo-instabilities. Furthermore, landsliding at some of these sites present a significant risk to society. Therefore, understanding the different processes involved in the ongoing deformation and deciphering their signature (e.g., fluid migration phenomena, slip planes) in high- to very-high-resolution becomes a critical aspect. In this respect, natural field laboratories - i.e., sites with clear societal implications that allow for an in-depth investigation of various features of 
direct relevance to instabilities - are important to improve our understanding of instabilities in a controlled and integrated way.

\section{Active deformation off West-Africa}

There is a wealth of evidence for active deformation in the Gulf of Guinea, south of the modern Niger Delta (for location, see Figure 2). The target site lies in water depths from around 1100 to $1250 \mathrm{~m}$. The multi-disciplinary approach to study these seabed deformation features consists of geophysical data (swath bathymetry and high-resolution seismic profiling), geotechnical data (CPTU and pore pressure measurements), sediment coring and analysis, temperature measurements and numerical modelling.

AUV swath bathymetry data (Georges and Cauquil, 2007) reveal numerous pockmarks with different shapes and sizes, with the largest features a few hundreds of metres wide and more than $100 \mathrm{~m}$ deep (Figure 13). Several pockmarks line up along fault structures. There are furthermore many smaller pockmarks with highly irregular and complex shapes and relief variations (both positive and negative) (Figure 13). Most of these pockmarks lie within a NW-SE trending depression between two structural lineaments on the seabed. These structures correspond to deep-rooted normal faults, which delineate a graben along the axis of an anticlinal structure. Massive hydrates are abundant in samples retrieved from many of the pockmark with flat tops (e.g., pockmarks A and C1, Figure 13) or positive relief, often flanked by sediment collapse features (e.g., pockmark C2, Figure 13).

The proximity of the hydrates to the seabed combined with their metastable state makes them a major hazard for sub-sea developments and infrastructure. Changes in bottom water temperature and/or in pressure generated by e.g., human activity on the seafloor (drilling, pipeline routing) can cause hydrate dissociation, and potentially result in slope failures or sediment deformations. Shallow hydrate accumulation can also be the source of in situ gas release that can affect the engineering properties of the sediment. It is, therefore, essential to detect and accurately quantify gas hydrate 
distribution within the area to properly evaluate and assess the implications with respect to sediment deformations and instabilities.

Figure 14 illustrates the combination of coring, geotechnical logging, and high-resolution deep-towed SYSIF profiling (Ker et al., 2008). Pockmark B is a 30 m deep depression, within an acoustically transparent to chaotic sub-surface facies. Pockmarks C1 and C2 incise the seabed much less. First evidence for the presence of shallow hydrate accumulations comes from shallow anomalous amplitude signature, likely caused by underlying free gas, in the immediate vicinity of the pockmarks. These anomalous amplitude patches occur at different sub-surface depths along the profile (Figure 14). Reprocessing of an exploration 3D seismic data set also revealed high interval velocities indicative of either hydrate or carbonate, in the top 15 to $30 \mathrm{~m}$ below the seabed (Sultan et al., 2010a). Piezocone measurements confirmed these findings later on. On these geotechnical logs, one can distinguish between gas hydrates (or any other stiff/hard materials, for instance carbonate concretions) from the typical background sediments by analysing the response on all logged parameters (see above). The hydrate signature has a high cone resistance accompanied by a significant increase in pore pressure response (Sultan et al., 2007b).

These observations suggest a causal relationship between sediment deformation, hydrate stability conditions, pockmark formation and fluid migration from deep-seated faults in the immediate vicinity (Sultan et al., 2010a). Sediment deformation surrounding the central parts of the pockmarks takes place in the upper sediments rather than at depth, and the hydrate occurrence zone relates to fluid migration pathways as well as pre-existing near-vertical zones of weakness within the shallow sediments. Dynamic fluid flow through the fault systems in combination with hydrate formation and dissolution can explain the origin of the pockmarks formation and their evolution (Sultan et al., 2010a)

Figure 15 presents the results of the numerical simulations, i.e., the evolution of porosity over time since 10000 years ago (for further details, see (Sultan et al., 2010a)), considering a reduction of 
methane concentration at the base of the gas hydrate occurrence zone (GHOZ) as the main hypothesis to initiate the hydrate dissolution process. The maximum initial hydrate fraction at the base of the gas hydrate occurrence zone (GHOZ) equals $10 \%$. The dissolution process and the subsequent compaction of the sediment generate excess pore pressures reaching the upper boundary of the GHOZ. Eventually, sufficiently high pore pressures can cause hydro-fracturing (dashed areas in Figure 15), and sediment failure. Thus, these simulation results demonstrate that hydrate melting due to a local decrease of the gas concentration or supply at the base of the GHOZ can explain sediment collapse and the formation of pockmarks in the area. A similar hypothesis with palaeo-gas migration and hydrate formation during glacial times (cold and lower sea level) and subsequent melting once the climate warmed can explain the occurrence of inactive pockmarks in the Troll area (Norwegian Channel), a giant gas reservoir within the Norwegian sector of the North Sea (Forsberg et al., 2007a).

Knowledge gaps: In this numerical model, the evolution of this type of pockmark formation strongly depends on several parameters for which little or no site-specific information is available. Amongst the most important parameters are the gas hydrate concentration and distribution in the area, the permeability and the mechanical behaviour of the hydrate-bearing sediment, but also kinetics of the hydrate dissolution. These findings based simulations remain conceptual and qualitative rather than proven fact, and one should evaluate - or collect further data to ground-truth - the model parameters and their uncertainty. In order to further improve our understanding in the dynamics of this coupled fluid flow and sediment deformation system, a French-German drilling cruise (GuinecoMeBo) took place between November and December 2011. Deep gas hydrate-bearing sediments were recovered (maximum depth of $57 \mathrm{mbsf}$ ) and multi-disciplinary analyses are in progress in order to better constrain the numerical modelling works. 


\section{Natural field laboratories I - Nice airport failure}

In October 1979, a slope failure removed the harbour under construction on the River Var prodelta, off the Nice airport (French Riviera) (for location, see Figure 2 and Figure 16). Within the six months preceding the failure, 110 episodic settlement or collapse events hampered the construction of the harbour (Dan et al., 2007). As instability in this area has direct societal implications, it became a natural laboratory for understanding the origin (precursors and triggers), development and consequences (e.g., tsunami, cable breaks) of submarine failures (Dan et al., 2007; Sahal and Lemahieu, 2011; Labbé et al., 2012). One particular aspect of the 1979 failure mechanism was the occurrence of a sandy gravel alluvial aquifer underneath finer grained, deltaic and prodeltaic sediments covering the narrow shelf and steep upper slope (Dan et al., 2007; Kopf et al., 2010; Stegmann et al., 2011).

Sediments of the River Var prodelta are mostly normally-consolidated silty clays, with undrained shear strength typically increasing linearly with depth (Mulder et al., 1994; Dan et al., 2007; Leynaud and Sultan, 2010; Sultan et al., 2010b). Coarser-grained sediments (sand, pebbles) occur within the 1979 slide scar. Geochemical analyses, free-fall CPTU data as well as long term pore pressure measurements suggest that these coarse-grained sediments are part of, or linked to, the confined alluvial aquifer recharged by inflows from both the River Var and rainfall (Kopf et al., 2010; Stegmann et al., 2011) (Figure 17). Freshwater seepage from this aquifer, and consequent leaching of sodium chloride in pore water is the most likely explanation for the high strength sensitivity (St $>8$ ) locally measured in silty clays (Dan et al., 2007). Because strength sensitivity promotes strain localisation and propagation of shear bands (Puzrin et al., 2004), this property is a critical preconditioning factor.

Numerical simulations indicate that creeping of sensitive clays may lie at the origin of the 1979 failure. (Dan et al., 2007). Pore pressure measurements within the 1979 failure scar suggest that progressive failure might have developed in response to aquifer pressure build-up and freshwater seepage (Figure 17) (Stegmann et al., 2011). Indeed, the overpressures measured at the Seamonice 
station (see Figure 16 and Figure 17) is sufficiently high to cause hydrofracturing, and thus weakening of the silty clays (Stegmann et al., 2011). There is indirect evidence of the latter on the shear strength profiles derived from CPTU data (sleeve friction) acquired along the shelf edge (Figure 18) (Leynaud and Sultan, 2010). Alternatively, the observed drop in shear strength may result from shearing and plastic deformations (Sultan et al., 2010b). Irrespective of the underlying mechanisms, all observations point to initiation of progressive failure mechanisms, confirming that every failure process is, at first, local with the formation of plastic zones, before general slope failure (Leroueil, 2001; Urciuoli et al., 2007).

Also at this site, partial gas saturation can play a role in preconditioning the failure. The core samples from the shelf show ample evidence of gas bubbles (Sultan et al., 2010b). Comparison of shear strength values derived from CPTU with those measured on sampled gassy sediments show that bubble growth can weaken the sediments. The presence of gas in samples does not imply that gas exsolution and/or and bubble growth occurred prior to core recovery. However, in situ P-wave measurements from an acoustic fork show very distinct negative anomalies $(750 \mathrm{~m} / \mathrm{s})$. Such low values, along with zones of acoustic wipe-out and plume features on high-resolution seismic reflection profiles, suggest that the prodelta silty clay sediments effectively contain free gas (Sultan et al., 2010b). Fishermen also noticed gas bubbling in the water in the hours preceding the slope failure (Anthony and Julian, 1997).

A significant drop in effective stress due to seepage from the alluvial aquifer is a likely candidate as the actual trigger of the 1979 slope failure (Dan et al., 2007; Stegmann et al., 2011). One reason is the high autumnal discharge (10 times higher than mean annual value) of the River Var just before the slope failed (Anthony and Julian, 1997). The onset of failure furthermore occurred on the day a 10year peak in flood level was reached.

Figure 19 shows the numerical simulation results (FEMUSLOPE software) obtained using drained geotechnical parameters (Seed et al., 1988). Because the aquifer pressure was not measured in 
October 1979, the model relies on the assumption that excess pore pressure exists at $20 \mathrm{~m}$ below the seabed (Stegmann et al., 2011). The simulations indicate that excess pore pressures of about $20 \%$ of the effective vertical stress bring the factor of safety (FoS) close to 1 (1.2), i.e., close to critical conditions. Adding the embankment load due to the harbour construction induces failure (FoS $<1$ ) (Figure 19). Whether similar pore pressure conditions can explain the occurrence of the shear zones along the shelf edge remains unclear (Sultan et al., 2010b). However, the 3D slope stability analysis on the steepest edge the shelf reveals that more extensive propagation of such shear zones has a $50 \%$ probability to set off a landslide of a thickness similar to the 1979 event (i.e. 30 m, Figure 19) (Leynaud and Sultan, 2010).

The 1979 event involved $8.7 \mathrm{Mm}^{3}$ of material, creating an $540 \mathrm{~m}$ wide slide escarpment on the narrow continental shelf (Assier-Rzadkiewicz et al., 2000). The failed mass evolved first into an erosive debris flow (Mulder et al., 1997; Dan et al., 2007; loualalen et al., 2010). According to submersible observations, the debris flow funnelled down several gullies before reaching the Var Canyon (Dan et al., 2007; Labbé et al., 2012). A variety of methods suggests peak velocities of about $10 \mathrm{~m} / \mathrm{s}$ during the first minutes (Hugot et al., 2001; Labbé et al., 2012). These dynamics explain why a tsunami struck the coast less than a minute after failure (Sahal and Lemahieu, 2011; Labbé et al., 2012). Although the debris flow progressively diluted, it remained sufficiently dense to erode the Var Canyon walls and floor and break two undersea cables (Mulder et al., 1997; Hugot et al., 2001). The timing of cable breaks at around 85 and $114 \mathrm{~km}$ from the shelf break yields frontal velocities of the mass flow of $5 \mathrm{~m} / \mathrm{s}$ and $2 \mathrm{~m} / \mathrm{s}$, respectively.

Knowledge gaps: Despite the long-term and multi-disciplinary efforts conducted to understand the Nice 1979 failure from preconditioning to consequences, there remain a number of poorly understood parameters and conditions. One of them is the actual in situ pore pressure before the onset of failure, which plays an important role in our current explanation of the failure mechanism. A second poorly known aspect is the explanation of the shear zones at shallow sub-surface depths 
along the shelf edge. These two aspects are the motivation behind the recent installation of a longterm monitoring array of piezometers, osmo-sampling systems and tilt meters in the slide scar and shelf area, in order to detect precursory signs of future instabilities and improve our understanding of the hydrologic processes in the area. These data are currently under evaluation. The shallow water depth also affects the depth of investigations of conventional seismic reflection data (seabed multiples). Therefore, the use of alternative seismic techniques, e.g., shear and surface waves generated by either conventional sources or more advanced seabed-coupled shear wave sources (Vanneste et al., 2011c) may be fruitful to investigate fluid circulation and deformation patterns over larger zones, even though this is challenging. As shear wave velocity relates directly to the smallstrain shear modulus, such an approach would also help quantifying their response to earthquake loading.

\section{Natural field laboratories II - Finneidfjord}

The second natural field laboratory is a fjord in northern Norway (for location, see Figure 2), famous for the retrogressive landslide that killed four people in 1996 (Longva et al., 2003). Due to its sheltered and accessible location, Finneidfjord has become a natural laboratory for testing highresolution and multidisciplinary techniques to improve our understanding of landslide development including the correlation of geological, geophysical and geotechnical data. The site has a history of landsliding. The 1996 event has many characteristics typical of submarine landslides (well-developed slip planes, outrunner blocks embedded in slide debris, peripheral thrusting and lateral spreading) (Longva et al., 2003) (Figure 20). The retrogressive failure encroached part of the shoreline and remobilized roughly one $\mathrm{Mm}^{3}$ of sediment. Shallow gas, identified from seismic data, is prominent immediately south-east of the landslide complex. Similar but smaller-scale landslides happened as well in 1978 and 2006 (Vardy et al., 2012; Vanneste et al., 2013).

Sørfjord is a $12 \mathrm{~km}$ long and up to $2 \mathrm{~km}$ wide side fjord to the Ranafjord system. The eastern part of the fjord hosts the 1996 landslide. The basin is less than $60 \mathrm{~m}$ deep, and has a $200 \mathrm{~m}$ thick 
succession of well stratified glacio-marine and fjord-marine sediments (clay to silty clays), largely derived from the Røssåga River. The flanks of the fjord are steep, with exposed bedrock. Following retreat of the glaciers, glacio-isostatic rebound affected the area, causing a relative fall in sea level, and the emergence of thick glacio-marine and marine deposits, locally overlain by coarser fluvial and littoral deposits. The upper marine limit lies approximately $125 \mathrm{~m}$ above present-day mean sea level. Groundwater flow and subsequent leaching of salt from the marine and glacio-marine deposits formed very sensitive clays and quick clays during the Holocene (L'Heureux et al., 2012). River erosion in the hinterland has triggered several large quick clay landslides. Today, pockets of quick clay occur along the shoreline but also offshore. Most of these brittle and soft deposits are covered by beach deposits, giving a false impression of stability.

Since the 1996 landslide, ICG and partners established an extensive multi-disciplinary data set across the landslide area. The database contains different vintages of swath bathymetry data and several dense seismic data networks using different sources and receivers (e.g., sleeve gun, sparker, boomer, TOPAS sub-bottom profiler data (SBP), very-high-resolution 3D chirp (VHR-3D), very-high-resolution 2D multi-channel data, ocean-bottom seismometers, land-based geophones) (Longva et al., 2003; Vardy et al., 2012; Vanneste et al., 2013). Frequency content and bandwidth of the different seismic data partly overlap, with total range between $50 \mathrm{~Hz}$ and $8 \mathrm{kHz}$. Figure 21 presents examples of TOPAS 2D and a VHR-3D in-line.

There are also various sediment cores (two $15 \mathrm{~m}$ long piston cores collected just outside the landslide complex, numerous shallow gravity cores across the basin (L'Heureux et al., 2012)), in situ geotechnical CPTU data (one $25 \mathrm{~m}$ long GOST CPTU and 38 free-fall CPTU (Steiner et al., 2012), including pore pressure dissipation tests) (Figure 22). All data were processed according to standard practice (Lunne et al., 1997) after applying additional corrections and processing with respect to datuming and bias, followed by some soft depth filtering. Conversion into undrained shear strength for the silty clays used $N_{\mathrm{kt}}$ values (cone factors) between 10 and 20 (Vanneste et al., 2013). The 
samples underwent a whole suite of sedimentological (MSCL, $X$-ray and $\mathrm{CT}$ imaging, $\mathrm{AMS}{ }^{14} \mathrm{C}$ dating on terrestrial plan remains and bivalves, $X$-ray fluorescence) (Figure 22) and geotechnical analyses, particularly focusing on the slip plane (GSD, water content, Atterberg limits, fall cone strength, DSS with permeability measurement, anisotropically-consolidated triaxial shear tests, constant-rate-ofstrain oedometer). Despite the fact that the piston coring system is a highly efficient coring system, designed to minimize sediment deformation, the sample quality is still less than good using the classification by (Lunne et al., 1998). For the advanced geotechnical tests, the samples were reconsolidated to the approximate in situ stress level. Since September 2012, four piezometer systems are monitoring pore pressure close to or within the slip plane behind the main escarpment with a 1 hour sampling interval (Figure 24).

The integrated data indicates a multi-phase and retrogressive landslide development for the 1996 event, with failure taking place within well-defined slip planes (Figure 21). The initial failure took place offshore, but retrogression, facilitated by quick clays, caused back-stepping onshore. Escarpments are a few metres high, and the upper slide scar area is nearly completely evacuated. The mass movement had a run-out of several hundreds of metres, with rafted blocks embedded in the debris deposit. Several blocks outran the deposit (Longva et al., 2003). Landslides on different sides of the basin slipped along the same failure planes (Vardy et al., 2012), despite the failures being physically disconnected and not occurring simultaneously (L'Heureux et al., 2012; Vanneste et al., 2013). Thus, regional sedimentary processes can influence stability locally. Seismic data illustrate that mass wasting took place repeatedly over the last 20000 years, with typically a higher-amplitude event underneath the mass transport deposit (MTD) (Vanneste et al., 2013). Similarly, the slip plane of the 1996 event (and others) coincides with a basin-wide high-amplitude event on seismic data. The VHR-3D data furthermore illustrate that this seismic event is essentially a composite reflection, composed of thin-bed events (Vardy et al., 2012). Part of this event is eroded underneath the MTD. To the south-east, this composite event caps a pronounced gas front, attenuation nearly all seismic signal. The FF- and GOST CPTU data do show a modest anomaly at the depth of the slip plane (Figure 
22). However, higher-resolution MSCL data show a distinct anomaly in bulk density and magnetic susceptibility at the depth of the slip plane, which is typically only a few tens of cm thick (Figure 22). $X$ - and CT-images and core descriptions confirm that the event bed has different lithofacies. From GSD analysis, we know that the event bed is composed of a $15 \mathrm{~cm}$ thick, grey silty clay with sharp base overlain by $20 \mathrm{~cm}$ of silty, clayey sand fining upwards to silt, and another $10 \mathrm{~cm}$ of silty clay at the top (Figure 23). As such, it has typical characteristics of a turbidite deposit (L'Heureux et al., 2012; Vanneste et al., 2012). Permeability is at least one to two orders of magnitude higher in the sand compared to the silty clays (Vanneste et al., 2012). Also sensitivity varies across throughout the event bed, between approximately 4 and 7 . In situ pore pressure measurements also indicate that there is presently excess pore pressure that varies between approximately 0 and $12 \%$ (mean value around 6\%) between October 2012 and May 2013, with lowest values during winter (Figure 24). Further analysis of these data, and the other piezometer records, is currently underway to find correlations with rainfall or snowmelt, or other variables.

Despite the fact that there are witness reports of the failure, the actual triggers remain a topic of debate. From 1D and 2D slope stability analysis, the factor of safety is close to 1 , thus the area has an intrinsic low natural stability (Gregersen, 1999; Cassidy et al., 2008). The ultimate trigger could well have been loading of the foreshore area combined with blasting, related to road works. The deposition and variations in lithology of the event bed evidently plays a crucial role. It likely originates from quick clay failures in the catchment zone of the river, followed by flooding and basin-wide deposition (L'Heureux et al., 2012). Datings indicate that this onshore failure happened around 450 to 500 years ago (Figure 22). The fact that only part of the event bed is eroded underneath the deposit indicates that shear took place mainly in the upper part of the event bed (L'Heureux et al., 2012; Vardy et al., 2012). There was also a period of heavy rainfall and snow melt shortly before the failure, which probably lead to changes in the groundwater conditions close to the shoreline (L'Heureux et al., 2012). The higher permeability of the sand may have allowed sub-lateral fluid migration and pore pressure build-up underneath low-permeable silty clays, thus the composition of the entire event bed 
is important. Some cores show evidence of gas (fissures, fractures, vesicles); however, this is likely the result of exsolution by pressure release when retrieving the core, as there is no direct connection between the shallow gas accumulation and the failure area. Inversion of the seismic data yields very small gas saturations, typically less than $0.1 \%$ (Morgan et al., 2012), and therefore, free gas is not a likely controlling factor (Vanneste et al., 2013).

Knowledge gaps: Similar to the Nice case, there is a wealth of geological, geophysical and geotechnical data available from the Finneidfjord area. Still, the actual role of excess pore pressure remains poorly understood, as there are no indications or measurements pre-dating the landslide. The geotechnical data are essential for slope stability modelling, but these are only spot measurements obtained from very few locations. One needs more extensive sampling and CPTU surveys to further investigate the different factors. More efforts are also needed to obtain remote physical properties from seismic data over the large frequency bands considered for these smallerscale landslide studies.

\section{Conclusions and Recommendations for future research}

In this paper, we presented various ways in which specific factors contributing to or playing a role in sediment deformation and instability processes were characterized for a number of carefully selected case studies. For each of these case studies, we use an integrated geo-scientific approach based on multi-disciplinary data and complementary geosciences, encompassing mapping, observation and description, sampling and measurements, monitoring and ultimately numerical modelling (see also Figure 25). For some cases (e.g., Nice), the integration of the different set of data helped to concentrate offshore investigations on restricted areas, to optimize (in terms of time and space) measurements and monitoring and to converge towards the most probable deformation or failure scenarios. Meeting the previously mentioned approach for effective and innovative landslide investigations, advanced geotechnical tools are often used or further developed in order to provide some of the critical elements for geohazard investigations (Figure 25). To this end, one attempts to go 
beyond a descriptive approach and too simplistic interpretations about triggering mechanisms of observed sediment deformations and submarine landslides, which is too often the case.

Whereas our understanding of the processes involved in submarine instabilities and deformation has improved significantly over the years, many facets require further investigation. For instance, acquiring reliable geotechnical data - i.e., in situ data including pore pressure as well as laboratory data - is essential for understanding and modelling instability and deformation processes. More specifically, when browsing through literature on submarine instabilities and deformation processes in combination with our findings illustrated above for the specific case studies, one can draw a number of conclusions on the current practise, with reference to Figure 25.

1. It is of critical importance to build a cross-disciplinary knowledge base and language to investigate and improve our understanding of sediment deformation and slope failure processes. Essential disciplines are geology, geomorphology and sedimentology, geophysics, geotechnics, geochemistry, but also computational geomechanics and fluid dynamics. It is the integration of such disciplines that allows establishing more complete or conceptual models constrained by sitespecific data and the geological history of the area.

2. Whereas the development of sediment instabilities and deformation processes are generic (preconditioning, triggering, dynamics, consequences), most of these processes are controlled by regional and local environmental conditions which must be taken into account in a proper assessment of the site under investigation ("Causes and Identification" in Figure 25).

3. The available data sets are often sparse, and far from complete, with respect to either spatial or vertical resolution or type of data collected. Core sample disturbance is bound to lead to erroneous interpretations and simulations due to interpolation ("Causes and Identification" in Figure 25).

4. Most of the submarine landslides develop within specific layers (e.g., Storegga, Ana, Vesterålen, Finneidfjord, Nice). Identifying these layers through geophysical and geotechnical analysis is of 
direct relevance for geohazard assessment and mitigation purposes. These layers do not have a unique signature on seismic data. They can be either fairly thick marine deposits (e.g., Storegga) or very thin layers with subtle variations in lithology and permeability (e.g., Finneidfjord). Whereas these layers clearly contribute to the landslide development, they may become weak under specific circumstances only (e.g., strain development under loading or unloading). These units are typically also deposited under different environmental conditions compared to the other sedimentary sequences ("Causes and Identification" in Figure 25).

5. With respect to the hazards posed by instabilities and deformation processes, understanding the frequency of their occurrence in (recent) geological times is essential. Therefore, one needs to properly identify such events in the stratigraphy, and obtain reliable ages of these events.

6. Whereas geophysical data become readily available, there is generally a paucity of geotechnical data (either laboratory measurements or in situ data) to evaluate the soil conditions. Nevertheless, high-quality laboratory tests (e.g., strength tests, lithology, rheology) and in situ geotechnical data are essential input parameters for numerical simulations (tsunami and impact), and therefore, crucial with respect to hazard and risk analysis. This implies that such analysis often have to rely on a limited data set ("Causes and Identification" in Figure 25).

7. Whereas one cannot dispute the overall value of geophysical data, there is a need to improve quantification and inversion procedures in combination with rock physical models, in order to provide a link between geophysics and geotechnics. For example, there remain large uncertainties in e.g., partial gas or hydrate saturation values and accumulation mode obtained from seismic inversion. Considering the uncertainty, the potential role of gas or hydrate in failure or deformation remains highly debatable. Including other than seismo-acoustic methods (e.g., electromagnetism) in a joint analysis and inversion routine may be beneficial. Ground-truth of inversion results with laboratory or in situ tests is important ("Causes and Identification" in Figure 25). 
8. In the same context, refining our understanding and establishing semi-empirical (site-specific) relationships between dynamic (e.g., geophysical properties such as shear wave velocity) and static (e.g., undrained shear strength) parameters can be useful with respect to defining the variables used in slope stability modelling.

9. It is challenging to obtain high-quality samples (i.e., with little deformation due to the sampling procedure) for advanced geotechnical tests, and sampling is a costly affair. Despite the enormous value of deep ocean drilling programmes like IODP for geological purposes, the samples collected within these programmes are often highly disturbed for geotechnical purposes, and therefore one cannot obtain high-quality geotechnical laboratory results from them. Mission-specific platforms or dedicated sampling tools should be used for this purpose, but this often lies beyond the budgets available for academic research ("Causes and Identification" and "Time, evolution" in Figure 25).

10. Whereas pore pressure is a critical parameter for slope instabilities and deformation processes, pore pressure is rarely measured in situ. Only in a few places, typically in the post-failure stage, long-term pore pressure monitoring programmes are in place (e.g., Finneidfjord, Nice). Deploying such instruments in deeper waters again comes at an expense ("Causes and Identification" and "Time, evolution" in Figure 25).

11. Numerical simulations of deformation processes and instabilities should carefully evaluate all input parameters, and the uncertainties involved. Whereas modelling per default implies a simplified situation compared to reality, one should attempt to include as much as possible field and laboratory data, and limit the number of assumptions needed. A critical reflection on the data is therefore needed, and it should include argumentation for the assumptions ("Time, evolution" in Figure 25).

12. One of the most challenging areas for improvement is our understanding of triggering mechanisms, as there are very few historic cases of instabilities and deformation processes, and even less for which base data (i.e., data prior to the event) are available. As such, most of the 
data come from back-calculation. There is a wealth of data available for the Nice (1979) and Finneidfjord (1996) landslides. Nevertheless, we have no conclusive evidence of the exact preconditioning and triggering mechanisms. Uncertainties only increase for pre-historic cases. Seismicity or large-magnitude earthquakes are often invoked at the main trigger, particularly for the larger landslides (e.g., Storegga). However, details of the time histories and PGA are often not available, and therefore, one has to rely on well-known earthquake signatures for the modelling (e.g., Vesterålen) ("Hazard and Risk, Consequences" and back-analysis).

13. Similar features can occur in different environmental settings (e.g., the Eivissa Channel landslides and the Vesterålen landslides), which are likely caused by different preconditioning and triggering factors. Why these landslides have their main escarpments at similar water depths remains a point of debate, but could be related to subtle changes in dip and/or depth-dependent gas solubility (back-analysis).

14. In case there is no direct implication for society of the seafloor instability or deformation, it does not present a risk, irrespective of its dimensions. Therefore, most of the so-called geohazard studies published in journals are stricto senso only discussing particular features without the risk part. This is different for site investigations and surveying conducted by the offshore industry, which has a dedicated focus on geohazard identification. Including the hazard part implies probability analysis, and design of mitigation measures (Nadim et al., 2005; Nadim, 2006) ("Hazard and Risk" in Figure 25).

15. The actual consequences of sediment instabilities and deformation processes lie beyond the scope of this work. Nevertheless, these are of direct relevance and importance to the offshore industry and coastal communities. Also these aspects require a multi-disciplinary approach, whether one looks at the impact of debris flows on infrastructure or the generation of tsunamis, including landslide dynamics, rheology, geophysical mapping and numerical simulations. Keeping in mind that risk is often more related to movements and rates of movements than to the failure as such, it is crucial to improve our capability to capture the field deformation behaviour and 
timing from the pre-failure to the post-failure stage. As such, there is a need for increasing deployments of sensor arrays for long-term in situ measurements. ("Hazard and Risk" in Figure 25).

16. Our predictive capabilities with respect to run-out distance are still rudimentary. A statistical approach exists for a few cases (e.g., relating run-out with released volume) (Issler et al., 2005), but in most situations, there are not sufficient events with similar properties to allow a proper statistical correlation. The use of dynamic models, on the other hands, suffers from uncertainties related to the evolving material properties during the flow. Developing models that account for the phenomenon of dynamic shear band propagation through an energy balance approach is important (Puzrin et al., 2010), as determining the consequences and risk of a particular slope instability inherently depends on the run-out and landslide dynamics ("Hazard and Risk" in Figure 25).

\section{Acknowledgements}

The authors thank the Chief Editor of Marine Geology, Dave Piper, for the invitation and encouragement to write this paper for this $50^{\text {th }}$ anniversary issue of Marine Geology. We acknowledge the constructive feedback from the Editor, Dave Mosher and Thierry Mulder. NGI and IFREMER provided partial financial support for writing this publication. This paper is the result of long-term investigations, from various consultancy and research projects. The work has benefited greatly from the support and fruitful discussions with the different partners from academia or research institutes (NGI, IFREMER, NGU, Universities of Southampton, Bergen, Troms $\varnothing$, Barcelona, MARUM) as well as the offshore industry (e.g., Statoil, Total). Special thanks to Oddvar Longva (NGU), Mark Vardy (Southampton University), Tore J. Kvalstad, Anders Solheim, Karl Henrik Mokkelbost, Tom Lunne (NGI). Specific R\&D projects from which this paper benefited are the Ormen Lange and C-DOG projects (Phases I to III; SEABED, Norwegian DeepWater Programme), the NERIS and ERIG3D projects, the French ANR project (ISIS), the LOSLOPE project (Norwegian Research Council), and MAREANO. 
Miquel Canals and Galderic Lastras provided the bathymetry data from the Eivissa Channel. Oddvar Longva provided the perspective image of the Finneidfjord area, as well as the TOPAS line. We also extend our appreciation to captains, crews and the craftsmanship of numerous laboratory staff, whom are essential for our work. Several figures were made with Generic Mapping Tools (GMT) (Wessel and Smith, 1991; Wessel et al., 2013). This paper is a contribution to the International Centre for Geohazards, publication number 427. 


\section{References}

Amaratunga, A., Grozic, J.L.H., 2009. On the undrained unloading behaviour of gassy sand. Canadian Geotechnical Journal 46, 1267-1276.

Andresen, L., Jostad, H.P., 2007. Numerical modeling of failure mechanisms in sensitive soft clay Application to offshore geohazards, in: OTC (Ed.), Offshore Technology Conference. OTC, Houston, p. OTC18650.

Anthony, E.J., Julian, M., 1997. The 1979 Var Delta landslide on the French Riviera: A retrospective analysis. Journal of Coastal Research 13, 27-35.

Assier-Rzadkiewicz, S., Heinrich, P., Sabatier, P.C., Savoye, B., Bourillet, J.F., 2000. Numerical Modelling of a Landslide-generated Tsunami: The 1979 Nice Event. Pure and Applied Geophysics 157, 17071727.

Baeten, N.J., Laberg, J.S., Forwick, M., Vorren, T.O., Vanneste, M., Forsberg, C.F., Kvalstad, T.J., Ivanov, M., 2013. Morphology and origin of smaller-scale mass movements on the continental slope off northern Norway. Geomorphology 187, 122-134.

Berndt, C., Costa, S., Canals, M., Camerlenghi, A., de Mol, B., Saunders, M., 2012. Repeated slope failure linked to fluid migration: The Ana submarine landslide complex, Eivissa Channel, Western Mediterranean Sea. Earth and Planetary Science Letters 319-320, 65-74.

Bøe, R., Longva, O., Lepland, A., Blikra, L.H., Sønstegaard, E., Haflidason, H., Bryn, P., Lien, R., 2004. Postglacial mass movement and their causes in fjords and lakes in western Norway. Norsk Geologisk Tidsskrift 84, 35-55.

Bouriak, S., Akhmetjanov, A., 1998. Origin of gas hydrate accumulations on the continental slope of the Crimea from geophysical studies, in: Henriet, J.-P., Mienert, J. (Eds.), Gas Hydrates; Relevance to World Margin Stability and Climatic Change. Geological Society of London,Special Publication, pp. 215-222.

Bouriak, S., Vanneste, M., Saoutkine, A., 2000. Inferred gas hydrates and clay diapirs near the Storegga Slide on the southern edge of the Vøring Plateau, offshore Norway. Marine Geology 163, 125-148.

Bourillet, J.F., Damy, G., Dussud, L., Sultan, N., Woerther, P., Migeon, S., 2007. Behaviour of a piston corer from accelerometers and new insights on quality of the recovery, in: SUT (Ed.), 6th International Offshore Site Investigation and Geotechnics Conference: Confronting New Challenges and Sharing Knowledge, London, UK, pp. 57-62.

Bryn, P., Berg, K., Forsberg, C.F., Solheim, A., Kvalstad, T.J., 2005. Explaining the Storegga Slide. Marine and Petroleum Geology 22, 11-19. 
Bugge, T., Belderson, R.H., Kenyon, N.H., 1988. The Storegga Slide. Philosophical Transactions of the Royal Society of London A 325, 357-388.

Bünz, S., Mienert, J., Berndt, C., 2003. Geological controls on the Storegga gas-hydrate system of the mid-Norwegian continental margin. Earth and Planetary Science Letters 209, 291-307.

Bünz, S., Mienert, J., Bryn, P., Berg, K., 2005. Fluid flow impact on slope failure from 3D seismic data: a case study in the Storegga Slide. Basin Research 17, 109-122.

Bünz, S., Polyanov, S., Vadakkepuliyambatta, S., Consolaro, C., Mienert, J., 2012. Active gas venting through hydrate-bearing sediments on the Vestnesa Ridge, offshore W-Svalbard. Marine Geology 332-334, 189-197.

Canals, M., Lastras, G., Urgeles, R., Casamor, J.L., Mienert, J., Cattaneo, A., De Batist, M., Haflidason, H., Imbo, Y., Laberg, J.S., Locat, J., Long, D., Longva, O., Masson, D.G., Sultan, N., Trincardi, F., Bryn, P., 2004. Slope failure dynamics and impacts from seafloor and shallow sub-seafloor geophysical data: case studies from the COSTA project. Marine Geology 213, 9-72.

Cartwright, J., Huuse, M., 2005. 3D seismic technology: the geological 'Hubble'. Basin Research 17, 120.

Cassidy, M.J., Uzielli, M., Lacasse, S., 2008. Probability risk assessment of landslides: A case study at Finneidfjord. Canadian Geotechnical Journal 45, 1250-1267.

Chen, Z., Wang, J., Wang, Y., Yin, J.-H., Haberfield, C., 2001a. A three-dimensional slope stability analysis method using the upper bound theorem Part II: numerical approaches, applications and extensions. International Journal of Rock Mechanics and Mining Sciences 38, 379-397.

Chen, Z., Wang, X., Haberfield, C., Yin, J.-H., Wang, Y., 2001b. A three-dimensional slope stability analysis method using the upper bound theorem: Part I: theory and methods. International Journal of Rock Mechanics and Mining Sciences 38, 369-378.

Cochonat, P., Cadet, J.-P., Lallemant, S.J., Mazzotti, S., Nouzé, H., Fouchet, C., Foucher, J.-P., 2002. Slope instabilities and gravity processes in fluid migration and tectonically active environment in the eastern Nankai accretionary wedge (KAIKO-Tokai'96 cruise). Marine Geology 187, 193-202.

Craig, R.F., 1997. Soil Mechanics, Sixth edition ed. Chapman \& Hall, London.

Dan, G., Sultan, N., Savoye, B., 2007. The 1979 Nice harbour catastrophe revisited: Trigger mechanism inferred from geotechnical measurements and numerical modelling. Marine Geology 245, 40-64.

Davies, R.J., Mathias, S.A., Moss, J., Hustoft, S., Newport, L., 2012. Hydraulic fractures: How far can they go? Marine and Petroleum Geology 37, 1-6.

Dowdeswell, J.A., Ottesen, D., Rise, L., 2006. Flow switching and large-scale deposition by ice streams draining former ice sheets. Geology 34, 313-316.

Ecker, C., Dvorkin, J., Nur, A., 2000. Estimating the amount of gas hydrate and free gas from marine seismic data. Geophysics 65, 565-573. 
Elverhøi, A., Breien, H., De Blasio, F., Harbitz, C., Pagliardi, M., 2010. Submarine landslides and the importance of the initial sediment composition for run-out length and final deposit. Ocean Dynamics 60, 1027-1046.

Engelmark, F., 2001. Using 4-C to characterize lithologies and fluids in clastic reservoirs. The Leading Edge 20, 1053-1055.

Evans, D., King, E.L., Kenyon, N.H., Brett, C., Wallis, D., 1996. Evidence for long-term instability in the Storegga Slide region off Western Norway. Marine Geology 130, 281-292.

Forsberg, C.F., Planke, S., Tjelta, T.I., Svan $\varnothing$, G., Strout, J.S., Svensen, H., 2007a. Formation of pockmarks in the Norwegian Channel, in: Technology, S.f.U. (Ed.), Offshore Site Investigations and Geotechnics, 6th International Conference: Confronting new challenges and sharing information. Society for Underwater Technology, Royal Geographical Society, London, UK, pp. 221-230.

Forsberg, C.F., Solheim, A., Kvalstad, T.J., Vaidya, R., Mohanty, S., 2007b. Slope instability and mass transport deposits on the Godavari river delta, east Indian margin from a regional geological perspective, 3rd International Symposium on Submarine Mass Movements and Their Consequences, Santorini, Greece, pp. 19-28.

Forwick, M., Baeten, N.J., Vorren, T.O., 2009. Pockmarks in Spitsbergen fjords. Norwegian Journal of Geology 89, 65-77.

Frey Martinez, J., Cartwright, J., Hall, B., 2005. 3D seismic interpretation of slump complexes: examples from the continental margin of Israel. Basin Research 17, 83-108.

Gauer, P., Kvalstad, T.J., Forsberg, C.F., Bryn, P., Berg, K., 2005. The last phase of the Storegga Slide: simulation of retrogressive slide dynamics and comparison with slide-scar morphology. Marine and Petroleum Geology 22, 171-178.

Gee, M.J.R., Uy, H.S., Warren, J., Morley, C.K., Lambiase, J.J., 2007. The Brunei slide: A giant submarine landslide on the North West Borneo Margin revealed by 3D seismic data. Marine Geology 246, 9-23.

Georges, R.A., Cauquil, E., 2007. AUV ultra-high-resolution 3D seismic technique for detailed subsurface investigations, in: OTC (Ed.), Offshore Technology Conference. OTC, Houston, TX, p. OTC18784.

Goldfinger, C., Kulm, L.D., McNeill, L.C., Watts, P., 2000. Super-scale failure of the Southern Oregon Cascadia Margin. Pure and Applied Geophysics 157, 1189-1226.

Gregersen, O., 1999. Kvikkleireskredet i Finneidfjord 20 juni 1996. Norwegian Geotechnical Institute (NGI), Oslo.

Guering, G., Goldberg, D., Meltser, A., 1999. Characterization of in situ elastic properties of gas hydrate-bearing sediments on the Blake Ridge. Journal of Geophysical Research 104, 17781-17795. 
Haflidason, H., Lien, R., Sejrup, H.P., Forsberg, C.F., Bryn, P., 2005. The dating and morphometry of the Storegga Slide. Marine and Petroleum Geology 22, 123-136.

Harbitz, C.B., Løvholt, F., Pedersen, G., Masson, D.G., 2006. Mechanics of tsunami generation by submarine landslides: a short review. Norwegian Journal of Geology 86, 255-264.

Hight, D.W., Leroueil, S., 2002. Characterisation of soils for engineering purposes, in: Tan, T.S., Phoon, K.K., Hight, D.W., Leroueil, S. (Eds.), Characterisation and engineering properties of natural soils. Balkema, Lisse, the Netherlands, pp. 255-360.

Hjelstuen, B.O., Eldholm, O., Faleide, J.I., 2007. Recurrent Pleistocene mega-failures on the SW Barents Sea margin. Earth and Planetary Science Letters 258, 605-618.

Hovland, M., Svensen, H., 2006. Submarine pingoes: Indicators of shallow gas hydrates in a pockmark at Nyegga, Norwegian Sea. Marine Geology 228, 15-23.

Hugot, A., Joseph, P., Savoye, B., Zaleski, S., 2001. Nouvelle modélisation des écoulements gravitaires sous-marins : application à l'effondrement de Nice de 1979. Comptes Rendus de I'Académie des Sciences - Series IIA - Earth and Planetary Science 333, 133-139.

Hustoft, S., Mienert, J., Bünz, S., Nouzé, H., 2007. High-resolution 3D-seismic data indicate focussed fluid migration pathways above polygonal fault systems of the mid-Norwegian margin. Marine Geology 245, 89-106.

Imran, J., Harff, P., Parker, G., 2001. A numerical model of submarine debris flow with graphical user interface. Computers \& Geosciences 27, 717-729.

Ioualalen, M., Migeon, S., Sardoux, O., 2010. Landslide tsunami vulnerability in the Ligurian Sea: case study of the 1979 October 16 Nice international airport submarine landslide and of identified geological mass failures. Geophysical Journal International 181, 724-740.

Issler, D., De Blasio, F.V., Elverhøi, A., Bryn, P., Lien, R., 2005. Scaling behaviour of clay-rich submarine debris flows. Marine and Petroleum Geology 22, 187-194.

Jakobsen, M., Hudson, J.A., Minshull, T.A., Singh, S.C., 2000. Elastic properties of hydrate-bearing sediments using effective medium theory. Journal of Geophysical Research 105, 561-577.

Judd, A., Hovland, M., 2007. Seabed fluid flow - The Impact on Geology, Biology and the Marine Environment. Cambridge University Press, Cambridge.

Katzman, R., Holbrook, W.S., Paull, C.K., 1994. Combined vertical-incidence and wide-angle seismic study of a gas hydrate zone, Blake Ridge. Journal of Geophysical Research 99, 17975-17995.

Ker, S., Le Gall, Y., Marsset, T., Leon, P., 2008. SYSIF, a low frequency seismic profiler for near-bottom marine geophysics, EAGE Conference and Exhibition, Rome, Italy.

Ker, S., Marsset, B., Garziglia, S., Le Gonidec, Y., Gibert, D., Voisset, M., Adamy, J., 2010. Highresolution seismic imaging in deep sea from a joint deep-towed/OBH reflection experiment: 
application to a Mass Transport Complex offshore Nigeria. Geophysical Journal International 182, 1524-1542.

Koldgaard Eriksen, P., 2012. Leakage detection utilizing active acoustic systems, in: OTC (Ed.), OTC Arctic Technology Conference 2012. OTC, Houston, TX, p. pp. 8.

Kopf, A., Kasten, S., Blees, J., 2010. Geochemical evidence for groundwater-charging of slope sediments: The Nice Airport 1979 landslide and tsunami revisited, in: Mosher, D.C., Shipp, C., Moscardelli, L., Chaytor, J., Baxter, C., Lee, H., Urgeles, R. (Eds.), Submarine mass movements and their consequences. Springer, pp. 203-214.

Kvalstad, T.J., 2007. What is the current best practise in offshore geohazard investigations? A state-ofthe-art review, Offshore Technology Conference. OTC, Houston, TX, USA, p. OTC 18545.

Kvalstad, T.J., Andresen, L., Forsberg, C.F., Berg, K., Bryn, P., Wangen, M., 2005a. The Storegga slide: evaluation of triggering sources and slide mechanics. Marine and Petroleum Geology 22, 245-256.

Kvalstad, T.J., Nadim, F., Kaynia, A.M., Mokkelbost, K.H., Bryn, P., 2005b. Soil conditions and slope stability in the Ormen Lange area. Marine and Petroleum Geology 22, 299-310.

L'Heureux, J.-S., 2009. A multidisciplinary study of shoreline landslides: From geological development to geohazard assessment in the bay of Trondheim, mid Norway. Norwegian University of Science and Technology (NTNU), Trondheim, p. 158.

L'Heureux, J.-S., Hansen, L., Longva, O., Eilertsen, R.S., 2011. Landslides along Norwegian fjords: causes and hazard assessment, Second World Landslide Forum, Rome, Italy.

L'Heureux, J.-S., Longva, O., Hansen, L., Vanneste, M., 2014. The 1930 landslide in Orkdalsfjorden: Geomorphology and failure mechanisms, in: Krastel, S.B., J.-H.; Völker, D.; Stipp, M.; Berndt, C.; Urgeles, R.; Chaytor, J.; Huhn, K.; Strasser, M.; Harbitz, C.B. (Ed.), 6th International Symposium on Submarine Mass Movements and Their Consequences, Kiel, Germany, pp. 239-248.

L'Heureux, J.-S., Longva, O., Steiner, A., Hansen, L., Vardy, M.E., Vanneste, M., Haflidason, H., Brendryen, J., Kvalstad, T.J., Forsberg, C.F., Chand, S., Kopf, A., 2012. Identification of Weak Layers and Their Role for the Stability of Slopes at Finneidfjord, Northern Norway, in: Yamada, Y., Kawamura, K., Ikehara, K., Ogawa, Y., Urgeles, R., Mosher, D.C., Chaytor, J., Strasser, M. (Eds.), Submarine Mass Movements and Their Consequences (5th International Symposium). Springer, pp. 321-330.

L'Heureux, J.-S., Vanneste, M., Rise, L., Brendryen, J., Forsberg, C.F., Nadim, F., Longva, O., Chand, S., Kvalstad, T.J., Haflidason, H., submitted. Stability, mobility and failure mechanism for landslides at the Upper Continental Slope off Vesterålen, Norway. Marine Geology.

L'Heureux, J.S., Vanneste, M., Rise, L., Brendryen, J., Forsberg, C.F., Nadim, F., Longva, O., Chand, S., Kvalstad, T.J., Haflidason, H., 2013. Stability, mobility and failure mechanism for landslides at the upper continental slope off Vesterålen, Norway. Marine Geology 346, 192-207. 
L’Heureux, J.-S., Eilertsen, R.S., Glimsdal, S., Issler, D., Solberg, A.H.S., Harbitz, C.B., 2011. The 1978 quick clay landslide at Rissa, mid-Norway: subaqueous morphology and tsunami simulations, in: Yamada, Y., Kawamura, K., Ikehara, K., Ogawa, Y., Urgeles, R., Mosher, D., Chaytor, J., Strasser, M. (Eds.), 5th International Symposium on Submarine Mass Movements and Their Consequences, Kyoto, Japan.

Labbé, M., Donnadieu, C., Daubord, C., Hébert, H., 2012. Refined numerical modeling of the 1979 tsunami in Nice (French Riviera): Comparison with coastal data. Journal of Geophysical Research: Earth Surface 117, F01008.

Lafuerza, S., Sultan, N., Canals, M., Lastras, G., Cattaneo, A., Frigola, J., Costa, S., Berndt, C., 2012. Failure mechanisms of Ana Slide from geotechnical evidence, Eivissa Channel, Western Mediterranean Sea. Marine Geology 307-310, 1-21.

Lastras, G., Canals, M., Amblas, D., Ivanov, M., Dennielou, B., Droz, L., Akhmetzhanov, A.M., 2006. Eivissa slides, western Mediterranean Sea: morphology and processes. Geo-Marine Letters 26, 225233.

Lastras, G., Canals, M., Urgeles, R., De Batist, M., Calafat, A.M., Casamor, J.L., 2004a. Characterisation of the recent BIG'95 debris flow deposit on the Ebro margin, Western Mediterranean Sea, after a variety of seismic reflection data. Marine Geology 213, 235-255.

Lastras, G., Canals, M., Urgeles, R., Hughes-Clarke, J.E., Acosta, J., 2004b. Shallow slides and pockmark swarms in the Eivissa Channel, western Mediterranean Sea. Sedimentology 51, 837-850.

Lastras, G., De Blasio, F.V., Canals, M., Elverhøi, A., 2005. Conceptual and numerical modeling of the Big'95 debris flow, western Mediterranean Sea. Journal of Sedimentary Research 75, 784-797.

Le, M.-H., Nauroy, J.F., De Gennaro, V., Delage, P., Flavigny, E., Thanh, N., Colliat, J.L., Peuch, A., Meunier, J., 2008. Characterization of soft deepwater West Africa clays: SHANSHEP testing is not recommended for sensitive structured clays, in: OTC (Ed.), OTC2008. OTC, Houston, TX, p. OTC 19193. Leroueil, S., 2001. Natural slopes and cuts: movements and failure mechanisms. Géotechnique 51, 197-243.

Levesque, C., L., Locat, J., Leroueil, S., 2006. Dating submarine mass movements triggered by earthquakes in the Upper Saguenay Fjord, Quebec, Canada. Norwegian Journal of Geology 86, 231242.

Leynaud, D., Sultan, N., 2010. 3-D slope stability analysis: A probability approach applied to the nice slope (SE France). Marine Geology 269, 89-106.

Locat, J., Lee, H.J., 2002. Submarine landslides: advances and challenges. Canadian Geotechnical Journal 39, 193-212. 
Longva, O., Janbu, N., Blikra, L.H., Bøe, R., 2003. The 1996 Finneidfjord Slide: seafloor failure and slide dynamics, in: Locat, J., Mienert, J. (Eds.), Submarine mass movements and their consequences. Kluwer Academic Publishers, Dordrecht, pp. 521-530.

Løvholt, F., Harbitz, C.B., Haugen, K.B., 2005. A parametric study of tsunamis generated by submarine slides in the Ormen Lange/Storegga area off western Norway. Marine and Petroleum Geology 22, 219-231.

Lunne, T., 2012. The CPT in offshore soil investigations - a historic perspective. Geomechanics and Geoengineering: An International Journal 1, 1-27.

Lunne, T., Berre, T., Strandvik, S., 1998. Sample disturbance effects in deepwater soil investigations, SUT Conference on Soil Investigations and Foundation Behaviour. SUT, London, pp. 199-220.

Lunne, T., Berre, T., Strandvik, S., Andersen, K.H., Tjelta, T.I., 2001. Deepwater sample disturbance due to stress relief, OTRC 2001 International Conference, Houston, TX, pp. 64-85.

Lunne, T., Robertson, P.K., Powell, J.J.M., 1997. Cone Penetration Testing In Geotechnical Practise. Spon Press, Taylor \& Francis Group, London and New York.

Masson, D.G., Canals, M., Alonso, B., Urgeles, R., Huhnerback, V., 1998. The Canary Debris Flow: source area morphology and failure mechanisms. Sedimentology 45, 411-432.

Meldahl, P., Heggland, R., Bril, B., de Groot, P., 2001. Identifying faults and gas chimneys using multiattributes and neural networks. The Leading Edge.

Michalowski, R.L., 1995. Stability of slopes: Limit analysis approach. Reviews in Engineering Geology $10,51-62$.

Mienert, J., Vanneste, M., Bünz, S., Andreassen, K., Haflidason, H., Sejrup, H.P., 2005. Ocean warming and gas hydrate stability on the mid-Norwegian margin at the Storegga Slide. Marine and Petroleum Geology 22, 233-244.

Milkov, A., 2000. Worldwide distribution of submarine mud volcanoes and associated gas hydrates. Marine Geology 167, 29-42.

Minshull, T.A., Singh, S.C., Westbrook, G.K., 1994. Seismic velocity structure at a gas hydrate reflector, offshore Western Columbia, from full waveform inversion. Journal of Geophysical Research 99, 47154734.

Moore, J.G., Clague, D.A., Holcomb, R.T., Lipman, P.W., Normark, W.R., Torresan, M.E., 1989. Prodigious submarine landslides on the Hawaiian Ridge. Journal of Geophysical Research 94, 1746517484.

Morgan, E.C., Vanneste, M., Lecomte, I., Baise, L.G., Longva, O., McAdoo, B., 2012. Estimation of free gas saturation from seismic reflection surveys by the genetic algorithm inversion of a P-wave attenuation model. Geophysics 77, R175-R187. 
Mosher, D., Bigg, S., LaPierre, A., 2006. 3D seismic versus multibeam sonar seafloor surface renderings for geohazard assessment: Case examples from the central Scotian Slope. The Leading Edge 25, 1484-1494.

Moss, J.L., Cartwright, J., Moore, R., 2012. Evidence for fluid migration following pockmark formation: Examples from the Nile Deep Sea Fan. Marine Geology 303-306, 1-13.

Mulder, T., Savoye, B., Piper, D.J.W., Syvitski, J.P.M., 1998. The Var submarine sedimentary system: understanding Holocene sediment delivery processes and their importance to the geological record, in: Stoker, M.S., Evans, D., Cramp, A. (Eds.), Geological Processes on Continental Margins: Sedimentation, Mass-Wasting and Stability. Geological Society, Special Publication, pp. 145-166.

Mulder, T., Savoye, B., Syvitski, J.P.M., 1997. Numerical modelling of a mid-sized gravity flow: the 1979 Nice turbidity current (dynamics, processes, sediment budget and seafloor impact). Sedimentology 44, 305-326.

Mulder, T., Tisot, J.-P., Cochonat, P., Bourillet, J.-F., 1994. Regional assessment of mass failure events in the Baie des Anges, Mediterranean Sea. Marine Geology 122, 29-45.

Nadim, F., 2006. Challenges to geo-scientists in risk assessment for submarine slides. Norwegian Journal of Geology 86, 351-362.

Nadim, F., Krunic, D., Jeanjean, P., 2003. Probabilistic slope stability analyses of the Sigsbee escarpment, Offshore Technology Conference, Houston, Texas, p. OTC paper 15203.

Nadim, F., Kvalstad, T.J., Guttormsen, T., 2005. Quantification of risks associated with seabed instability at Ormen Lange. Marine and Petroleum Geology 22, 311-318.

Ottesen, D., Dowdeswell, J.A., Rise, L., 2005. Submarine landforms and the reconstruction of fastflowing ice streams within a large Quaternary ice sheet: the 2500-km-long Norwegian-Svalbard margin $\left(57^{\circ}-80^{\circ} \mathrm{N}\right)$. Geological Society of America Bulletin 117, 1033-1050.

Panieri, G., Camerlenghi, A., Cacho, I., Cervera, C.S., Canals, M., Lafuerza, S., Herrera, G., 2012. Tracing seafloor methane emissions with benthic foraminifera: Results from the Ana submarine landslide (Eivissa Channel, Western Mediterranean Sea). Marine Geology 291-294, 97-112.

Perez-Garcia, C., Berndt, C., Klaeschen, D., Mienert, J., Haffert, L., Depreiter, D., Haeckel, M., 2011. Linked halokinesis and mud volcanism at the Mercator mud volcano, Gulf of Cadiz. Journal of Geophysical Research: Solid Earth 116, B05101.

Perez-Garcia, C., Feseker, T., Mienert, J., Berndt, C., 2009. The Håkon Mosby mud volcano: 330000 years of focused fluid flow activity at the SW Barents Sea slope. Marine Geology 262, 105115.

Pestana, J.M., Nadim, F., 2000. Non-linear site response analysis of submerged slopes, Geotechnical Engineering Report. Department of Civil and Environmental Engineering, University of California, Berkeley, p. 51. 
Pickrill, R.A., 1993. Shallow seismic stratigraphy and pockmarks of a hydrothermally influenced lake, Lake Rotoiti, New Zealand. Sedimentology 40, 813-828.

Pilcher, R., Argent, J., 2007. Mega-pockmarks and linear pockmark trains on the West African continental margin. Marine Geology 244, 15-32.

Pinson, L.J.W., Henstock, T.J., Dix, J.K., Bull, J.M., 2008. Estimating quality factor and mean grain size of sediments from high-resolution marine seismic data. Geophysics 73, G19-G28.

Piper, D.J.W., Cochonat, P., Morrison, M.L., 1999. The sequence of events around the epicentre of the 1929 Grand Banks earthquake: initiation of debris flows and turbidity current inferred from sidescan sonar. Sedimentology 46, 79-97.

Pride, S.R., Berryman, J.G., Harris, J.M., 2004. Seismic attenuation due to wave-induced flow. J. Geophys. Res. 109, B01201.

Puzrin, A.M., Germanovich, L.N., Kim, S., 2004. Catastrophic failure of submerged slopes in normally consolidated sediments. Géotechnique 51, 634-643.

Puzrin, A.M., Saurer, E., Germanovich, L.N., 2010. A dynamic solution of the shear band propagation in submerged landslides. Granular Matter 12, 253-265.

Reine, C., van der Baan, M., Clark, R., 2009. The robustness of seismic attenuation measurements using fixed- and variable-window time-frequency transforms. Geophysics 74, WA123-WA135.

Rogers, J.N., Kelley, J.T., Belknap, D.F., Gontz, A., Barnhardt, W.A., 2006. Shallow-water pockmark formation in temperate estuaries: A consideration of origins in the western gulf of Maine with special focus on Belfast Bay. Marine Geology 225, 45-62.

Sahal, A., Lemahieu, A., 2011. The 1979 nice airport tsunami: mapping of the flood in Antibes. Natural Hazards 56, 833-840.

Seed, H.B., Seed, R.B., Schlosser, F., Blondeau, F., Juran, I., 1988. The landslide at the port of Nice on October 16, 1979. Earthquake Engineering Research Centre.

Sobkowicz, J.C., Morgenstern, N.R., 1984. The undrained equilibrium behaviour of gassy sediments. Canadian Geotechnical Journal 21, 439-448.

Socco, V.L., Maraschini, M., Boiero, D., Vanneste, M., Madshus, C., Westerdahl, H., Duffaut, K., Skomedal, E., 2011. On the use of NGI's prototype seabed-coupled shear wave vibrator for shallow soil characterization - Part II: Joint inversion of multi-modal Love and Scholte Surface Waves. Geophysical Journal International 185, 237-252.

Solheim, A., Berg, K., Forsberg, C.F., Bryn, P., 2005a. The Storegga Slide complex: repetitive large scale sliding with similar cause and development. Marine and Petroleum Geology 22, 97-107.

Solheim, A., Bryn, P., Sejrup, H.P., Mienert, J., Berg, K., 2005b. Ormen Lange - an integrated study for the safe development of a deep-water gas field within the Storegga Slide Complex, NE Atlantic continental margin; executive summary. Marine and Petroleum Geology 22, 1-9. 
St-Onge, G., Mulder, T., Francus, P., Long, B., 2007. Continuous physical properties of cored marine sediments, in: Hillaire-Marcel, C., de Vernal, A. (Eds.), Proxies in Late Cenozoic Paleoceanography. Elsevier, pp. 63-98.

Stegmann, S., Sultan, N., Kopf, A., Apprioual, R., Pelleau, P., 2011. Hydrogeology and its effect on slope stability along the coastal aquifer of Nice, France. Marine Geology 280, 168-181.

Steiner, A., L'Heureux, J.-S., Kopf, A., Vanneste, M., Longva, O., Lange, M., Haflidason, H., 2012. An Insitu Free-Fall Piezocone Penetrometer for Characterizing Soft and Sensitive Clays at Finneidfjord (Northern Norway), in: Yamada, Y., Kawamura, K., Ikehara, K., Ogawa, Y., Urgeles, R., Mosher, D.C., Chaytor, J., Strasser, M. (Eds.), Submarine Mass Movements and Their Consequences (5th International Symposium). Springer, pp. 99-109.

Stewart, R.R., Gaiser, J.E., Brown, R.J., Lawton, D.C., 2003. Converted-wave seismic exploration: Applications. Geophysics 68, 40-57.

Strasser, M., Stegmann, S., Bussmann, F., Anselmetti, F.S., Rick, B., Kopf, A., 2007. Quantifying subaqueous slope stability during seismic shaking: Lake Lucerne as model for ocean margins. Marine Geology 240, 77-97.

Strout, J.M., Tjelta, T.I., 2005. In situ pore pressures: What is their significance and how can they be reliably measured? Marine and Petroleum Geology 22, 275-285.

Sultan, N., Cochonat, P., Foucher, J.P., Mienert, J., 2004. Effect of gas hydrates melting on seafloor slope instability. Marine Geology 213, 379-401.

Sultan, N., De Gennaro, V., Peuch, A., 2012. Mechanical behaviour of gas-charged marine plastic sediments. Géotechnique 62, 751-766.

Sultan, N., Gaudin, M., Berné, S., Canals, M., Urgeles, R., Lafuerza, S., 2007a. Analysis of slope failures in submarine canyon heads: An example from the Gulf of Lions. Journal of Geophysical Research 112, F01009, doi:01010.01029/02005JF000408.

Sultan, N., Marsset, B., Ker, S., Marsset, T., Voisset, M., Vernant, A.M., Bayon, G., Cauquil, E., Adamy, J., Colliat, J.L., Drapeau, D., 2010a. Hydrate dissolution as a potential mechanism for pockmark formation in the Niger delta. Journal of Geophysical Research: Solid Earth 115, B08101.

Sultan, N., Riboulot, V., Ker, S., Marsset, B., Géli, L., Tary, J.B., Klingelhoefer, F., Voisset, M., Lanfumey, V., Colliat, J.L., Adamy, J., Grimaud, S., 2011. Dynamics of fault-fluid-hydrate system around a shalecored anticline in deepwater Nigeria. J. Geophys. Res. 116, B12110.

Sultan, N., Savoye, B., Jouet, G., Leynaud, D., Cochonat, P., Henry, P., Stegmann, S., Kopf, A., 2010b. Investigation of a possible submarine landslide at the Var delta front (Nice continental slope, southeast France). Canadian Geotechnical Journal 47, 486-496. 
Sultan, N., Voisset, M., Marsset, T., Vernant, A.M., Cauquil, E., Colliat, J.L., Curinier, V., 2007b. Detection of free gas and gas hydrate based on 3D seismic data and cone penetration testing: An example from the Nigerian Continental Slope. Marine Geology 240, 235-255.

Tinivella, U., Carcione, J.M., 2001. Estimation of gas-hydrate concentration and free-gas saturation from log and seismic data. The Leading Edge, 200.

Tjelta, T.I., Svanø, G., Strout, J.M., Forsberg, C.F., Planke, S., Johansen, H., 2007. Gas Seepage and Pressure Buildup at a North Sea Platform Location: Gas Origin, Transport Mechanisms, and Potential Hazards, Offshore Technology Conference. OTC, Houston, TX, USA, p. 11.

Urciuoli, G., Picarelli, L., Leroueil, S., 2007. Local soil failure before general slope failure. Geotechnical and Geological Engineering 25, 103-122.

Urlaub, M., Talling, P.J., Masson, D.G., 2013. Timing and frequency of large submarine landslides: implications for understanding triggers and future geohazard. Quaternary Science Reviews 72, 63-82. Van Rensbergen, P., De Batist, M., Klerkx, J., Poort, J., Hus, R., Vanneste, M., Granin, N., Krinitsky, P., 2002. Sub-lacustrine mud volcanoes and cold seeps caused by dissociation of gas hydrates in Lake Baikal. Geology 30, 631-634.

Vanneste, M., Forsberg, C.F., Glimsdal, S., Harbitz, C.B., Issler, D., Kvalstad, T.J., Løvholt, F., Nadim, F., 2011a. Submarine Landslides and Their Consequences: What do we know, what can we do? (Keynote presentation and paper), 2nd World Landslide Forum, Rome, Italy, p. pp. 11.

Vanneste, M., Harbitz, C.B., De Blasio, F.V., Glimsdal, S., Mienert, J., Elverhøi, A., 2011b. HinlopenYermak Landslide, Arctic Ocean - Geomorphology, Landslide Dynamics, and Tsunami Simulations, in: Shipp, R.C., Weimer, P., Posamentier, H. (Eds.), Mass-Transport Deposits in Deepwater Settings. Society for Sedimentary Geology, Tulsa, Oklahoma, pp. 509-527.

Vanneste, M., L'Heureux, J.-S., Baeten, N., Brendryen, J., Vardy, M.E., Steiner, A., Forsberg, C.F., Kvalstad, T.J., Laberg, J.S., Chand, S., Longva, O., Rise, L., Haflidason, H., Hjelstuen, B.O., Forwick, M., Morgan, E., Lecomte, I., Kopf, A., Vorren, T.O., Reichel, T., 2012. Shallow Landslides and their Dynamics in Coastal and Deepwater Environments, Norway, in: Yamada, Y., Kawamura, K., Ikehara, K., Ogawa, Y., Urgeles, R., Mosher, D.C., Chaytor, J., Strasser, M. (Eds.), Submarine Mass Movements and Their Consequences (5th International Symposium). Springer, pp. 29-41.

Vanneste, M., Longva, O., L'Heureux, J.-S., Vardy, M.E., Morgan, E., Forsberg, C.F., Kvalstad, T.J., Strout, J.M., Brendryen, J., Haflidason, H., Lecomte, I., Steiner, A., Kopf, A., Mörz, T., Kreiter, S., 2013. Finneidfjord, a Field Laboratory for Integrated Submarine Slope Stability Assessement and Characterization of Landslide-prone Sediments: a Review, Offshore Technology Conference (OTC2013). OTC, Houston, TX, p. pp. 17.

Vanneste, M., Madshus, C., Socco, L.V., Maraschini, M., Sparrevik, P.M., Westerdahl, H., Duffaut, K., Skomedal, E., Bjørnarå, T.I., 2011c. On the use of NGI's prototype seabed-coupled shear wave vibrator 
for shallow soil characterization - Part I: Acquisition and processing of surface waves. Geophysical Journal International 185, 221-236.

Vanneste, M., Mienert, J., Bünz, S., 2006. The Hinlopen Slide: A giant, submarine slope failure on the northern Svalbard margin, Arctic Ocean. Earth and Planetary Science Letters 245, 373-388.

Vanneste, M., Westerdahl, H., Sparrevik, P., Madshus, C., Lecomte, I., Zühlsdorff, L., 2007. Shear-Wave Source for Offshore Geohazard Studies: A Pilot Project to Improve Seismic Resolution and Better Constrain the Shear Strength of Marine Sediments, in: OTC (Ed.), Offshore Technology Conference. OTC, Houston, pp. OTC-18756.

Vardy, M.E., L'Heureux, J.-S., Vanneste, M., Longva, O., Steiner, A., Forsberg, C.F., Haflidason, H., Brendryen, J., 2012. Multidisciplinary investigation of a shallow near-shore landslide, Finneidfjord, Norway. Near Surface Geophysics 10, 267-277.

Vardy, M.E., Pinson, L.J.W., Bull, J.M., Dix, J.K., Henstock, T.J., Davis, J.W., Gutowski, M., 2010. 3D seismic imaging of buried Younger Dryas mass movement flows: Lake Windermere, UK. Geomorphology 118, 176-187.

Vaunat, J., Leroueil, S., 2002. Analysis of post-failure slope movements with the framework of hazard and risk analysis. Natural Hazards 26, 83-109.

Webb, K.E., Hammer, Ø., Lepland, A., Gray, J.S., 2009. Pockmarks in the inner Oslofjord, Norway. GeoMarine Letters 29, 111-124.

Weitemeyer, K.A., Constable, S., Tréhu, A.M., 2011. A marine electromagnetic survey to detect gas hydrate at Hydrate Ridge, Oregon. Geophysical Journal International, no-no.

Wessel, P., Smith, W.H.F., 1991. Free software helps map and display data. EOS Transactions of the American Geophysical Union 72, 441, 445-446.

Wessel, P., Smith, W.H.F., Scharroo, R., Luis, J., Wobbe, F., 2013. Generic Mapping Tools: Improved version released. EOS, Transaction of the American Geophysical Union 94, 409-410.

Westbrook, G.K., Bünz, S., Camerlenghi, A., Carcione, J., Chand, S., Dean, S., Foucher, J.P., Flüh, E., Gei, D., Haacke, R.R., Klingelhoefer, F., Long, C., Madrussani, G., Mienert, J., Minshull, T.A., Nouzé, H., Peacock, S., Rossi, G., Roux, E., Reston, T., Vanneste, M., Zillmer, M., 2005. Measurement of P- and Swave velocities, and the estimation of hydrate concentration at sites in the continental margin of Svalbard and the Storegga region of Norway, in: Austvik, T. (Ed.), 5th International Conference on Natural Gas Hydrates. Tapir Academic Press, Trondheim, Norway, pp. 726-735 (paper 3004).

Westbrook, G.K., Chand, S., Rossi, G., Long, C., Bünz, S., Camerlenghi, A., Carcione, J.M., Dean, S., Foucher, J.P., Gei, D., Haacke, R., Madrussani, G., Mienert, J., Minshull, T.A., Nouzé, H., Peacock, S., Reston, T.J., Vanneste, M., Zillmer, M., 2008. Estimation of methane hydrate concentrations from multi-component seismic data at sites in the continental margins of NW Svalbard and the Storegga region of Norway. Marine and Petroleum Geology 25, 744-758. 
Wheeler, S.J., 1988a. A conceptual model for soils containing large gas bubbles. Géotechnique 38, 389-397.

Wheeler, S.J., 1988b. The undrained shear strength of soils containing large gas bubbles. Géotechnique 38, 399-413.

Yilmaz, O., 2001. Seismic data analysis: Processing, inversion and interpretation of seismic data, second edition ed. Society of Exploration Geophysicists, Tulsa.

Yuan, T., Spence, G.D., Hyndman, R.D., Minshull, T.A., Singh, S.C., 1999. Seismic velocity studies of a gas hydrate bottom-simulating reflector on the northern Cascadia continental margin: amplitude modelling and full waveform inversion. Journal of Geophysical Research 104, 1179-1191.

Zakeri, A., 2008. Submarine Debris Flow Impact on Pipelines, Faculty of Mathematics and Natural Sciences. University of Oslo, Oslo.

\section{Table and Figure Captions}

Table 1: Overview of academic and applied engineering methods and tools for geotechnical characterization.

Table 2: Interaction between the mechanical behaviour of materials and triggering mechanisms. Open squares indicate the most critical conditions in terms of sediment deformations and geohazards.

Table 3: Summary of dynamic slope stability analysis for the Vesterålen area (L'Heureux et al., 2013). 
Figure 1: Various geohazards may occur along the continental slopes. These include slope failures, impact of debris on infrastructure, dissociation of hydrates, shallow gas pockets, overpressure (shallow water flows), fluid escape features (gas chimneys, mud volcanoes), diapirism, and seismicity. Submarine slope failures can also generate highly destructive tsunamis.

Figure 2: Overview map of the selected case studies on the Norwegian margin (Storegga, Finneidfjord, Vesterålen; NC = Norwegian Channel, NSF = North Sea Fan, TNS = Trænadjupet-Nyke landslide), the Western Mediterranean Sea (WMS) (Ana, Nice) and the Gulf of Guinea (GoG).

Figure 3: Examples of state-of-the-art technology for sediment sampling, in situ measurements and monitoring.

Figure 4: Typical examples of sample disturbance in triaxial compression tests (left) and constant-rateof-strain oedometer tests (right). The smaller the sample diameter (core liner), the larger the effect compared to a block sample which is virtually undisturbed (Lunne et al., 1998).

Figure 5: Different constitutive relations exist between materials and loading/unloading conditions. (Top) Gas exsolution in fine-grained sediments causes a reduction in peak shear strength under triaxial compression. The gas percentage corresponds to dissolved gas with respect to the solubility before decompression (Lunne et al., 2001). (Bottom) Results from anisotropically-consolidated undrained triaxial tests under compression on a typical Gulf of Guinea clay between in situ and SHANSEP type reconsolidation show a sharp decrease in shear properties under increasing stress levels. This behaviour is due to the progressive destructuring of the natural material (Le et al., 2008).

Figure 6: Perspective view of part (200 by $200 \mathrm{~km}^{2}$ ) of the Holocene Storegga event, off Norway seen from the seaside towards the upper headwall. Note the multiple escarpments, and complex morphology and high variability across the slide scar area. The grey line adjacent to the upper escarpment represents the Ormen Lange gas field, currently under development. Data courtesy of Norsk Hydro (now Statoil). 
Figure 7: Composite, interpreted seismic profile across the Storegga landslide complex at intermediate water depth. A large-magnitude earthquake is the most likely trigger. With respect to preconditioning, lateral migration of excess pore pressure, driven by glacial loading adjacent of the failure area, may have caused weakened conditions and facilitated the failure process (Bryn et al., 2005).

Figure 8: Photographs of different sediment units, being glacial clay (left) and marine clay (right) after anisotropically-consolidated triaxial compression tests, clearly showing the different behaviour with failure developing within the marine clays. Note the parallel inclined stripes (lower left to upper right) across the sample are imprints of the drainage filter rather than shear bands.

Figure 9: Dip magnitude map of part of the Eivissa Channel, Mediterranean Sea, characterized by several smaller-scale submarine mass movements, with headwalls at around $600 \mathrm{~m}$ water depth. Red circles are the borehole locations across the Ana slide, of which CPTU results are presented in Figure 10. Same scale is used as in Figure 11. The parallel stripes are noise features (acquisition artefacts).

Figure 10: Corrected cone resistance $q_{t}$ from 5 different CPTU tests in the Eivissa Channel (for location, see Figure 2). The dashed line is representative for normally-consolidated fine-grained sediments in the area, using PFM-06S1 and PFM-06S2 as a reference. Comparing this reference line with the data from the other three boreholes reveals the overconsolidated state at the other sites, related to removal of part of the overburden due to landsliding.

Figure 11: Dip magnitude map of the Vesterålen area characterized by several smaller-scale submarine mass movements, with headwalls between 500 and $800 \mathrm{~m}$. The core location outside of the landslide areas is marked by the dark red circle, and the blue line corresponds to the TOPAS SBP, both presented in Figure 12. Same scale is used as in Figure 9.

Figure 12: (Top) TOPAS sub-bottom profile across two of the smaller-scale landslides off the Vesterålen margin with marked regional slip planes and the core locations. For location of the profile, 
see Figure 11. (Bottom) Core log of the $12 \mathrm{~m}$ long piston core with lithology, sand fraction, strength tests (fall cone, torvane, DSS, CAUc), water content logs and Atterberg limits. The X-ray images show the two distinct lithologies, being a clay with IRD (facies I, taken from about $2 \mathrm{mbsf}$ ) and finely laminated clays virtually free of IRD (facies II, taken from around $4 \mathrm{mbsf}$ ).

Figure 13: AUV bathymetry data ( $3 \mathrm{~m}$ by $3 \mathrm{~m}$ bin size) from the pockmark fields in the Gulf of Guinea. The pockmarks have different geomorphologies (shapes, sizes) (Georges and Cauquil, 2007).

Figure 14: SYSIF seismic reflection profile across pockmarks $B$ and $C$, characterized by different acoustic facies in the sub-surface. The CPTU data (locations projected on profile) show indications of hemipelagic sediments (grey shading), but also signatures indicative of partial hydrate saturations (cyan) (Sultan et al., 2010a).

Figure 15: Modelling of the dynamic response of methane hydrate stability and the dissolution process as a result of decreasing methane concentration at the base of the model. The colours represent fractional porosity. The different panels show how porosity varies within the model over time (from a to h), giving rise to a zone of hydro-fracturing as a result of hydrate dissociation and subsequent excess pore pressure build-up (Sultan et al., 2010a).

Figure 16: (a) Map of the Nice airport area and the harbour extension that was remobilized by the 16 October 1979 landslide. The blue line indicates the location of the modelled cross-section (see Figure 19).

Figure 17: Pore pressure fluctuations recorded at four different depth levels below the seabed within the 1979 failure scar. The blue shading represents monthly precipitations recorded onshore at the airport (Stegmann et al., 2011).

Figure 18: CPTU logging data obtained from different boreholes in the Nice failure area. (a) $P$-wave velocity log; (b) to (d) Undrained shear strength derived from corrected cone resistance and pore 
pressure response using $N_{k t}$ factor of 15 for different boreholes. The blue lines represent the undrained shear strength profile for normally-consolidated sediments.

Figure 19: Numerical simulations of the horizontal displacement, using FEMUSLOPE, with excess pore pressure development with (top) and without (bottom) staged loading (embankment, harbour construction). Arrows indicate direction and magnitude of the total displacement.

Figure 20: Swath bathymetry image (top) and perspective view (bottom) of the Sørfjord basin and the 1996 Finneidfjord landslide, with the location of the seismic lines (black for TOPAS, white box for VHR-3D), borehole locations, and pore pressure data presented in Figure 21 to Figure 24. Data courtesy of NGU.

Figure 21: (Top) $1.7 \mathrm{~km}$ long TOPAS 2D sub-bottom profiler data (courtesy of NGU) across the Sørfjord basin showing evidence of several mass transport deposits (MTD, shaded areas), typically overlying an enhanced reflection (Vanneste et al., 2013). (Bottom) $950 \mathrm{~m}$ long VHR-3D chirp profile (in-line, courtesy of C-Dog consortium), across the borehole location (see Figure 21) across the main 1996 MTD. The continuous composite reflection that is partly eroded underneath the MTD corresponds to the event bed described in the text. Note the presence of a pronounced shallow gas front to the SE (Vanneste et al., 2012).

Figure 22: In situ CPTU data (three panels to the left: corrected tip resistance $q_{t}$, pore pressure response $u_{2}$, undrained shear strength $s_{u}$ ) and MSCL data (two panels to the right; bulk density $\rho$, magnetic susceptibility MS) collected adjacent to the Finneidfjord 1996 landslide. The CPTU data are collected using MARUM's GOST system (coloured lines) and Free-fall system (dark grey lines). Undrained shear strength range (grey shading) uses a cone factor of 10 to 20 , with 10 highlighted in orange. The green curve is a running average from fall cone strength measurements (triangles). The table contains AMS ${ }^{14} \mathrm{C}$ dating results, in calibrated years BP. The yellow horizontal shading corresponds to the event beds identified on the seismic and core log data, hosting the slip plane. 
Figure 23: GSD from the event bed (top) and reference depth (bottom) show significant variations in lithology in part of the event bed. Core imaging, using $\mathrm{CT}$ and $X$-rays, also reveals structural variability within the event bed. The image to the bottom right is taken from further upslope but shows a similar sedimentary sequence.

Figure 24: Evolution of in situ pore pressure ratio, i.e. the ratio between excess pore pressure and the difference between lithostatic and hydrostatic pressure, at one location behind the 1996 Finneidfjord escarpment (undisturbed zone). Total pressures are logged once per hour, and the values are corrected for both the tidal effects and atmospheric pressure variations. The bold orange line presents a running average with a length of 48 hours.

Figure 25: Proper analysis and improving our understanding of seafloor instabilities and deformation processes requires a multi-disciplinary and integrated approach, both for identification of such features (active and palaeo), their development over time, and the risks involved. 


\begin{tabular}{|c|c|c|c|}
\hline & & \multicolumn{2}{|c|}{ Purpose } \\
\hline Mode & Method, tool & Academic & Applied Engineering Purpose \\
\hline \multicolumn{4}{|c|}{ CPTU } \\
\hline Downhole & FUGRO-WISON CPT & Lafuerza et al. (2008) & Lunne (2012) \\
\hline Seabed Rig & IFREMER-Penfeld & Sultan et al. (2010) & \\
\hline Seabed Rig & MARUM-GOST & Vanneste et al. (2013) & \\
\hline Free-Fall & ODIM BOT Harpoon FFCPT & Mosher et al. (2007) & \\
\hline Free-Fall & MARUM CPT Lance & Steiner et al. (2012) & \\
\hline Free-Fall & MARUM Nimrod & Corella et. (2013) & $\nabla$ \\
\hline \multicolumn{4}{|c|}{ Strength/bearing capacity } \\
\hline Free Fall & MARUM-LIRmeter & Stephan et al. (2012) & \\
\hline \multicolumn{4}{|c|}{ Pressure/temperature } \\
\hline Downhole & FUGRO-McCLELLAND's Piezoprobe & Flemings et al. (2008) & Peuchen (2013) \\
\hline Downhole & IODP-DVTPP (Davis-Villinger Temperature Pressure Probe) & Flemings et al. (2008) & \\
\hline Downhole & IODP-CORK (Circulation Obviation Retrofit Kits) & Sawyer et al. (2008) & \\
\hline Downhole & NGI-Piezoprobe & Leynaud et al. (2007) & Tjelta et al. (2007) \\
\hline Free Fall & IFREMER-Differential Piezometer & Sultan et al. (2010) & \\
\hline Free Fall & IOS-PUPPI & Urgeles et al. (2000) & \\
\hline Free Fall & Oxford-Differential Piezometer & Sills and Thomas (2002) & \\
\hline
\end{tabular}

Table 1 


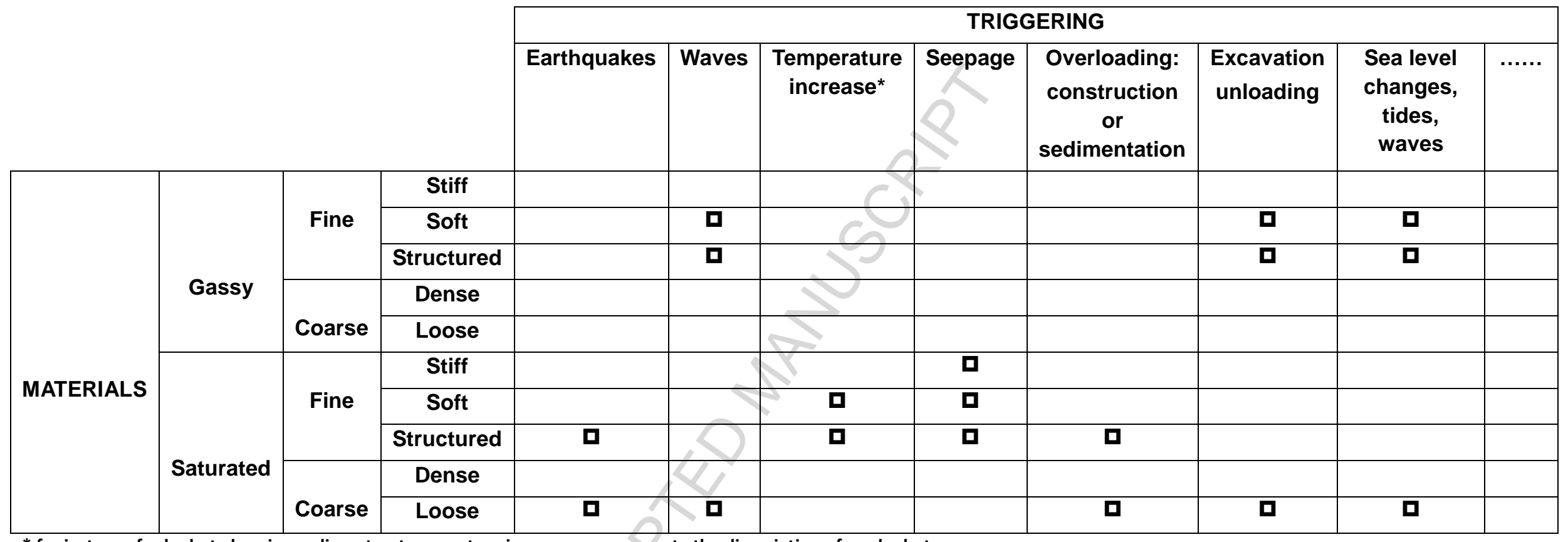

* for instance for hydrate bearing sediments a temperature increase may generate the dissociation of gas hydrates.

Table 2 


\begin{tabular}{|c|c|c|}
\hline Type of analysis & $\begin{array}{c}\text { Factor of safety, } \\
\text { FoS }\end{array}$ & Comments \\
\hline $\begin{array}{l}\text { Pseudo-static analysis, } \\
\mathrm{S}_{\mathrm{u}} / \square_{\mathrm{vc}}^{\prime} \mathrm{DSS}^{2}=0.27 \\
\quad \mathrm{~S}_{\mathrm{u}} / \square_{\mathrm{vc}}^{\prime}{ }^{\text {DSS }} \text { increased to } 0.35\end{array}$ & $\begin{array}{c}\mathrm{FS}>2 \\
\mathrm{FS}=1\end{array}$ & $\begin{array}{l}\text { For } 475-y r \text { earthquake } \\
\text { For } 10,000-y r \text { earthquake }\end{array}$ \\
\hline 1D dynamic earthquake analyses & $\begin{array}{c}\text { FS }=1 \\
\text { Fails in layer } 11.5 \mathrm{~m}\end{array}$ & $\begin{array}{l}\text { Accumulation of } \\
\text { deformations in top } 10 \mathrm{~m} \text {, } \\
\text { 10,000-yr earthquake }\end{array}$ \\
\hline $\begin{array}{l}\text { Post-earthquake slope stability } \\
\text { analysis }\end{array}$ & $\mathrm{FS}=1$ & For 475-yr earthquake \\
\hline
\end{tabular}

Table 3 


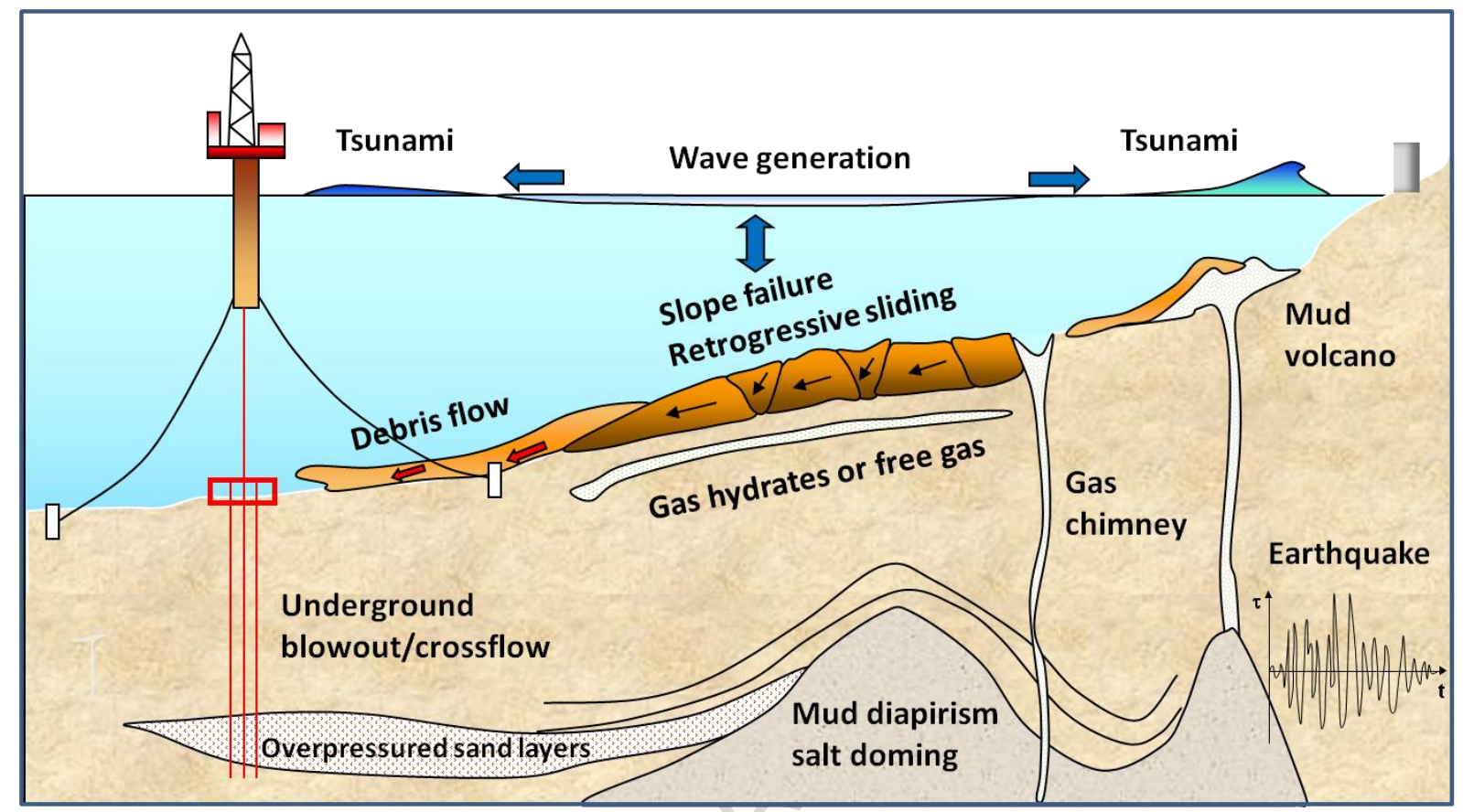

Figure 1 


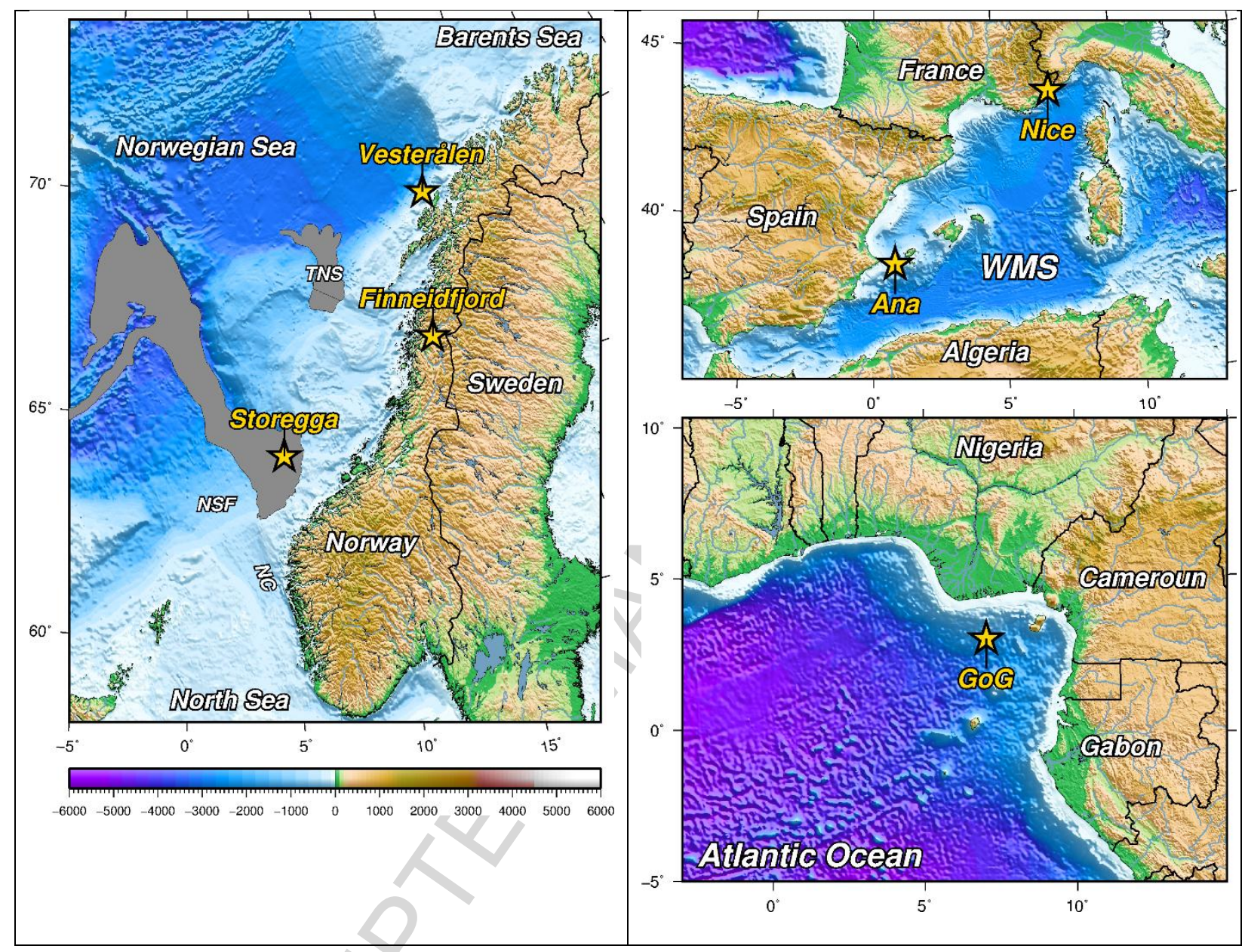

Figure 2 


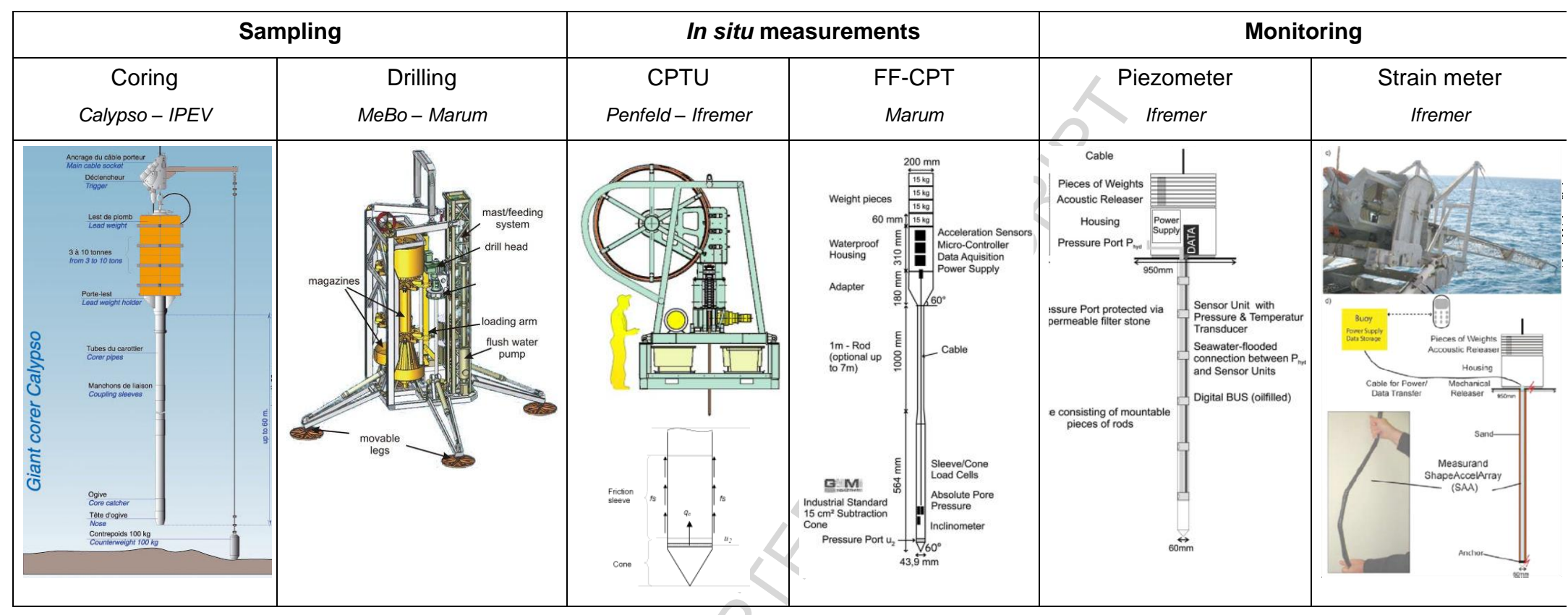

Figure 3 


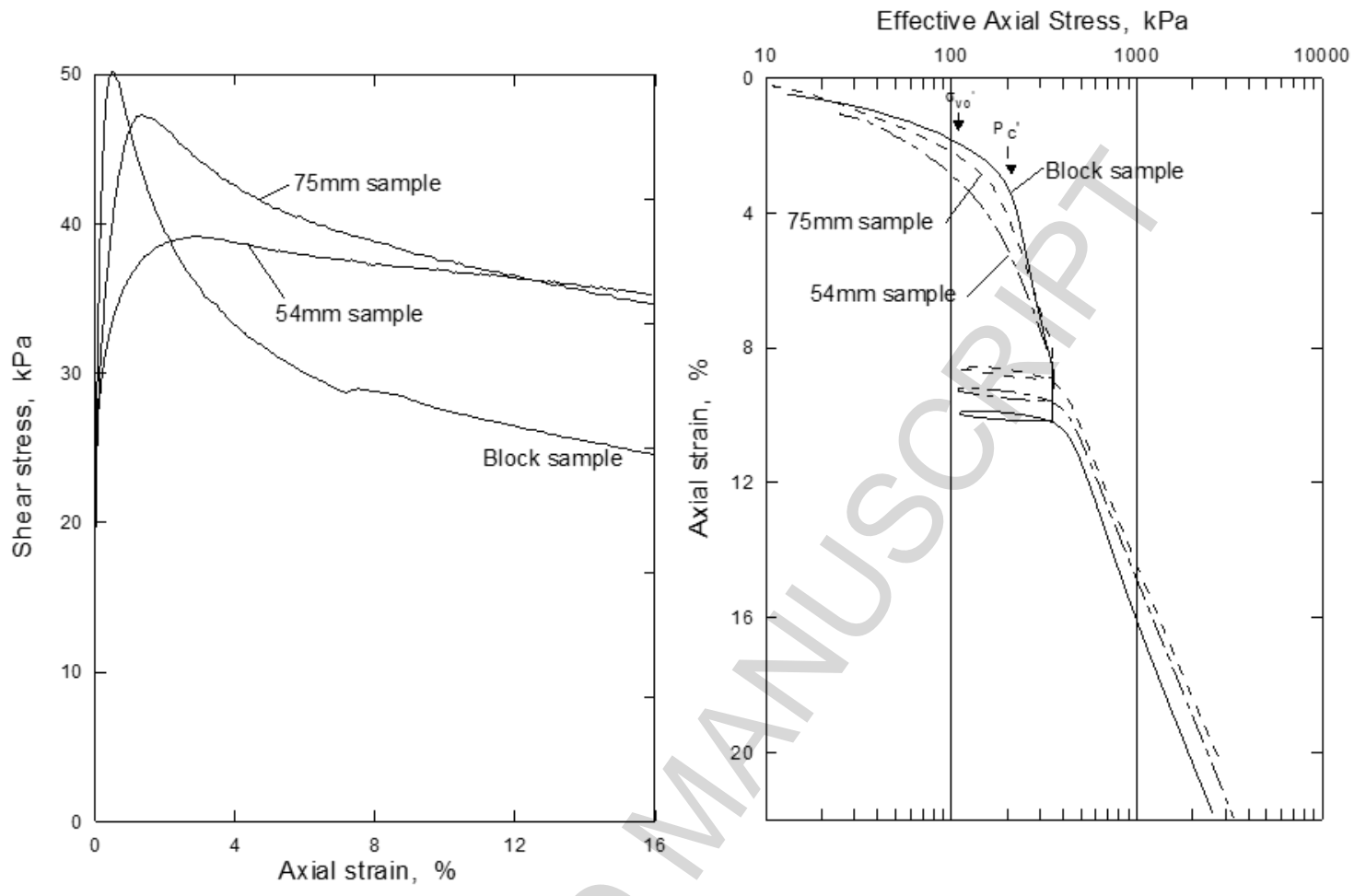

Figure 4 

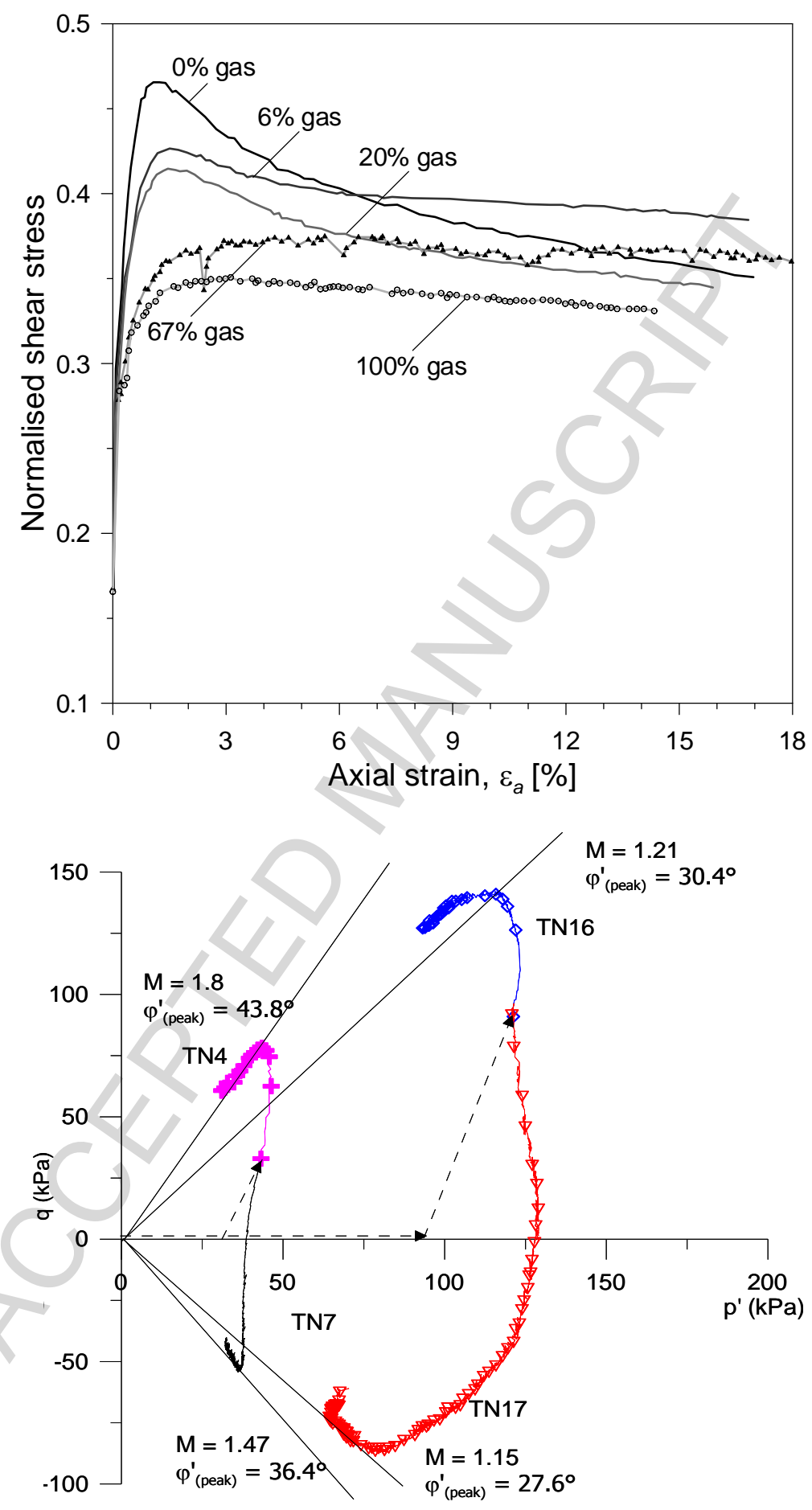

Figure 5 


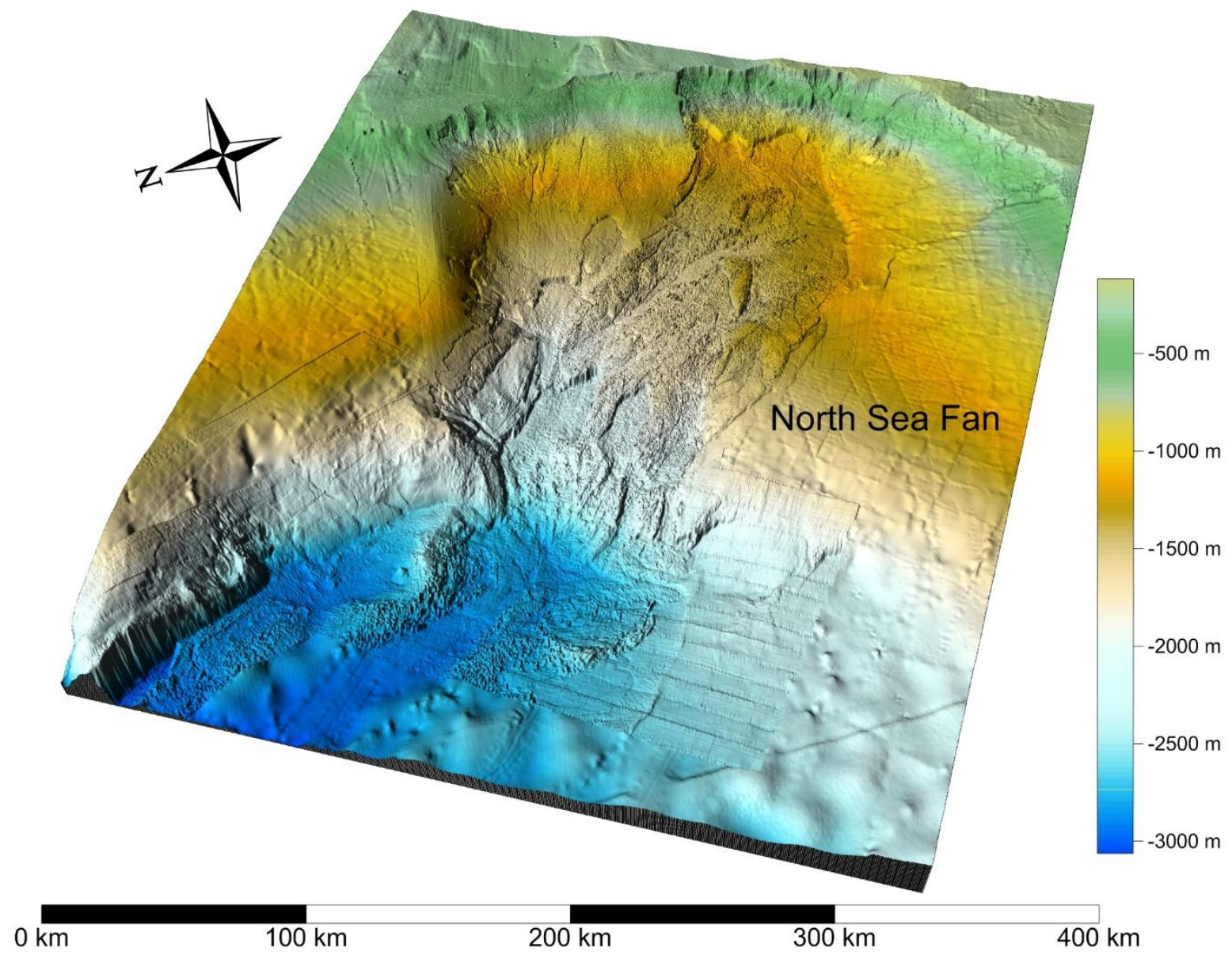

Figure 6 


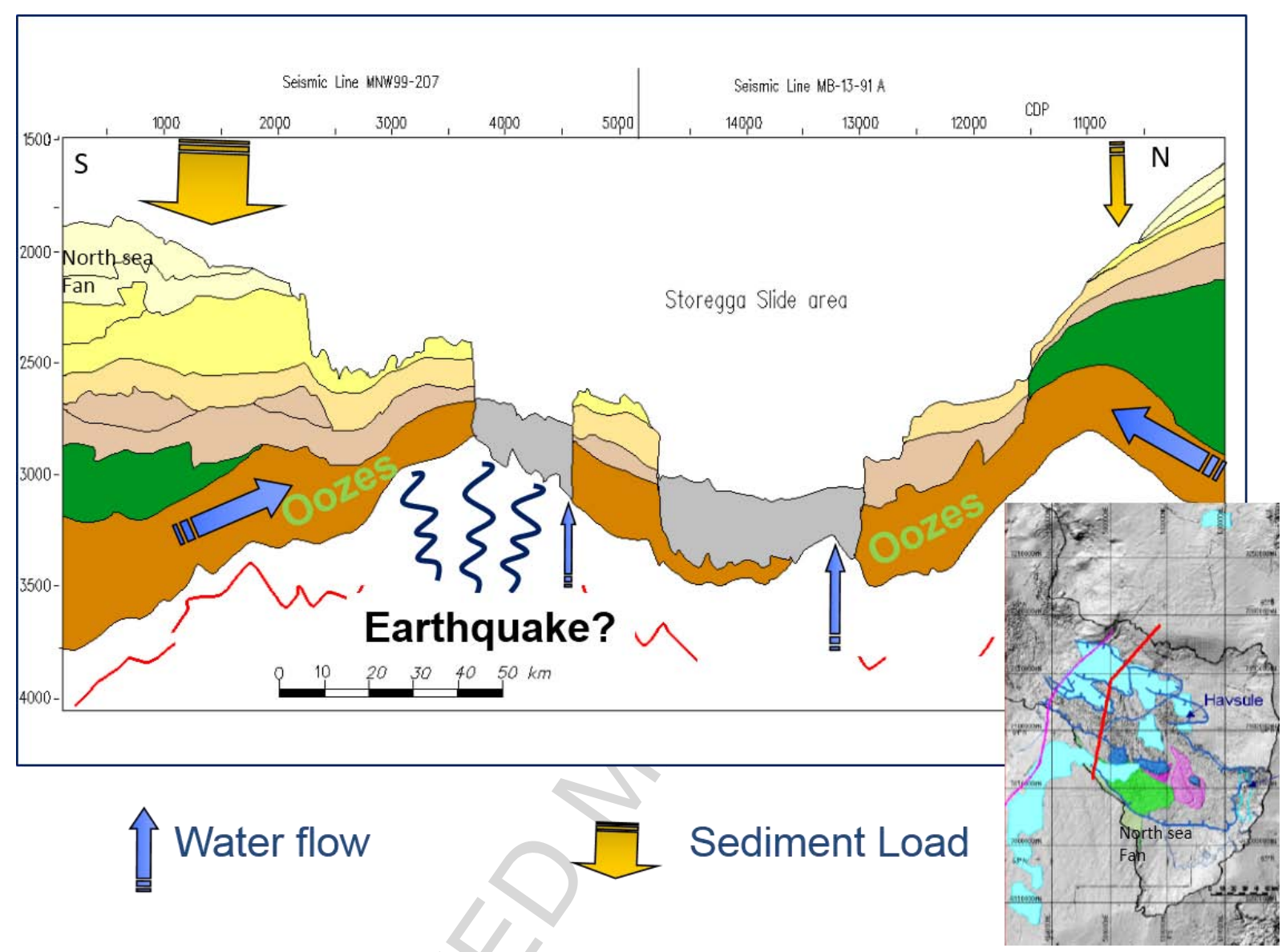

Figure 7 


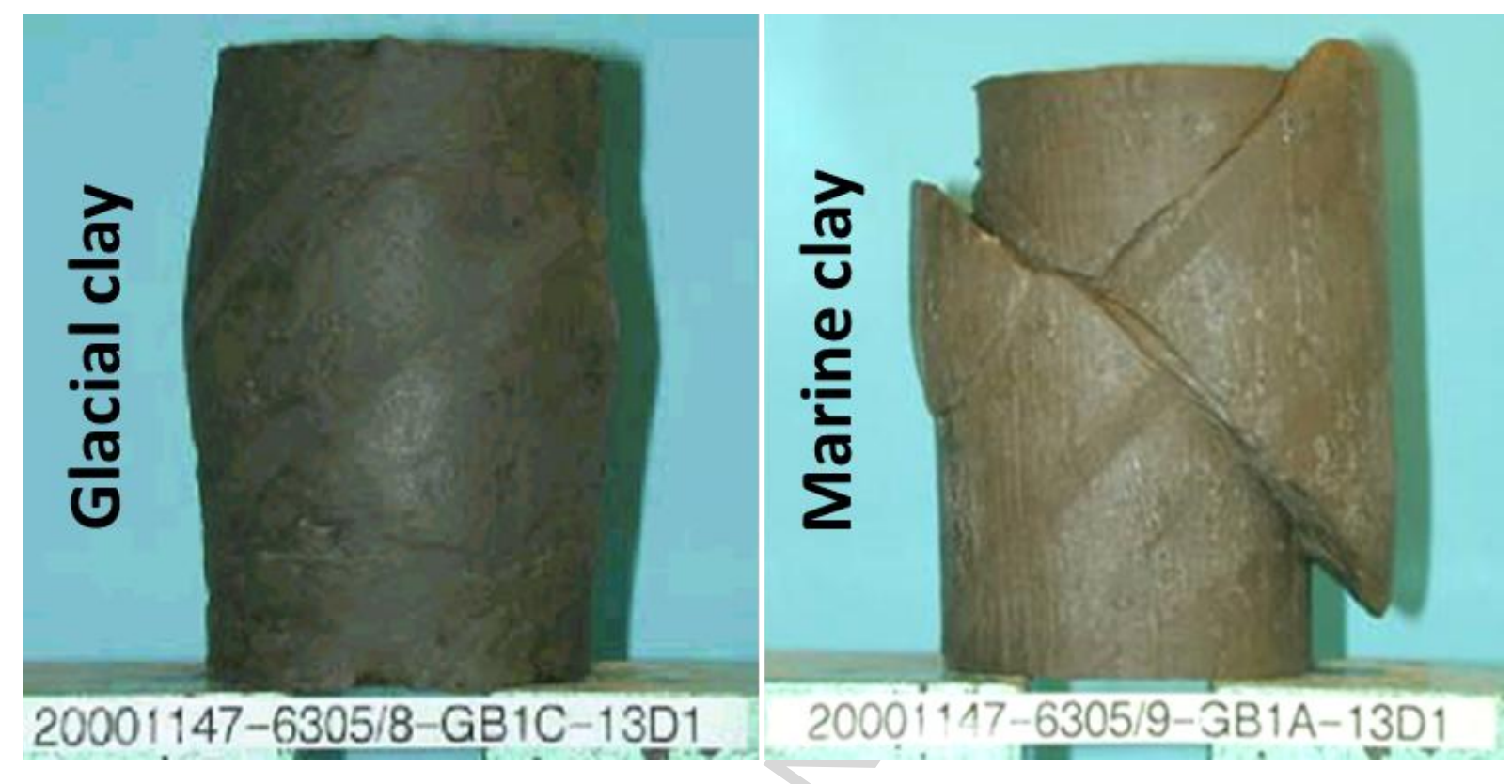

Figure 8 


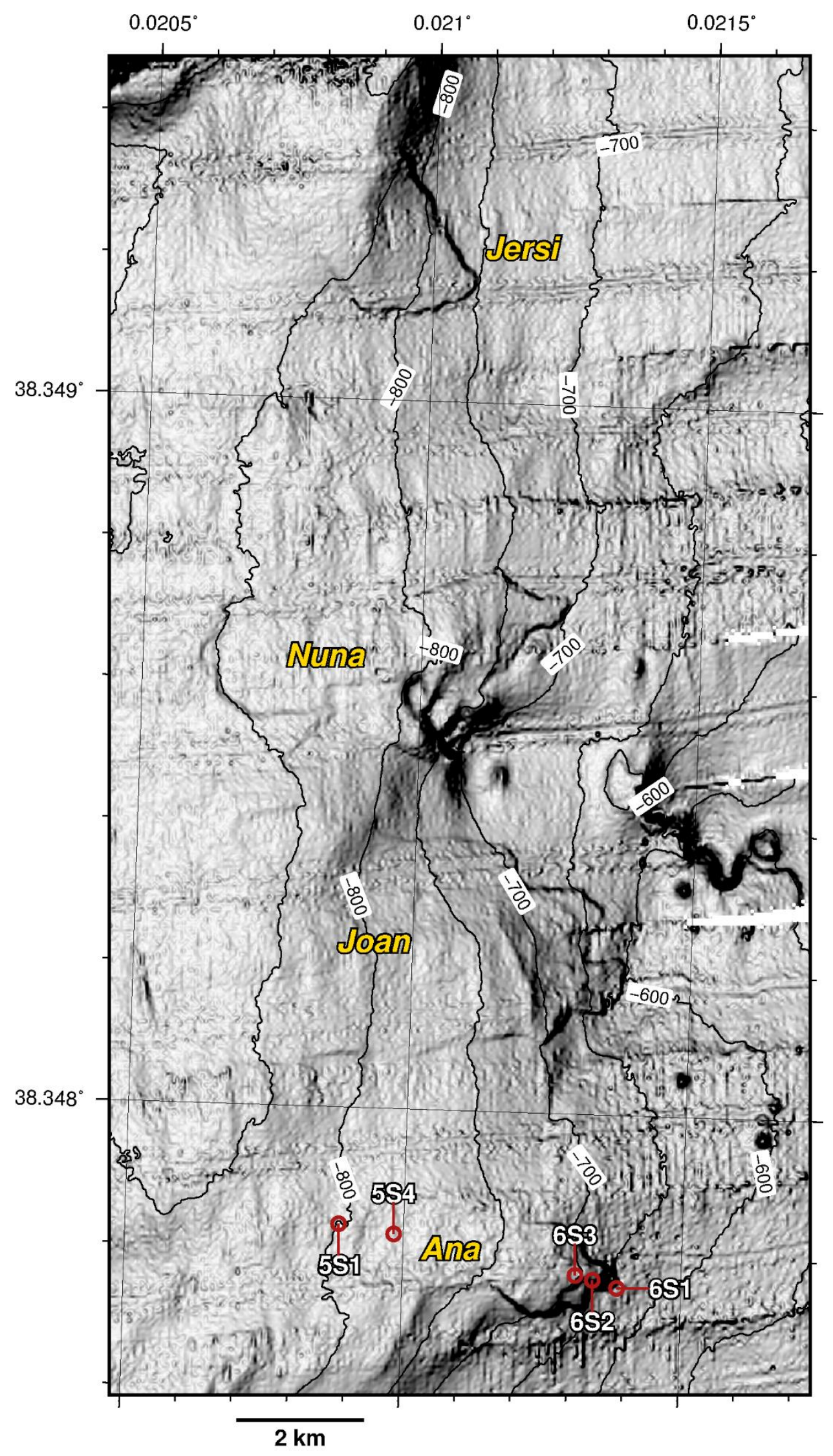

Figure 9 

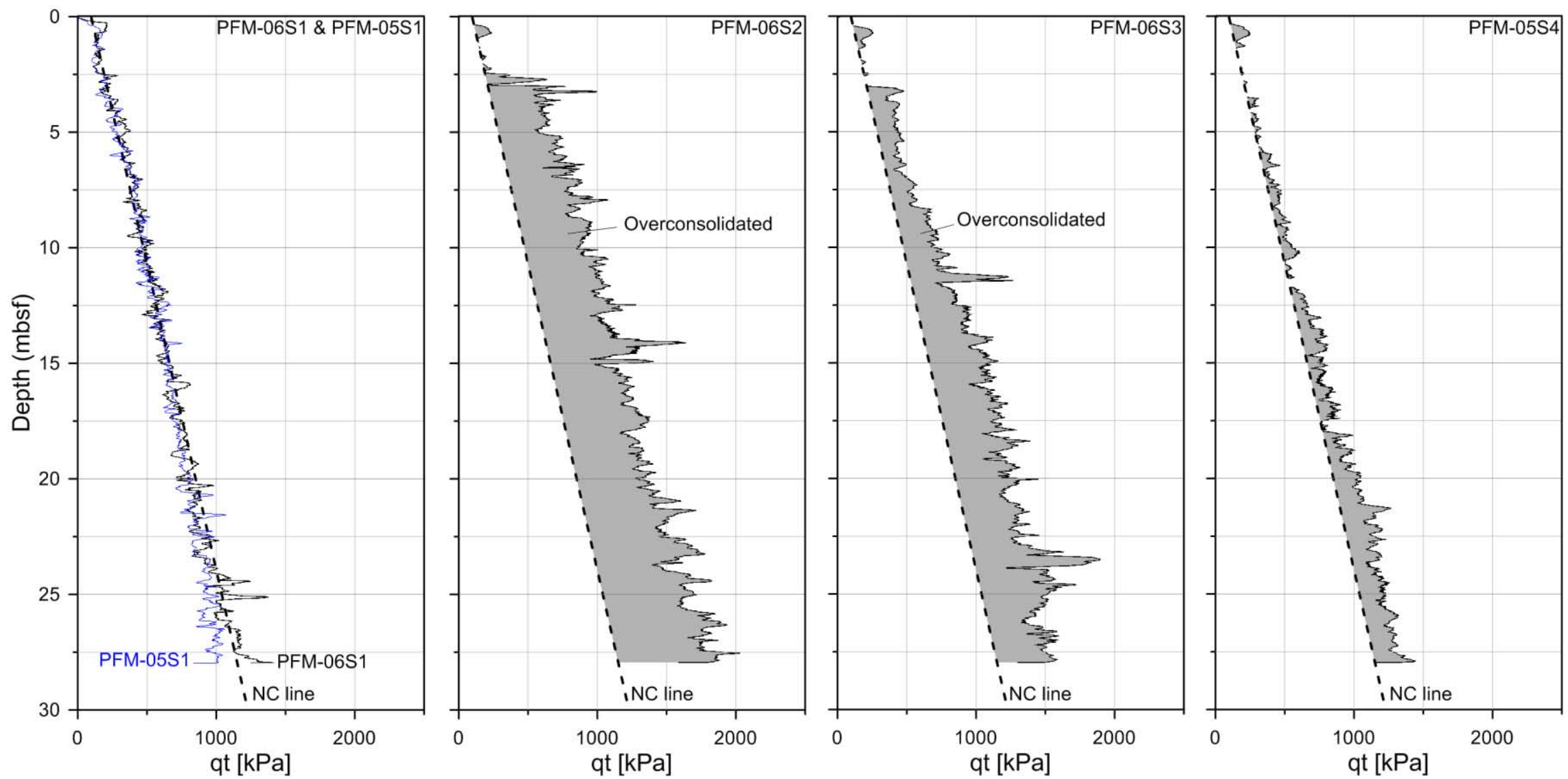

Figure 10 


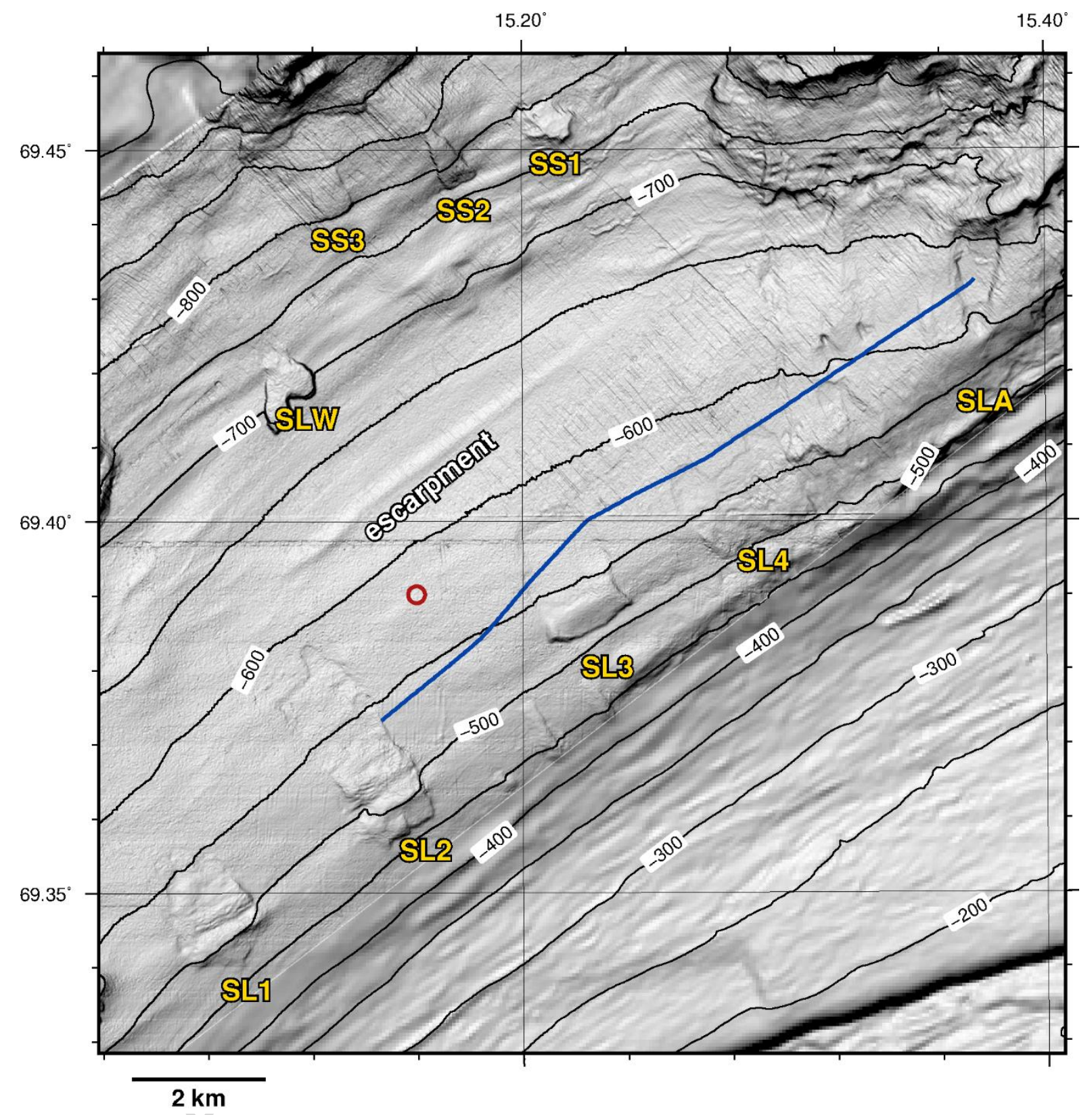

Figure 11 

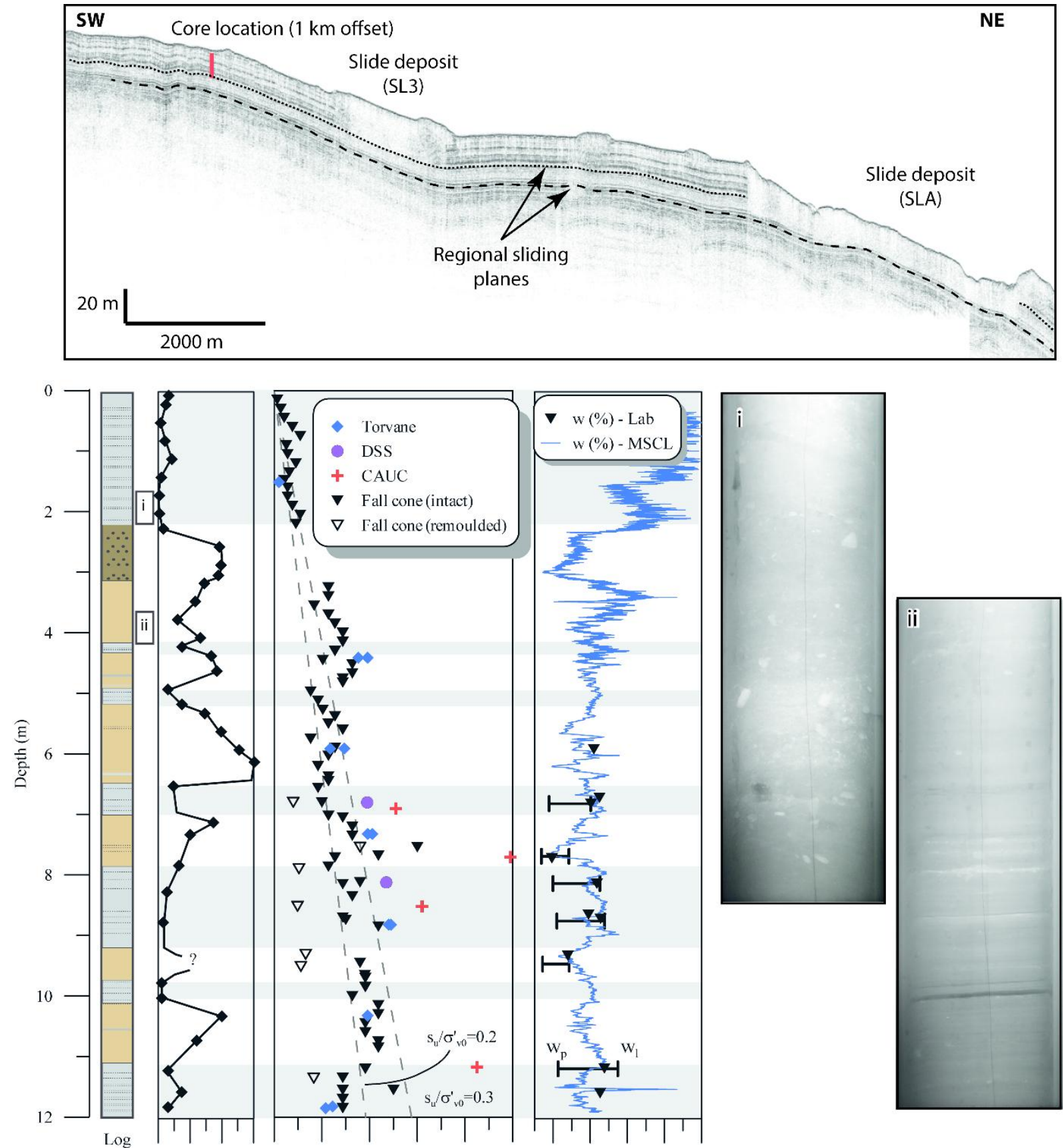

$\square$ Sorted sand $\quad 0 \quad 15 \quad 30 \quad 45 \quad 0$

$\square$ Sandy clay

Sand content $(\%)$

$\begin{array}{cccc}10 & 20 & 30 & 40\end{array}$

$\begin{array}{lllll}20 & 40 & 60 & 80 & 100\end{array}$

Water content

$\square$ Silty clay

Figure 12 


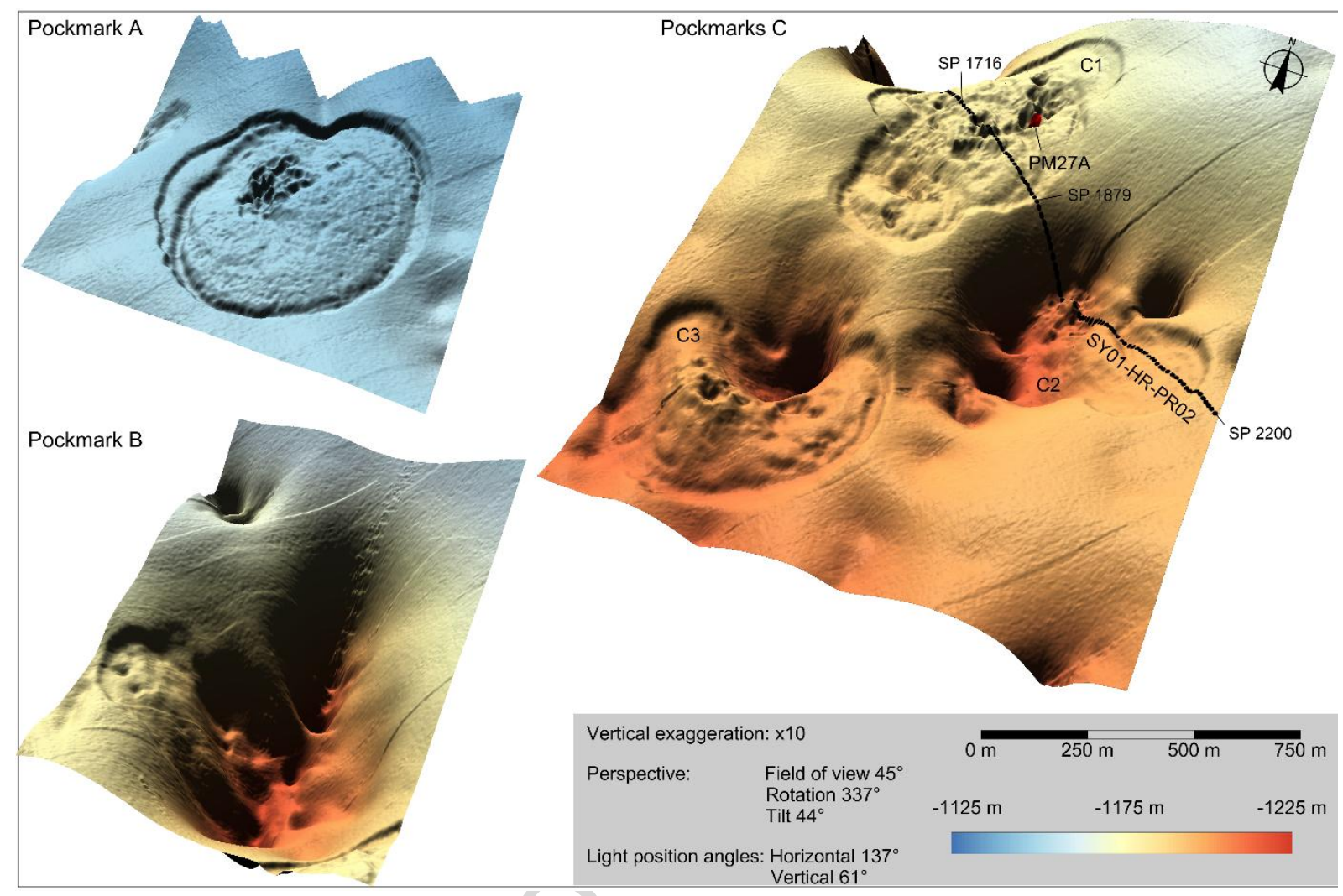

Figure 13 


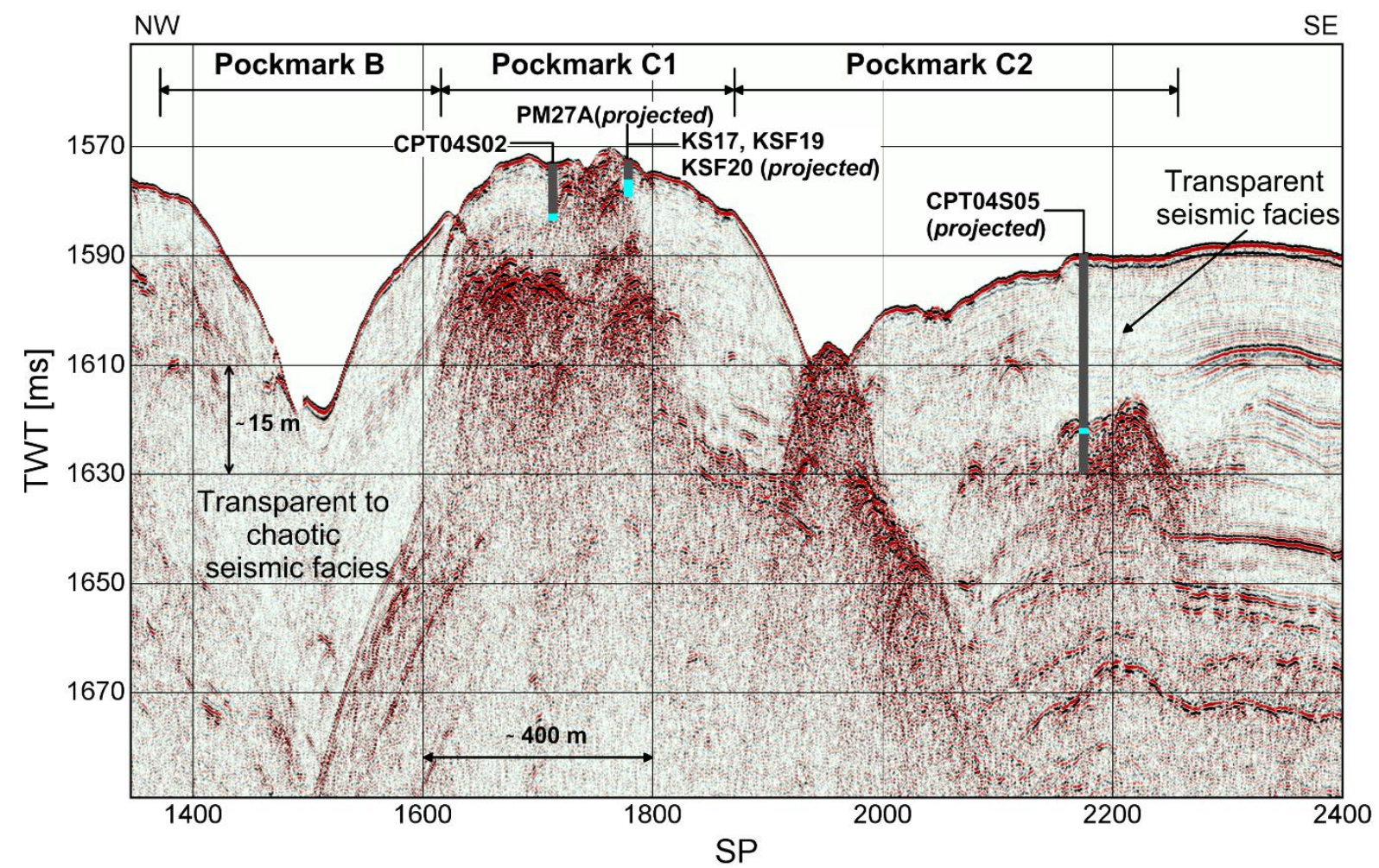

Figure 14 


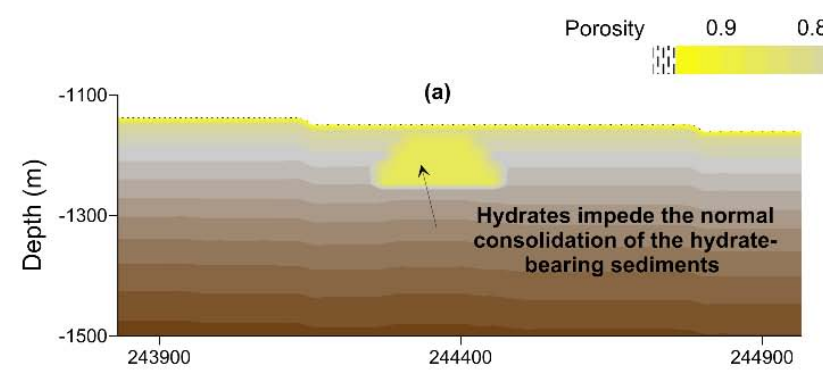

$\begin{array}{lll}0.7 & 0.6 & 0.5\end{array}$
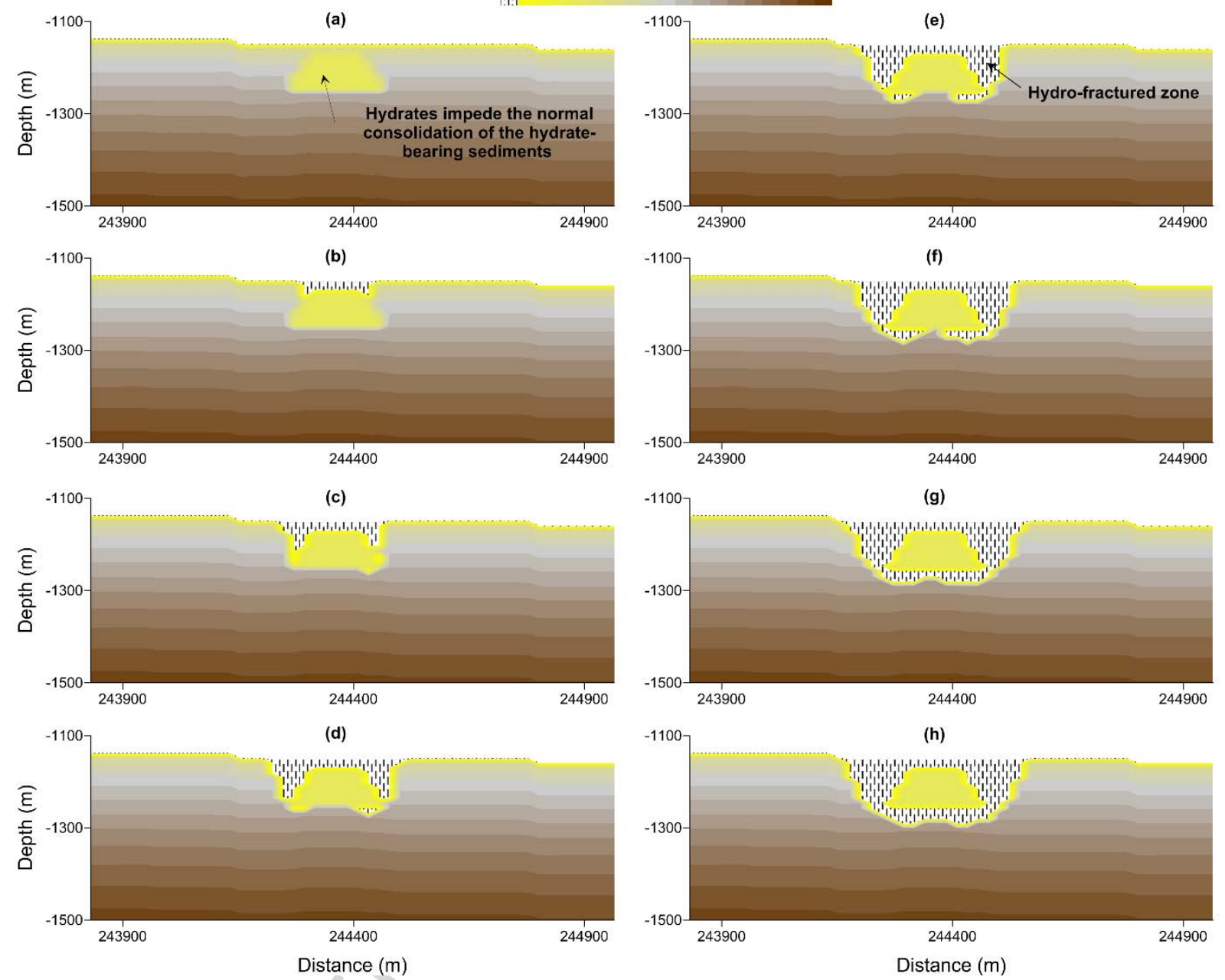

Figure 15 

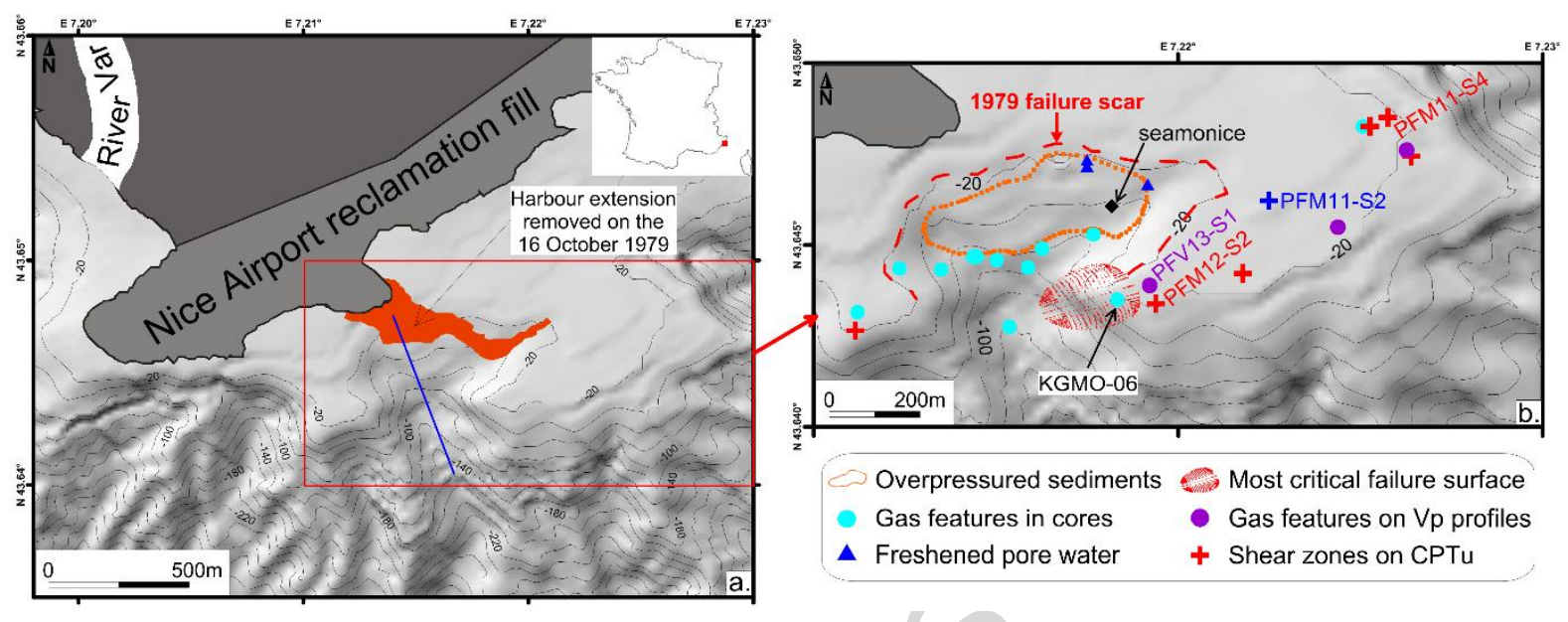

Figure 16 


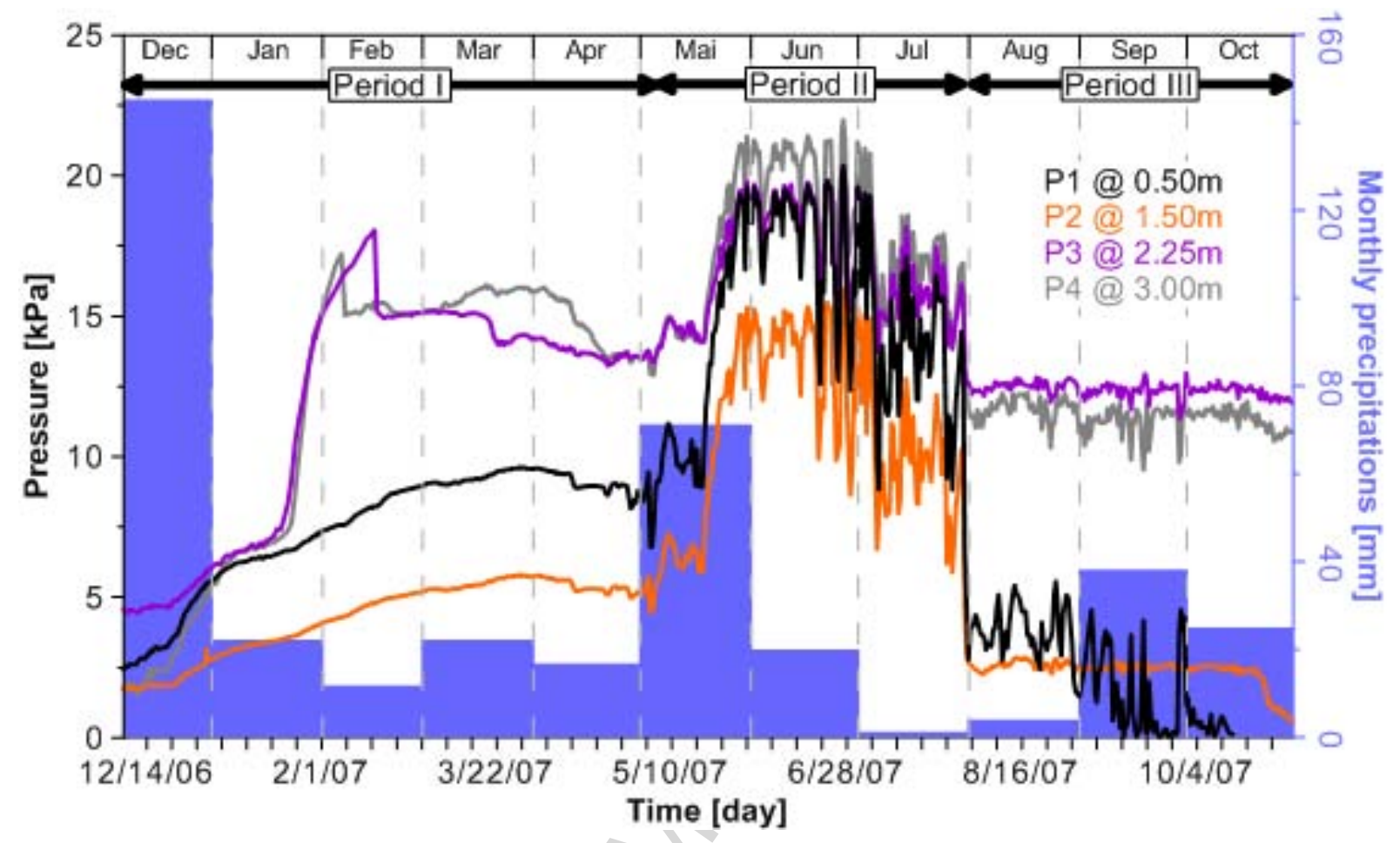

Figure 17 
a) PFV13-S1

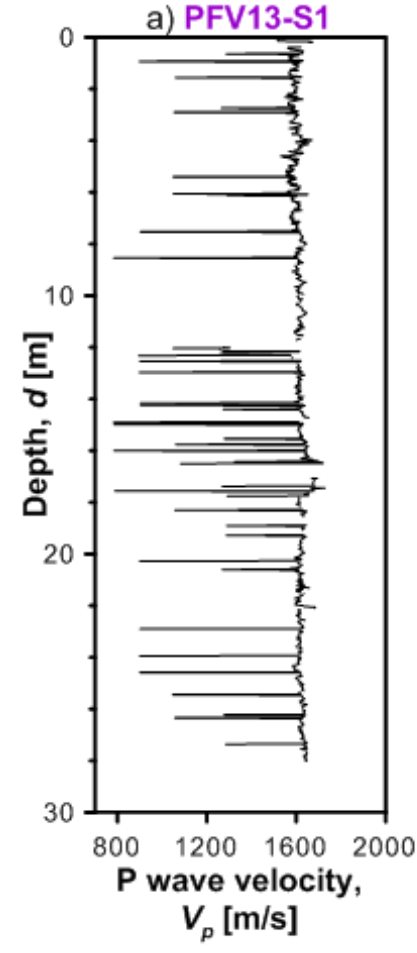

$V_{p}[\mathrm{~m} / \mathrm{s}]$ b) PFM12-S2

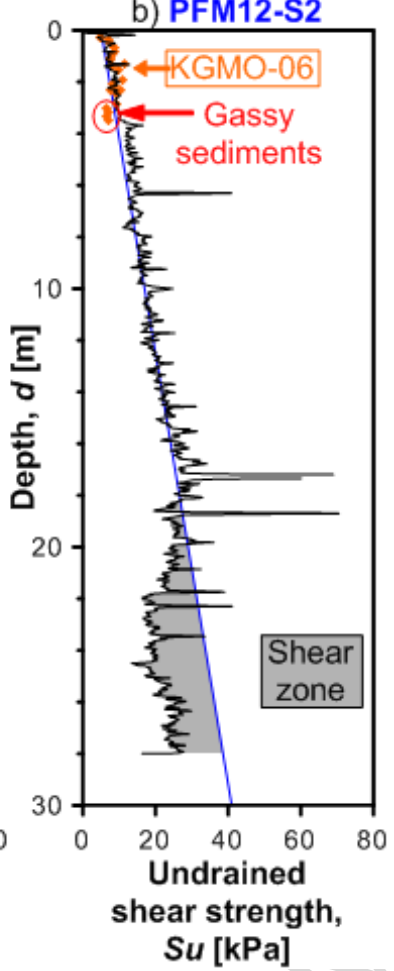

c) PFM11-S2

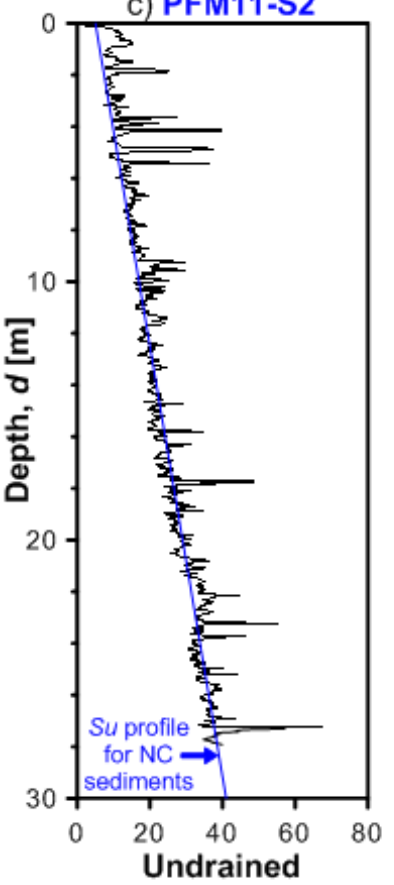

shear strength, $\mathrm{Su}$ [kPa] d) PFM11-S4

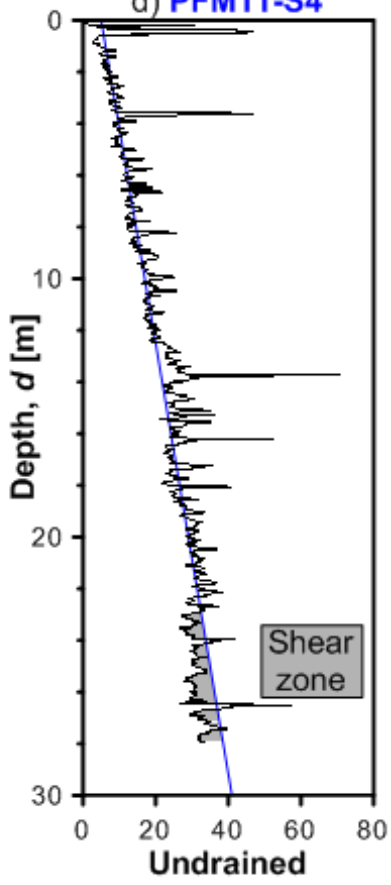

shear strength, $\mathrm{Su}$ [kPa]

Figure 18 


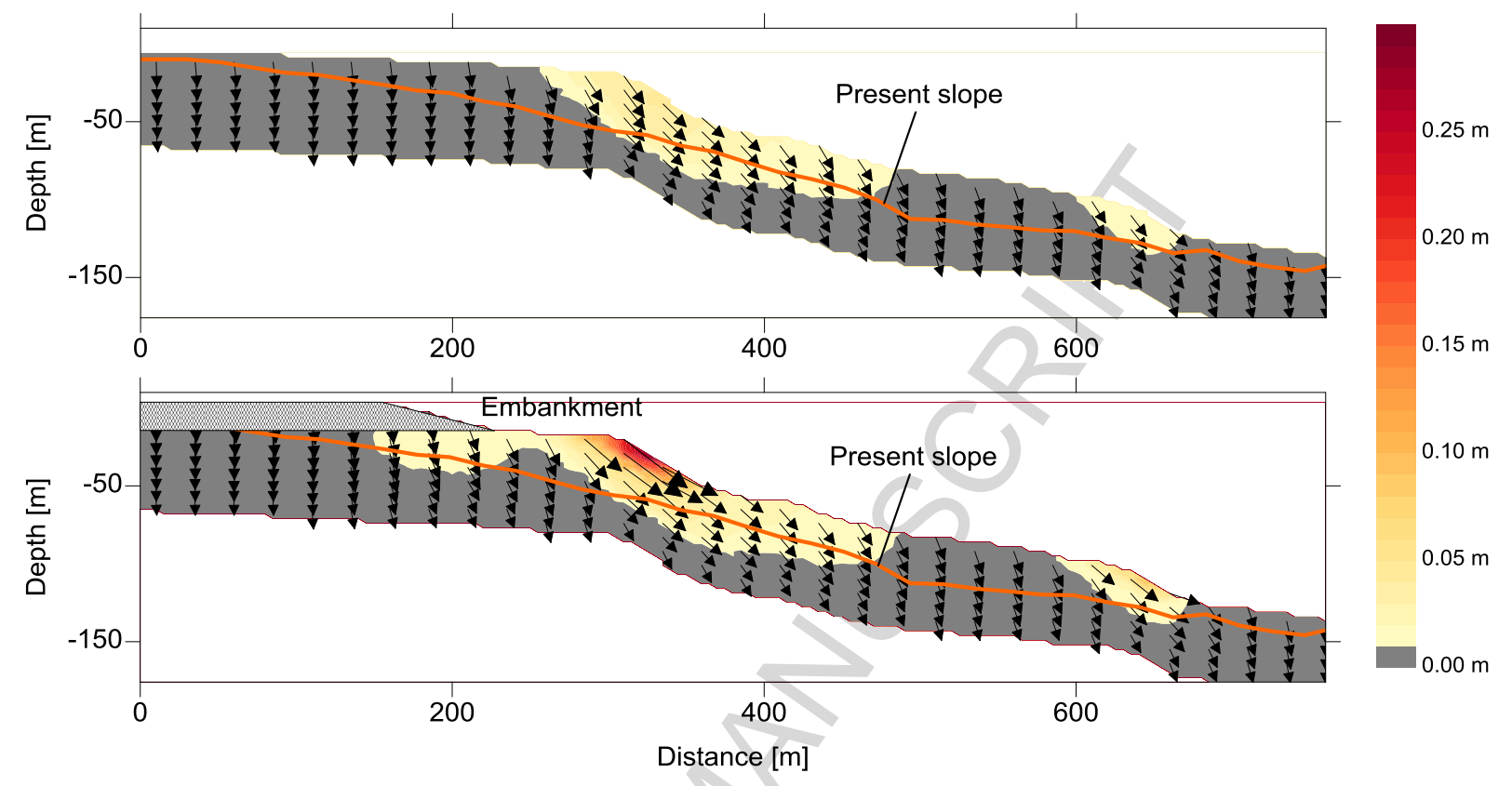

Figure 19 

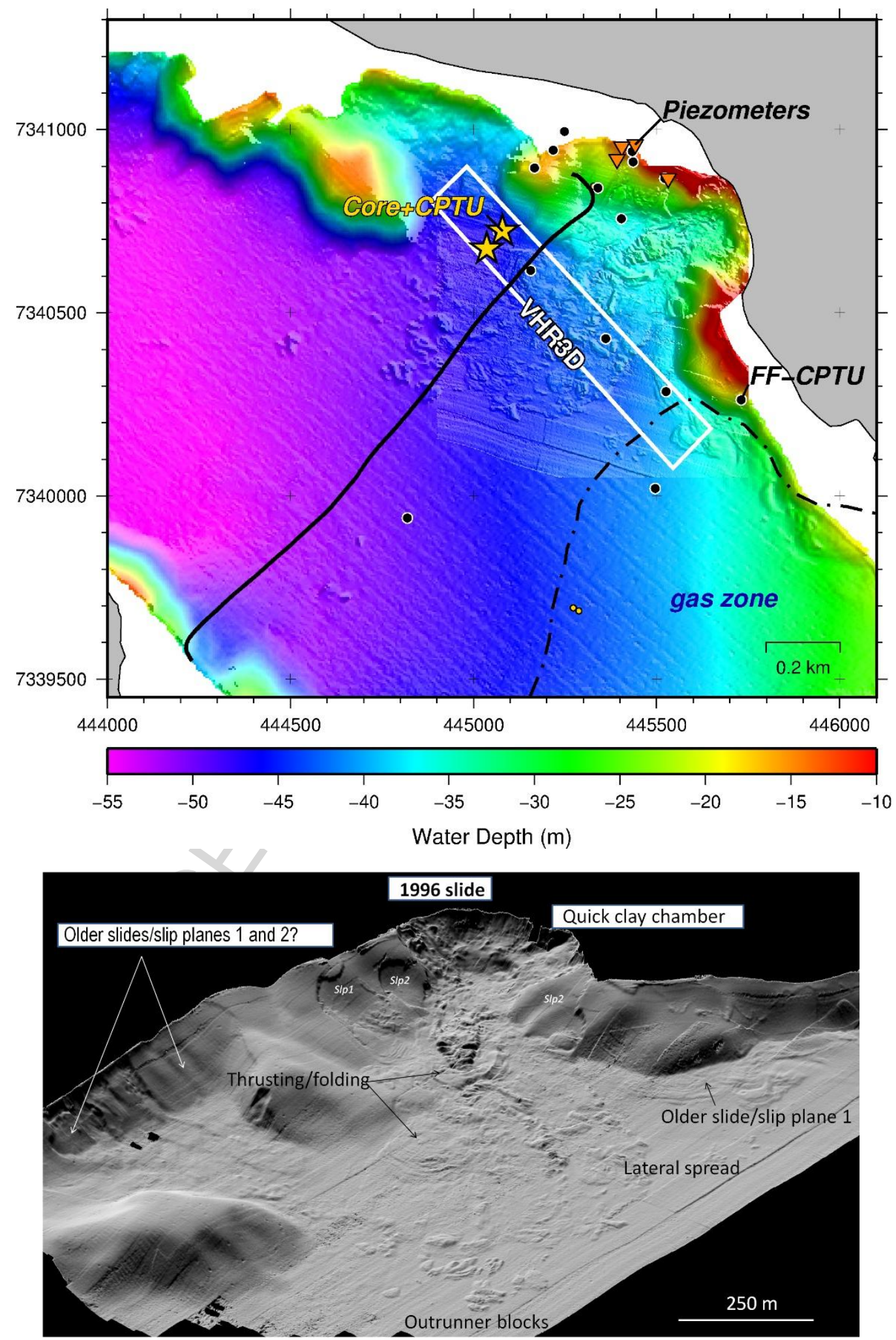

Figure 20 

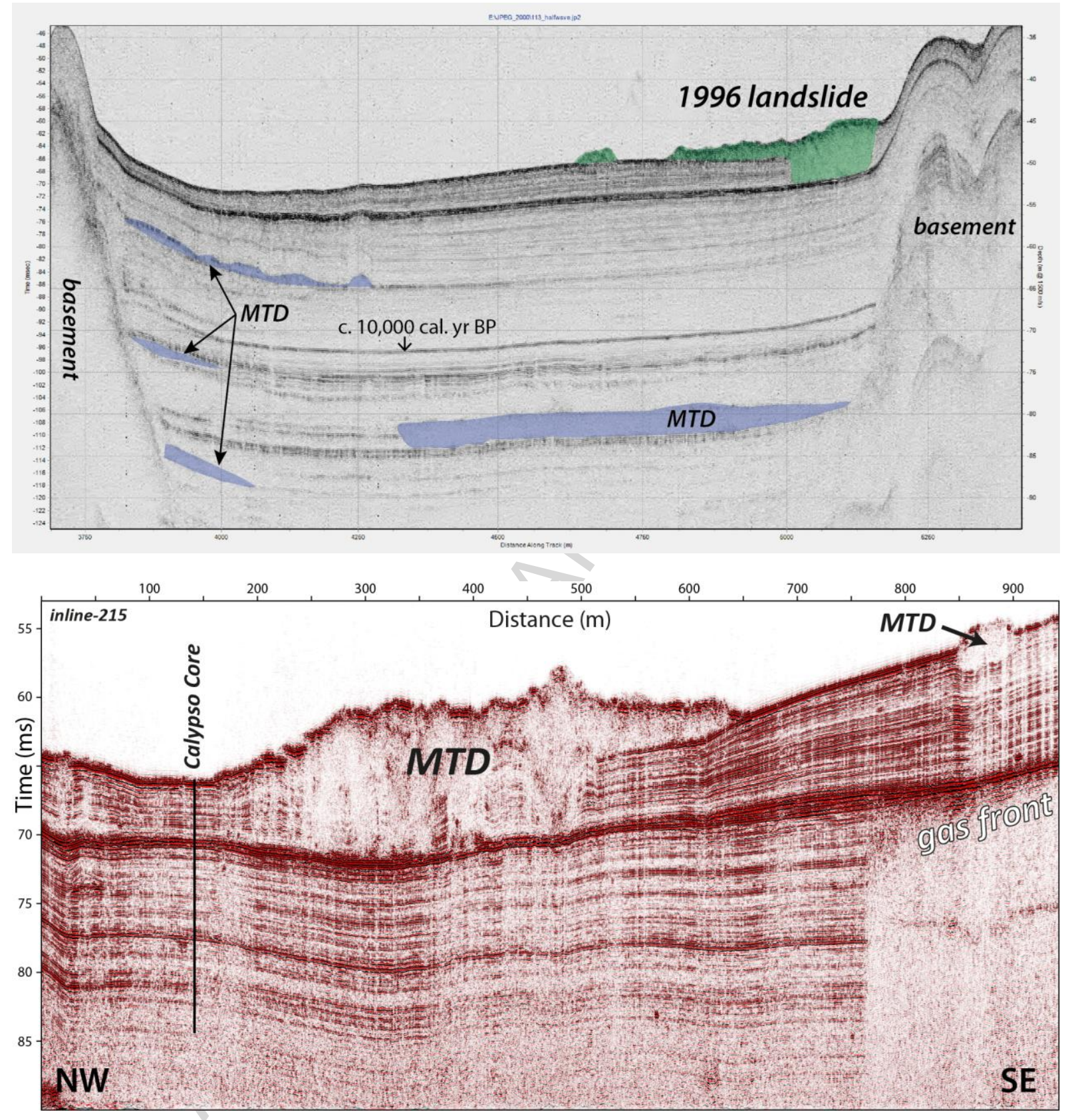

Figure 21 


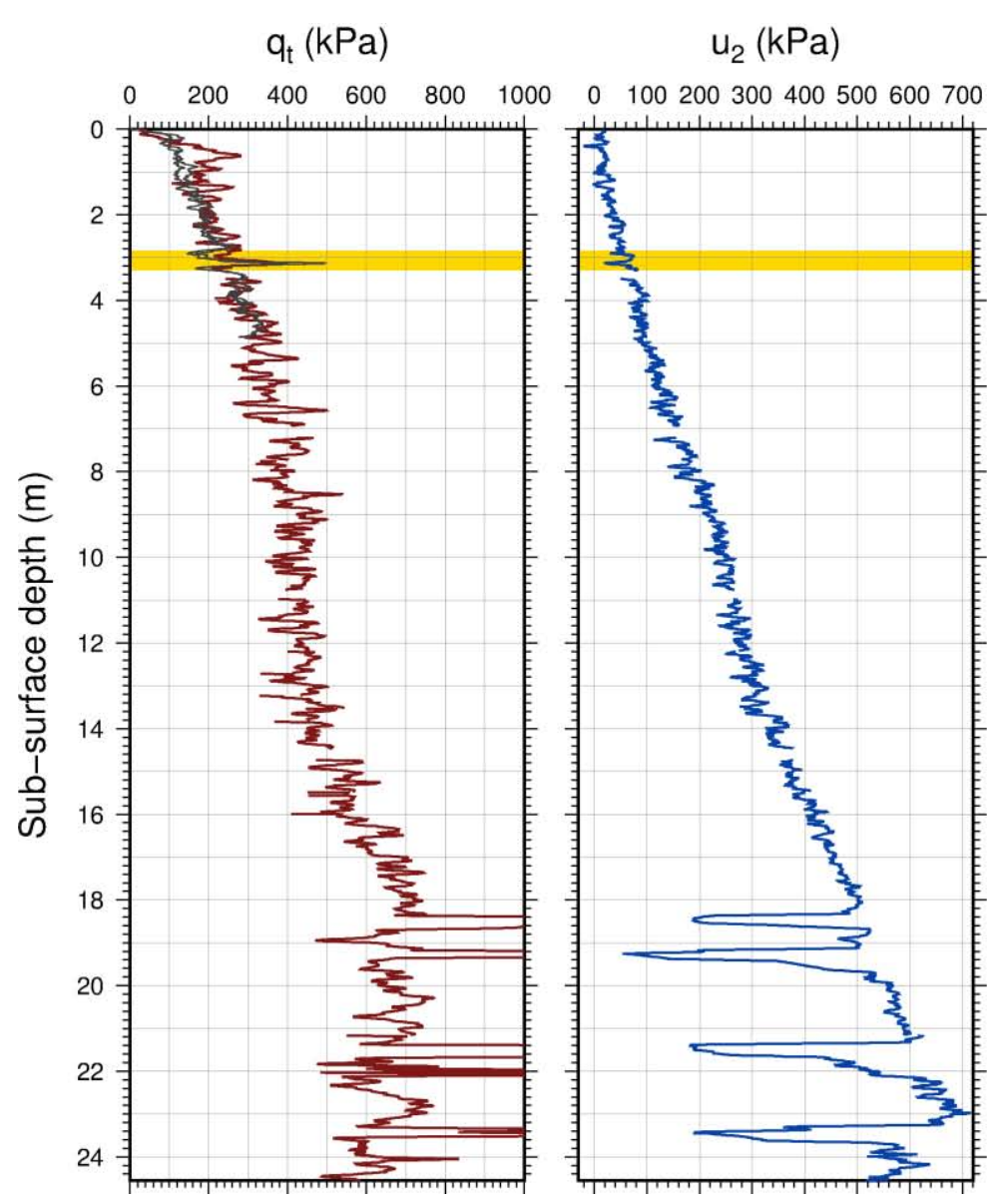

$\mathrm{u}_{2}(\mathrm{kPa})$

$\mathrm{s}_{\mathrm{u}}(\mathrm{kPa})$

$\rho(g / c c)$

MS (SI, 10-5)
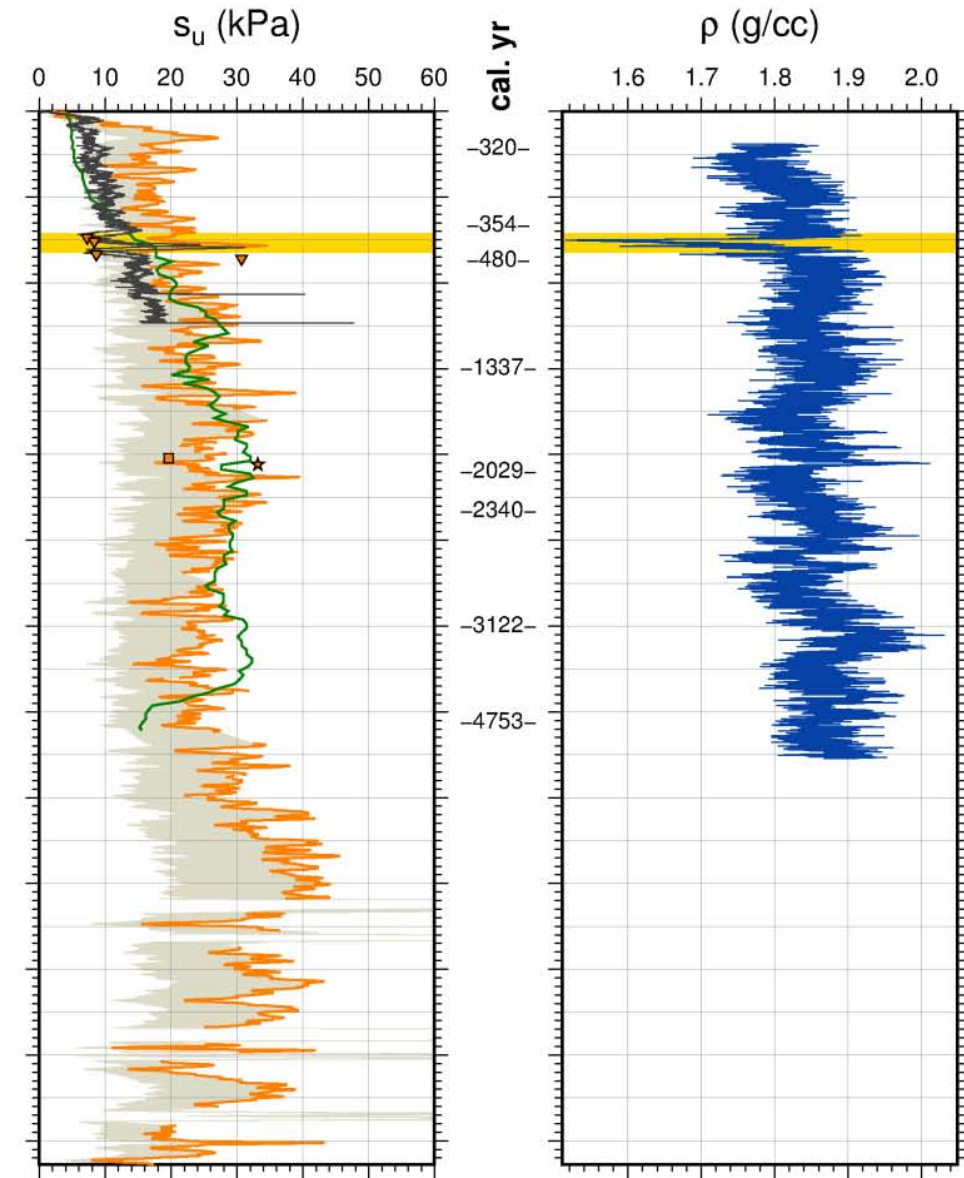

$\begin{array}{lllllll}15 & 20 & 25 & 30 & 35 & 40 & 45\end{array}$

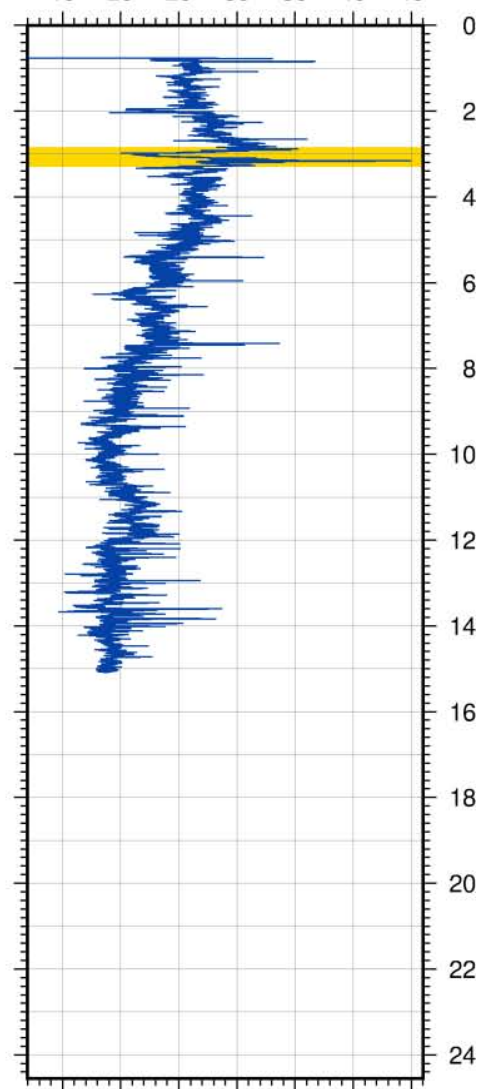

Figure 22 


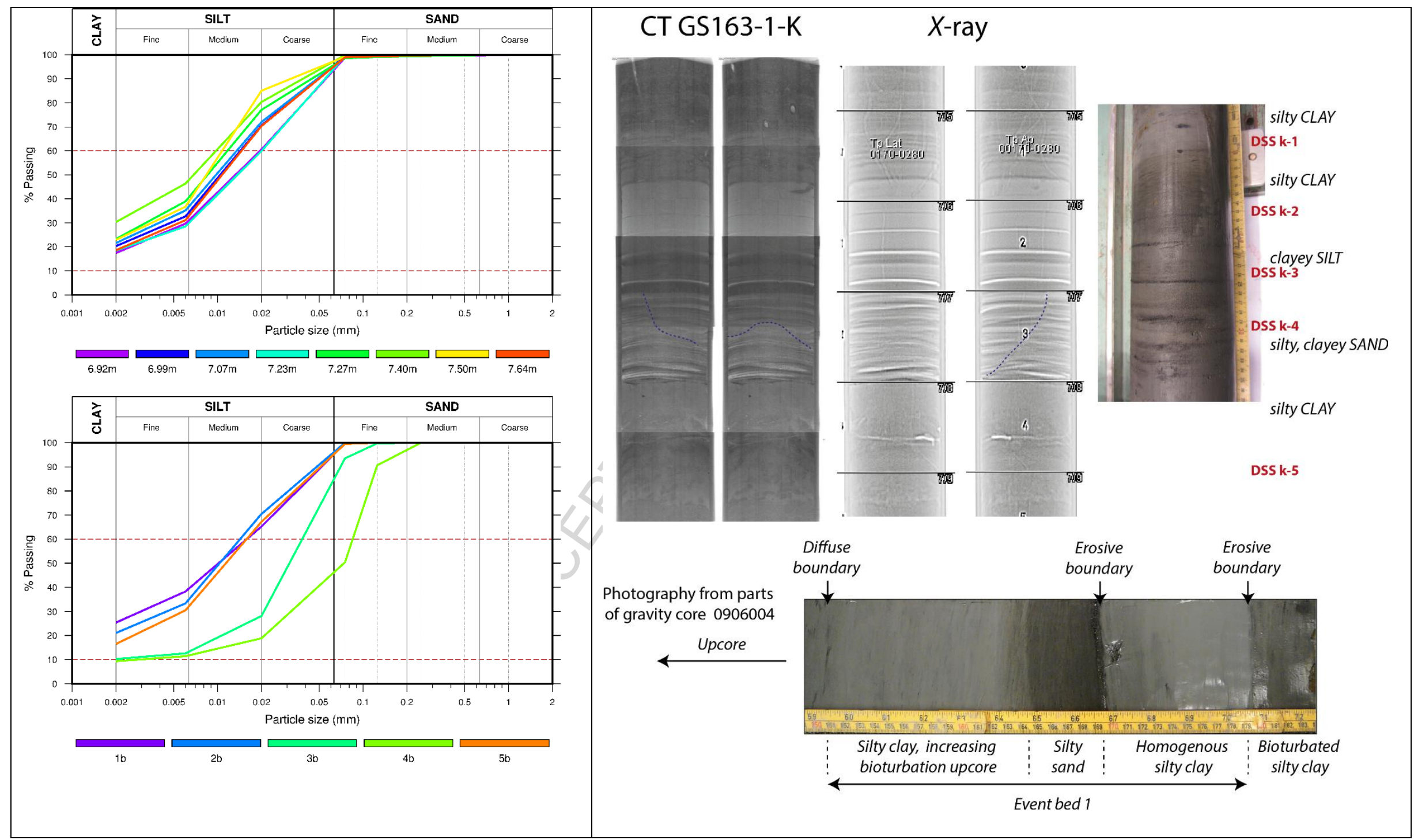

Figure 23 


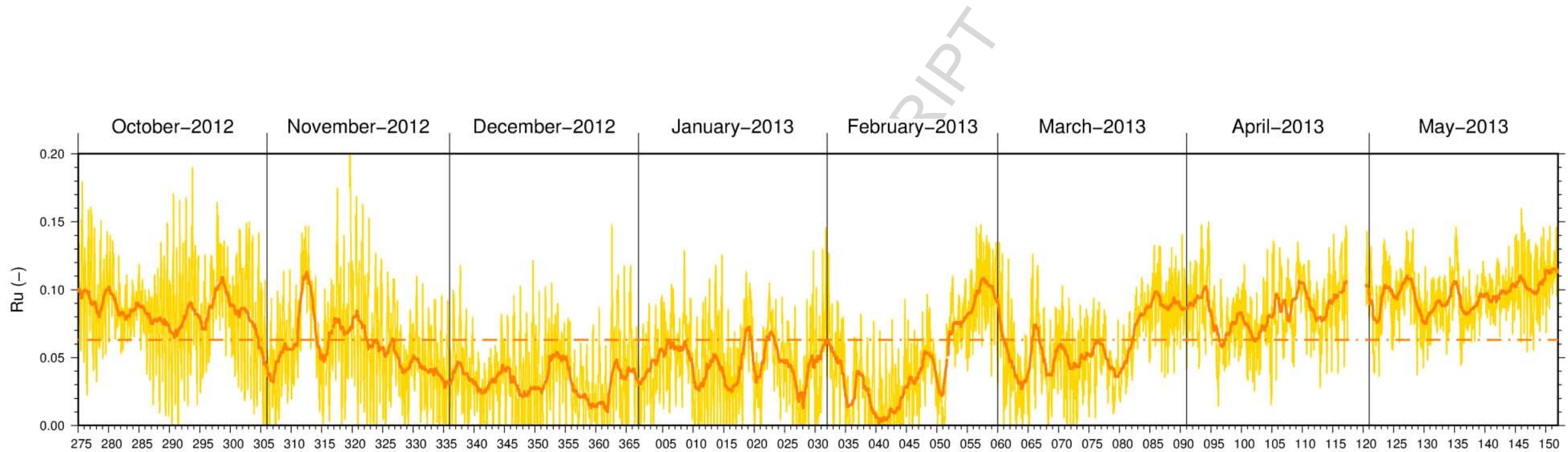

$275280285290295300305310315320325330335340345350355360365005010015020025030035040045050055060065070075080085090 \quad 095 \quad 100 \quad 105 \quad 110115120125130135140 \quad 145 \quad 150$ Day in year

Figure 24 


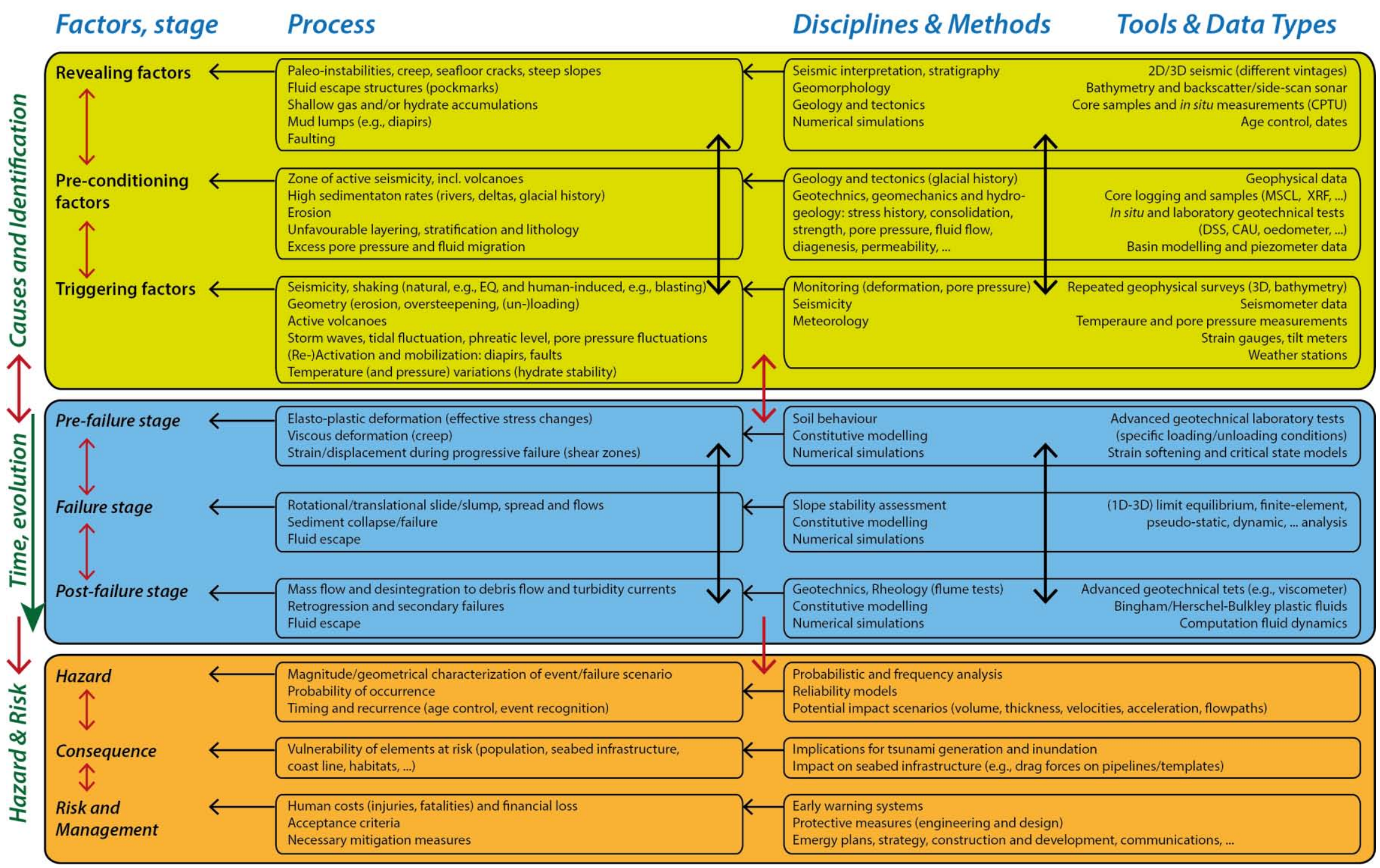

Figure 25 